\title{
Avaliação experimental do metabolismo energético em dois protocolos de sobrecarga sistólica do ventrículo direito
}

Tese apresentada à Faculdade de Medicina da Universidade de São Paulo para obtenção do título de Doutor em Ciências

Programa de: Cirurgia Torácica e Cardiovascular

Orientador: Prof. Dr. Renato Samy Assad

SÃO PAULO 
Dados Internacionais de Catalogação na Publicação (CIP)

Preparada pela Biblioteca da

Faculdade de Medicina da Universidade de São Paulo

Oreprodução autorizada pelo autor

\section{Atik, Fernando Antibas}

Avaliação experimental do metabolismo energético em dois protocolos de sobrecarga sistólica do ventrículo direito / Fernando Antibas Atik. -- São Paulo, 2012.

Tese(doutorado)--Faculdade de Medicina da Universidade de São Paulo.

Programa de Cirurgia Torácica e Cardiovascular.

Orientador: Renato Samy Assad.

Descritores: 1.Ventrículos cardíacos 2.Hipertrofia/fisiopatologia 3.Hipertrofia ventricular direita 4.Transposição dos grandes vasos/cirurgia 5.Procedimentos cirúrgicos cardíacos/métodos 6.Artéria pulmonar 7.Cabras

USP/FM/DBD-062/12 
Dedicatória 
Aos meus pais, Edmar e Mariana, cujo apoio e orientação constantes serviram de base sófida para o enfrentamento dos desafios impostos pela vida e pela profissão. Sem dúvida nenhuma, são verdadeiros exemplos a serem seguidos.

Aos meus avós Elias, Ivete, Liam, Jorge e Odete, que embora falecidos, permanecem constantemente na minha memória e certamente se orgulhariam desta conquista.

Aos meus irmãos, Guilherme e Carolina, que foram verdadeiros companheiros nesta trajetória.

Aos meus tios maternos Pedro, Nádia e Eliana que mantém a união familiar e o exemplo dos sentimentos mais valiosos da vida e são pessoas muito queridas.

Aos meus tios paternos Edmon, Edna, Alberto, Gilferto e Lilian, que representam muito para mim pelo convívio do passado, que infelizmente não pode voltar mais, mas estão guardados no meu coração. 
À minha amada esposa, Lilian. É muito difícil expressar em palavras o maior e mais intenso dos sentimentos. Seu amor, companheirismo, afeto e apoio incondicionais foram determinantes no início de nosso relacionamento, quando residimos fora do Brasil. Estes sentimentos amadureceram e se consolidaram ao longo dos anos e esta conquista profissional só tem sentido com a sua presença.

Aos nossos filhos, Gustavo e Lucas que nos mantêm muito ocupados, cansados, mas muito felizes por termos o privilégio de acompanhar seu crescimento e desenvolvimento e quiçá poder guiá-los na formação de homens de bem. 
Agradecimento especial 
Ao Prof. Dr. Renato Samy Assad, orientador, cirurgião dotado de uma perseverança, entusiasmo e paixão pela ciência impressionantes e contagiantes. $O$ amor pelo que fazemos é a mola propulsora das grandes inovações e descobertas da ciência. 
Agradecimentos 
À equipe da divisão de Fisiologia Aplicada do Instituto do Coração, e a todos os funcionários do biotério, pelo apoio nos experimentos desta tese.

A equipe do Laboratório de Genética e Cardiologia Molecular do Instituto do Coração, chefiada pelo Prof. Dr. José Eduardo Krieger, cuja participação foi essencial no desenho deste projeto de pesquisa e na interpretação dos resultados encontrados.

A Dra. Maria Cristina A6duch, responsável pela avaliação ecocardiográfica seriada dos animais desta linha de pesquisa.

A Dra. Miriam Fonseca-Alaniz, responsável pela dosagem das enzimas do metabolismo energético desta tese, e que muito contribuiu na elucidação das vias do metabolismo energético e interpretação dos resultados encontrados.

Ao Dr. Gustavo Justo Silva, cuja participação na análise dos dados estatísticos foi de grande valia. 
A Dra. Fernanda Oliveira, que não poupou esforços durante a execução dos experimentos e acompanhamento da coleta de dados.

Ao Prof. Dr. Luiz Felipe Pinho Moreira, cuja análise sempre crítica do trabalho científico lapida e engrandece a produção científica de qualidade.

Aos meus colegas do Instituto de Cardiologia do Distrito Federal, que me apoiaram nos períodos de ausência profissional para a execução desta pósgraduação e entenderam a importância da mesma.

A todos aqueles que contribuíram para a minha formação profissional. Seria injusto citar alguns pois certamente ignoraria a contribuição dos demais na Faculdade de Medicina do ABC, na Universidade Federal de São Paulo, no Instituto do Coração do Hospital das Clínicas da FMUSPe na Cleveland Clinic Foundation. 
PAG.

1. LISTA DE ABREVIATURAS E SIGLAS............................................. 14

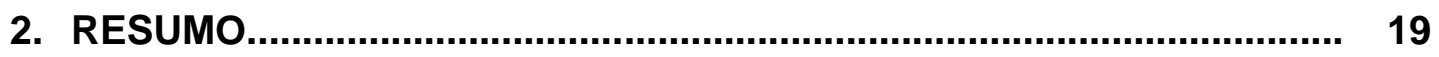

3. SUMMARY

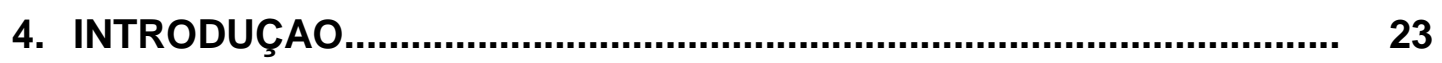

4.1. Hipertrofia miocárdica fisiológica versus patológica........................ 26

4.2. Condicionamento físico e hipertrofia miocárdica............................. 29

4.3. Metabolismo energético e hipertrofia miocárdica........................... 32

4.3.1. Hexoquinase e Lactato Desidrogenase na Hipertrofia 32

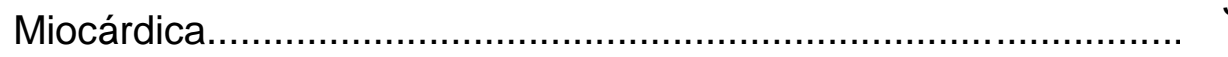

4.3.2. Glicose 6 Fosfato Desidrogenase: papel no estresse oxidativo e redutivo

5. OBJETIVOS

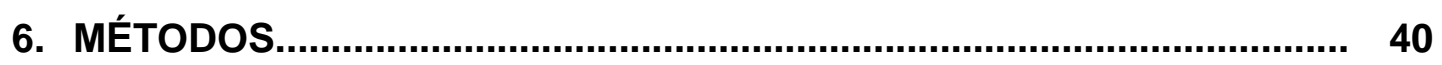

6.1. Avaliação pré-operatória.............................................................. 41

6.2. Anestesia ........................................................................... 42

6.3. Procedimento cirúrgico................................................................ 42

6.4. Dispositivo de bandagem do tronco pulmonar............................. 45

6.5. Protocolo de sobrecarga sistólica do ventrículo direito................... 47

6.5.1. Grupo contínuo................................................................ 48

6.5.2. Grupo intermitente............................................................ 48

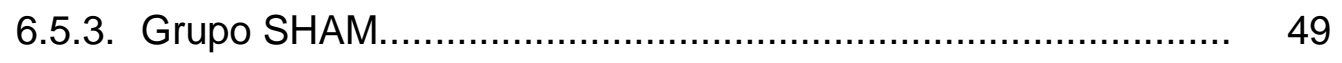

6.6. Estudo ecocardiográfico........................................................... 49 
6.7. Coleta das amostras cardíacas.................................................. 52

6.8. Conteúdo de água dos tecidos................................................... 53

6.9. Análise do metabolismo energético.............................................. 53

6.9.1. Atividade da enzima Glicose 6 Fosfato Desidrogenase........ 54

6.9.2. Atividade da enzima Hexoquinase ...................................... 55

6.9.3. Atividade da enzima Lactato Desidrogenase ........................ 55

6.10 Análise estatística................................................................. 56

7. RESULTADOS......................................................................... 57

7.1. Medidas hemodinâmicas........................................................... 58

7.1.1. Pressão arterial sistêmica....................................................... 58

7.1.2. Gradiente de pressão entre VD e TP..................................... 59

7.1.3. Relação de pressões entre VD e aorta.................................... 61

7.2. Achados ecocardiográficos........................................................... 63

7.2.1. Espessura da parede livre do VD........................................... 63

7.2.2. Espessura do septo interventricular (SIV) ............................... 65

7.2.3. Espessura da parede posterior do VE................................... 66

7.2.4. Volume diastólico final do ventrículo direito............................. 67

7.2.5. Avaliação funcional do VD..................................................... 69

7.3. Achados morfológicos............................................................... 72

7.3.1. Pesagem das massas cardíacas .............................................. 72

7.3.2. Conteúdo de água das massas cardíacas ................................ 73

7.3.3. Razão volume/massa do VD.................................................. 74

7.4. Metabolismo energético ………………………….................... 74

7.4.1. Atividade máxima da enzima Glicose 6 Fosfato 74 Desidrogenase....

7.4.2. Atividade máxima da enzima Hexoquinase.............................. 77

7.4.3. Atividade máxima da enzima Lactato Desidrogenase............... 79 
8. DISCUSSÃO

8.1. Achados principais.................................................................... 82

8.2. Parâmetros hemodinâmicos.......................................................... 83

8.3. Parâmetros ecocardiográficos...................................................... 84

8.4. Parâmetros morfológicos.......................................................... 86

8.5. Metabolismo energético …………………………................. 88

8.6. Limitações do Estudo............................................................... 91

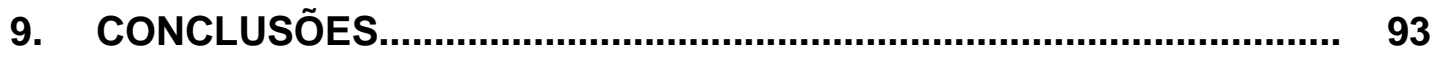

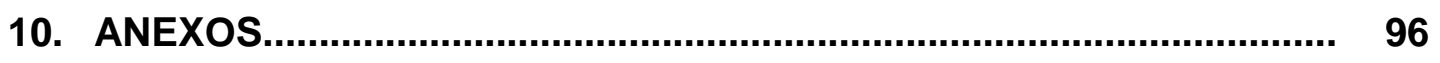

11. REFERÊNCIAS BIBLIOGRÁFICAS.................................................. 109 


\section{Lista de Abreviaturas e Siglas}

\begin{tabular}{|c|c|}
\hline ANOVA & Análise de variância \\
\hline ATP & TriFosfato de adenosina \\
\hline $\mathrm{CA}$ & Conteúdo de água \\
\hline DNA & Ácido deoxiribonucleico \\
\hline FEVD & Fração de ejeção do ventrículo direito \\
\hline $\mathrm{G}$ & Grama \\
\hline G6PD & Glicose 6 Fosfato Desidrogenase \\
\hline $\mathrm{H}$ & Horas \\
\hline $\mathrm{HCl}$ & Ácido clorídrico \\
\hline HK & Hexoquinase \\
\hline $\mathrm{IDM}_{\mathrm{VD}}$ & Índice de desempenho miocárdico do ventrículo direito \\
\hline $\mathrm{Kg}$ & Kilograma \\
\hline LDH & Lactato Desidrogenase \\
\hline $\mathrm{Mg}$ & Miligrama \\
\hline $\mathrm{MgCl}_{2}$ & Cloreto de magnésio \\
\hline $\mathrm{MHz}$ & Mega Hertz \\
\hline Min & Minuto \\
\hline $\mathrm{Ml}$ & Mililitro \\
\hline $\mathrm{Mm}$ & Milímetro \\
\hline $\mathrm{mmHg}$ & Milímetro de mercúrio \\
\hline $\mathrm{NADPH}$ & Nicotinamida adenina diFosfato \\
\hline $\mathrm{nmol}$ & Nanomol \\
\hline Ps & Peso seco \\
\hline
\end{tabular}




$\begin{array}{ll}\mathrm{Pi} & \text { Peso inicial } \\ \text { RV } & \text { Right ventricle } \\ \text { Sham } & \text { Controle negativo } \\ \text { TCIV } & \text { Tempo de contração isovolumétrica } \\ \text { TE } & \text { Tempo de ejeção } \\ \text { TGA } & \text { Transposição das grandes artérias } \\ \text { TP } & \text { Tronco pulmonar } \\ \text { TRIV } & \text { Tempo de relaxamento isovolumétrico } \\ \text { U } & \text { Unidade } \\ \text { VD } & \text { Ventrículo direito } \\ \text { VDF } & \text { Volume diastólico final } \\ \text { VE } & \text { Ventrículo esquerdo } \\ \text { VSF } & \text { Volume sistólico final } \\ { }^{\circ} \mathrm{C} & \text { Graus Celsius } \\ \mu \mathrm{m} & \text { Micrômetro }\end{array}$




\section{Lista de Tabelas}

Pág.

Tabela 1. Peso dos animais dos grupos Sham, Contínuo e intermitente

Tabela 2. Pressão sistólica sistêmica dos grupos Sham, Contínuo e 59 Intermitente, medida pelo cateter vascular

Tabela 3. Espessuras do ventrículo direito (VD) nos grupos Sham, Contínuo e Intermitente, medidas pelo ecocardiograma

Tabela 4. Espessuras do septo interventricular nos grupos Sham, Contínuo e Intermitente, medidas pelo ecocardiograma

Tabela 5. Espessuras do ventrículo esquerdo (VE) nos grupos Sham, Contínuo e Intermitente, medidas pelo ecocardiograma

Tabela 6. Volume diastólico final do VD nos grupos Sham, Contínuo e Intermitente, medido pelo ecocardiograma

Tabela 7. Fração de ejeção do VD nos grupos Sham, Contínuo e Intermitente, medido pelo ecocardiograma

Tabela 8. Conteúdo de água das massas cardíacas no VD, septo interventricular e VE, de acordo com os grupos de estudo

Tabela 9. Relação volume / massa do VD após 96 horas de estudo, medidos pelo ecocardiograma e por balança de precisão, respectivamente nos grupos Sham, Contínuo e Intermitente

Tabela 10. Atividade máxima da enzima Glicose 6-Fosfato Desidrogenase (G6PD) no ventrículo direito (VD), septo interventricular e ventrículo esquerdo (VE) dos grupos Sham, Contínuo e Intermitente

Tabela 11. Atividade máxima da enzima Hexoquinase (HK) no ventrículo direito (VD), septo interventricular e ventrículo esquerdo (VE) dos grupos Sham, Contínuo e Intermitente

Tabela 12. Atividade máxima da enzima Lactato Desidrogenase (LDH) no ventrículo direito (VD), septo interventricular e ventrículo esquerdo (VE) dos grupos Sham, Contínuo e Intermitente 


\section{Lista de Figuras}

Pág.

Figura 1. Esquema simplificado do metabolismo da Glicose e dos ácidos graxos e as funções das enzimas Hexoquinase e Lactato Desidrogenase.

Figura 2. Esquema simplificado do metabolismo da via das pentoses Fosfato destacando o papel da enzima Glicose 6-Fosfato Desidrogenase na geração de ânions superóxido.

Figura 3. Foto cirúrgica do dispositivo de bandagem no tronco pulmonar e o posicionamento de cateteres de monitorização no ventrículo direito e artéria pulmonar.

Figura 4. Animal após o implante do dispositivo, com cateteres e dreno pleural exteriorizados através da parede torácica. Presença da incisão da toracotomia lateral esquerda.

Figura 5. Animal em recuperação anestésica na maca especial para quadrúpedes.

Figura 6. Dispositivo de bandagem ajustável do tronco pulmonar.

Figura 7. Diagrama cronológico da coleta de dados do grupo Intermitente

Figura 8. Evolução do gradiente pressórico sistólico entre o ventrículo direito e tronco pulmonar nos grupos Sham, Contínuo e Intermitente.

Figura 9. Painel A: Padrões de sobrecarga sistólica dos grupos Sham, Contínuo e Intermitente. Painel B: Áreas de sobrecarga sistólica dos grupos Sham, Contínuo e Intermitente.

Figura 10. Evolução da relação de pressões sistólicas entre o ventrículo direito e aorta nos grupos Sham, Contínuo e Intermitente.

Figura 11. A: Razão de pressões sistólicas entre VD e aorta dos grupos Sham, Contínuo e Intermitente. B: Áreas da razão 
de pressões entre VD e aorta dos grupos Sham, Contínuo e Intermitente.

Figura 12. Variações percentuais da espessura da parede livre do VD dos grupos submetidos à sobrecarga sistólica contínua e intermitente.

Figura 13. Variação percentual do volume diastólico do VD dos grupos Sham, Contínuo e Intermitente.

Figura 14. Evolução do índice de desempenho miocárdico nos grupos Sham, Contínuo e Intermitente durante o protocolo de estudo.

Figura 15. Massas do VD, Septo e VE (indexada para o peso corporal) nos grupos Sham, Contínuo e Intermitente.

Figura 16. Atividade máxima da enzima Glicose-6-Fosfato Desidrogenase (G6PD) no miocárdio dos grupos Sham, Contínuo e Intermitente de acordo com o local de análise no miocárdio.

Figura 17. Razão da atividade máxima da enzima Glicose-6-Fosfato Desidrogenase (G6PD) do ventrículo direito, normalizada para sua atividade do ventrículo esquerdo nos grupos Sham, Contínuo e Intermitente.

Figura 18. Atividade máxima da enzima Hexoquinase (HK) do ventrículo direito, ventrículo esquerdo e septo interventricular dos grupos Sham, Contínuo e Intermitente.

Figura 19. Razão da atividade máxima da enzima Hexoquinase do ventrículo direito, normalizada para sua atividade do ventrículo esquerdo nos grupos Sham, Contínuo e Intermitente.

Figura 20. Atividade máxima da enzima Lactato Desidrogenase (LDH) do ventrículo direito, septo interventricular e ventrículo esquerdo dos grupos Sham, Contínuo e Intermitente.

Figura 21. Razão da atividade máxima da enzima Lactato Desidrogenase do ventrículo direito, normalizada para sua atividade do ventrículo esquerdo nos grupos Sham, Contínuo e Intermitente. 


\section{RESUMO}

ATIK FA. Avaliação experimental do metabolismo energético em dois protocolos de sobrecarga sistólica do ventrículo direito [tese]. São Paulo: Faculdade de Medicina, Universidade de São Paulo; 2012.

Objetivo: Alterações do metabolismo energético tem sido identificadas em processos de hipertrofia miocárdica, sendo algumas consideradas benéficas, porém outras estão associadas a insuficiência cardíaca. O objetivo deste trabalho foi comparar a atividade de três enzimas do metabolismo energético em dois protocolos de sobrecarga sistólica do ventrículo direito (VD) num modelo experimental em cabritos.

Métodos: 27 cabritos jovens foram divididos em três grupos: Sham (sem sobrecarga), Contínuo (sobrecarga sistólica constante) e Intermitente (4 períodos de 12 horas de sobrecarga sistólica, intercalados com 12 horas de descanso). Durante as 96 horas do protocolo, a sobrecarga sistólica foi ajustada a fim de atingir relação de pressão entre a aorta e o VD de 0,7. Medidas ecocardiográficas e hemodinâmicas foram realizadas antes e após o período de sobrecarga diariamente até o término do protoloco. Após o término do mesmo, os animais foram sacrificados a fim de obter dados morfológicos e a atividade máxima das enzimas Glicose 6 Fosfato Desidrogenase (G6PD), Hexoquinase (HK) e Lactato Desidrogenase (LDH).

Resultados: Houve aumento de $92,1 \%$ e $46,5 \%$ nas massas do VD e septal no grupo Intermitente, respectivamente, quando comparado ao grupo Sham, enquanto que no grupo Contínuo houve incremento de $37,2 \%$ somente na massa septal. O VD e Septo dos grupos submetidos à sobrecarga sistólica contínua e intermitente do VD apresentaram um aumento discreto, porém 
significativo, do conteúdo de água (VD, $p=0,0014$; Septo, $p=0,0004)$ em relação ao grupo Sham. Ao final do protocolo, foi observado um aumento significativo de $103,8 \%$ da espessura do VD no grupo Intermitente, comparado a um aumento de $38,4 \%$ do grupo Contínuo. Houve também dilatação ventricular significativa no grupo Contínuo ao longo do protocolo, quando comparado aos outros grupos $(p<0,001)$. Piores índices de desempenho miocárdico ocorreram no grupo Contínuo no momentos 72 e 96 horas, quando comparados ao grupos Sham $(P<0,039)$ e Intermitente $(P<0,001)$. A razão da atividade máxima da G6PD do VD pelo VE revelou um aumento de $130,1 \%$ no grupo contínuo ( $p=$ $0,012)$ e de $39,8 \%$ no grupo Intermitente $(p=0,764)$, quando comparados ao grupo Sham. O processo de hipertrofia aguda do VD não afetou a atividade enzimática da HK e LDH nos grupos estudados.

Conclusões: Apesar de haver uma sobrecarga sistólica proporcionalmente menor no VD do grupo intermitente, a bandagem intermitente do TP promoveu maior hipertrofia do VD. A maior atividade da G6PD observada no grupo contínuo sugere maior produção de radicais livres via NADPH oxidase, haja vista que o ciclo das pentoses Fosfato incrementa a disponibilidade de NADPH citoplasmático, ocasionados pela maior demanda de um estímulo de sobrecarga miocárdica constante, um importante mecanismo de insuficiência cardíaca. Este estudo sugere que a preparação do ventrículo sub-pulmonar com a sobrecarga sistólica intermitente poderá proporcionar melhor resultado para a cirurgia de Jatene em dois estágios que a sobrecarga contínua.

Descritores: 1. Ventrículos cardíacos; 2. Hipertrofia / fisiopatologia; 3. Hipertrofia ventricular direita; 4. Transposição dos Grandes Vasos / cirurgia; 5. Procedimentos cirúrgicos cardíacos / métodos; 6. Artéria Pulmonar; 7. Cabras. 


\section{SUMMARY}

ATIK FA. Experimental evaluation of energy metabolism in two right ventricle systolic overload protocols [thesis]. São Paulo: "Faculdade de Medicina, Universidade de São Paulo"; 2012.

Objective: Altered energy metabolism has been identified in myocardial hypertrophy. Some processes are considered beneficial, whereas others are linked to heart failure. The purpose of this study was to compare the activity of three different energy metabolism enzymes in two different protocols of right ventricle (RV) systolic overload in young goats.

Methods: 27 young goats were separated into three groups: Sham (no overload), Continuous (continuous systolic overload) and Intermittent (4 periods of 12-hour systolic overload, alternated with a 12-hour resting period). During a 96-hour protocol, systolic overload was adjusted to achieve a $0.7 \mathrm{RV} /$ aortic pressure ratio. Echocardiographic and hemodynamic evaluations were performed before and after systolic overload every day postoperatively. After the study period, the animals were humanely killed for morphological and Glucose6-phosphate dehydrogenase (G6PD), hexoquinase (HK) and lactate dehydrogenase (LDH) activity assessment.

Results: There was a $92.1 \%$ and $46.5 \%$ increase in RV and septal masses of Intermittent group, respectively, as compared to Sham group, while Continuous systolic overload resulted in $37.2 \%$ increase of only septal mass. There was a small, but significant increase in water content in RV and septum of Intermittent and Continuous groups, as compared to Sham group (RV, $p=0.0014$; Septum, 
$p=0.0004)$. At the end of protocol, it was observed a greater increase in RV thickness (103.8\%) in Intermittent group, as compared to Continous group (38.4\%). There was also a significant right ventricle dilatation in Continuos group along the protocol, as compared to the other groups $(p<0.001)$. A worsening RV myocardial performance index occurred in the continuous group at 72 hours and 96 hours, compared with the sham $(P<0.039)$ and intermittent groups $(P<0.001)$. Compared to Sham, RV to LV G6PD activity ratio was elevated by $130.1 \%$ in Continuous group $(p=0,012)$ and by $39.8 \%$ in Intermittent group $(p=0.764)$. The acute hypertrophic process in the RV did not altered the HK and LDH enzymatic activity among study groups.

Conclusions: Despite of a proportional lesser exposure to systolic overload, intermittent pulmonary trunk banding promoted greater RV hypertrophy. This study indicates that continuous systolic overload for ventricle retraining causes upregulation and hyperactivity of myocardial G6PD. Since pentose phosphate pathway enhances cytosolic NADPH availability, this altered energy substrate metabolism can elevate levels of free radicals by NADPH oxidase, an important mechanism in the pathophysiology of heart failure. It suggests that Intermittent systolic overload may provide better results for 2-stage Jatene operation as compared to continuous protocol.

Descriptors: 1. Heart ventricles; 2. Hypertrophy / Physiopathology; 3. Right ventricular hypertrophy; 4. Transposition of the Great Vessels / surgery; 5. Cardiac surgical procedures; 6. Pulmonary Artery; 7. Goats. 
Introdução 


\section{Introdução}

A bandagem do tronco pulmonar como forma de treinamento ventricular tem sido indicada em pacientes portadores de transposição simples das grandes artérias (TGA) que se apresentam além do período neonatal $^{1,2}$, em pacientes com disfunção ventricular tardiamente após a correção a nível atrial e em pacientes com transposição corrigida das grandes artérias.

Do ponto de vista fisiopatológico, a sobrecarga pressórica aguda imposta ao ventrículo induz síntese protéica e consequente hipertrofia miocárdica, cuja magnitude seria suficiente para suportar a elevada resistência vascular sistêmica imposta pela correção anatômica da TGA em poucos dias ${ }^{3}$. Baseado nesses conceitos, Jonas e colaboradores introduziram o conceito de treinamento rápido do $\mathrm{VE}$, demonstrando que a cirurgia de bandagem pulmonar associada a um shunt sistêmico-pulmonar seria capaz de induzir uma hipertrofia adequada do VE, em um período médio de nove dias, realizando, então, a correção anatômica a seguir ${ }^{4}$.

Apesar de grande entusiasmo inicial com esta abordagem, os bons resultados alcançados pelo grupo do Children's Hospital de Boston não foram reprodutíveis em outros centros pela elevada morbidade e mortalidade relacionada a período de adaptação da função ventricular, que requer atendimento pós-operatório otimizado ${ }^{5}$. Além disso, observaram-se problemas com a bandagem do tronco pulmonar durante o seguimento. Houve maior ocorrência de insuficiência aórtica, dilatação do anel pulmonar, 
necessidade frequente de ajuste da bandagem, que se tornava frouxa ao longo do tempo. Mais importante foram as alterações celulares encontradas no miocárdio submetido a sobrecarga aguda de pressão; focos de necrose e edema celular indicavam sinais de dano celular e indução de hipertrofia patológica, seguidos de disfunção ventricular tardia. ${ }^{6,7,8,9,10,11,12,13}$

Desta forma, o estudo da hipertrofia miocárdica induzida pela bandagem do tronco pulmonar é essencial para o perfeito entendimento dos mecanismos envolvidos na diferenciação entre a desejável hipertrofia "fisiológica" e a deletéria hipertrofia "patológica". As informações obtidas nesta linha de pesquisa seriam importantes para o desenvolvimento de uma hipertrofia ventricular durável, sem disfunção ventricular. Tanto a definição da freqüência e da quantidade de sobrecarga ideais para desenvolvimento de hipertrofia miocárdica fisiológica não estão ainda estabelecidos. Este estudo procura analisar e aprimorar este processo de re-hipertrofia do ventrículo sub-pulmonar, buscando no conceito de programas de condicionamento físico da musculatura estriada esquelética de atletas, alternativas para melhorar a qualidade da hipertrofia do músculo estriado cardíaco. A seguir, abordar-se-ão os mecanismos envolvidos na diferenciação entre hipertrofia miocárdica fisiológica versus patológica. 
4.1. Hipertrofia Miocárdica Fisiológica versus Patológica. A hipertrofia cardíaca é definida por aumento anormal da massa miocárdica, que é funcionalmente e morfologicamente distinta do crescimento pós-natal e embriônico, por alterações características da forma e volume do cardiomiócito. ${ }^{14} \mathrm{~A}$ hipertrofia ocorre em resposta a estímulos extrínsecos que, via de regra, causariam sobrecarga de volume ou de pressão. A resposta do miocárdio ao estresse hemodinâmico imposto depende do tipo de estímulo, sendo a hipertrofia concêntrica relacionada à sobrecarga de pressão e a excêntrica relacionada à sobrecarga de volume. ${ }^{15}$ No entanto, os mecanismos moleculares que regulam a resposta hipertrófica ainda são mal compreendidos. Meerson ${ }^{16}$ definiu a hipertrofia cardíaca como uma resposta universal do coração à injúria ou sobrecarga que, de acordo com a lei de Laplace, objetiva a normalização do elevado estresse de parede (relação do raio da cavidade pela espessura da parede ventricular). $\mathrm{Na}$ hipertrofia concêntrica, a diminuição compensatória do estresse de parede promove vantagens mecânicas a fim de normalizar o volume sistólico, em virtude de maior pós-carga. ${ }^{17}$ Entretanto, se ocorrer um estímulo hemodinâmico persistente e prolongado, como ocorre na hipertensão arterial sistêmica e na estenose aórtica, a hipertrofia passa a ser patológica, pois os mecanismos adaptativos estariam esgotados. Por outro lado, a hipertrofia fisiológica, como ocorre na gravidez e nos atletas, é funcionalmente uma resposta adaptativa ao maior requerimento fisiológico, caracterizada por aumento anormal da massa de cardiomiócitos com maior expressão gênica, que é completamente reversível e sem seqüelas. ${ }^{18} \mathrm{~A}$ explicação para alguns 
estímulos serem considerados patológicos e outros fisiológicos é tema de grande debate na literatura. Todavia, uma das teorias mais aceitas seria que as sobrecargas fisiológicas são por natureza intermitentes e as patológicas contínuas ou crônicas. ${ }^{19}$

O estudo da hipertrofia do ventrículo direito através de estresse sistólico gradual induzido por cateter balão e/ou manguito hidráulico tem sido objeto de vários estudos do nosso laboratório, há mais de uma

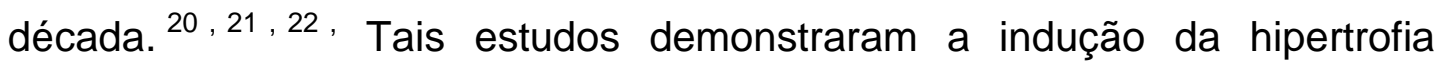
ventricular em 96 horas, através de sobrecargas sistólicas progressivas, sem aumento do edema extracelular ou fibrose intersticial. ${ }^{3,23,24,25} \mathrm{~A}$ busca por um processo hipertrófico mais próximo do fisiológico tem sido almejada através de evidências que suportem a teoria de que a sobrecarga intermitente seja o caminho ideal. ${ }^{26,27,28} \mathrm{O}$ mecanismo pelo qual o coração se adapta as sobrecargas fisiológicas ou patológicas, produzindo respostas adaptativas ou mal adaptativas, é desconhecido. É também possível que sobrecargas quantitativamente diferentes tenham repercussões distintas no coração, mesmo que aplicadas pelo mesmo período, produzindo respostas fenotípicas ambíguas. Isso indica que a hipertrofia cardíaca relacionada à sobrecarga pressórica é um processo dependente da composição genética celular, responsável pela adaptação ou descompensação a nível celular. A informação a respeito da expressão gênica de enzimas envolvidas no processo hipertrófico relacionado à bandagem do tronco pulmonar representa uma lacuna na literatura. Tal estudo infelizmente não pode ser 
desenvolvido, pela falta de ensaio específico para a espécie animal do presente estudo.

A seguir, abordar-se-á a relação entre condicionamento físico e hipertrofia miocárdica, a fim de estabelecer o racional para a intermitência de treinamento ventricular proposta com a bandagem ajustável do tronco pulmonar. 
4.2. Condicionamento Físico e Hipertrofia Miocárdica. A sobrecarga sistólica do exercício físico desencadeia um processo hipertrófico fisiológico, adaptado para manter uma demanda aumentada do débito cardíaco durante a atividade física, através da diminuição da freqüência cardíaca de repouso e do exercício físico, com conseqüente aumento do tempo de enchimento diastólico e de retorno venoso. ${ }^{29,30,31}$ Embora a hipertrofia desencadeada por meio da hipertensão arterial crônica apresente graus semelhantes ao do coração do atleta, existem diferenças funcionais e estruturais entre os dois padrões de hipertrofia. A hipertrofia cardíaca patológica da hipertensão arterial sistêmica induz à diminuição da função cardíaca $^{32}$ e pode ocasionar a insuficiência cardíaca, ao passo que o aumento da massa cardíaca observada em indivíduos treinados caracteriza-se por padrão excêntrico e é acompanhada de aumento do volume sistólico. ${ }^{33,34,35}$ É interessante notar que a aquisição de massa ventricular esquerda durante o condicionamento físico de atletas que praticam natação, por exemplo, atinge o pico em apenas uma semana de treinamento. Posteriormente, a massa ventricular permanece relativamente constante. Parece lógico que, em qualquer forma de treinamento físico, sejam necessários períodos para descanso ou recuperação aeróbica muscular. Uma situação de exercício físico ininterrupto, principalmente partindo de uma sobrecarga aguda elevada, pode resultar em danos musculares variados, muitos somente detectados em seguimentos tardios. Estudos de treinamento físico em atletas demonstraram que o comportamento muscular é peculiar, dependente do treinamento aplicado e de resposta individualizada, necessitando de um 
programa de treinamento particular para obtenção de uma adaptação mais fisiológica e, conseqüentemente, um desempenho muscular mais eficaz. ${ }^{36,37,38,39,40}$ Desta forma, o treinamento deve-se basear em princípios (sobrecarga, especificidade, diferenças individuais, reversibilidade) e manipulado de acordo com variáveis como a freqüência do treino, intensidade da carga utilizada, duração da sessão de treino e volume, isto é, número total de estímulos num dado programa de treinamento físico. ${ }^{41} \mathrm{O}$ preparo do ventrículo sub-pulmonar desadaptado também é uma forma de treinamento para hipertrofia e ganho de massa muscular. O conceito do condicionamento físico em atletas, cujo treinamento físico deve permitir alternância com períodos de descanso (atividade física aeróbica), para promover uma hipertrofia muscular mais fisiológica, seria aplicado no processo de treinamento ventricular por meio de sobrecarga sistólica ajustável do tronco pulmonar. Provavelmente, o mecanismo deste processo hipertrófico desencadeia uma cascata de eventos que pode se desenvolver em boas condições durante os períodos de descanso e transporte de oxigênio ideal, e, por isso, sem o desenvolvimento de fibrose decorrente de isquemia. Esta hipótese é corroborada pelos estudos experimentais de Le Bret et al. ${ }^{42}$, que compararam a bandagem clássica do tronco pulmonar com a bandagem de duas horas diárias, durante um período de cinco semanas. Os autores demonstraram hipertrofia de magnitude semelhante nos grupos treinados, porém com várias áreas de fibrose evidenciadas apenas nos animais submetidos à bandagem clássica. Portanto, a sobrecarga intermitente foi capaz de induzir a hipertrofia ventricular sem fibrose 
miocárdica. A bandagem ajustável do tronco pulmonar poderia atuar como uma sobrecarga sistólica semelhante ao exercício físico de atletas, pela possibilidade de ser utilizada com períodos alternados de repouso, evitando assim a sobrecarga sistólica continua.

A seguir, abordar-se-á a relação entre o metabolismo energético do miocárdio e o processo de hipertrofia miocárdica. 


\subsection{Metabolismo Energético e Hipertrofia Miocárdica. O miocárdio} demanda energia relacionada à manutenção de processos celulares especializados, incluindo o transporte de íons, a função dos sarcômeros e a homeostase do cálcio intracelular. A demanda e a disponibilidade de energia estão em fluxo contínuo, sendo que o miocárdio tem uma capacidade limitada de armazenamento de substratos energéticos. Assim, as vias geradoras de ATP devem responder proporcionalmente às flutuações dinâmicas da demanda fisiológica e liberação de substratos energéticos. $\mathrm{O}$ coração normal e aquele submetido a situações de treinamento hipertrófico fisiológico utilizam preferencialmente os ácidos graxos como fonte de energia, representando aproximadamente $70 \%$ de toda a produção de ATP no coração normal. ${ }^{43,44,45,46,47,48}$ Os ácidos graxos derivam de lipoproteínas circulantes ricas em triglicerídeos e ácidos graxos não esterificados ligados à albumina, que são oxidados na matriz mitocondrial pelo processo de beta oxidação, produzindo acetilcoenzima A e coenzima nicotinamida adenina dinucleotideo Fosfato (NADPH). A acetilcoenzima A entra no ciclo de Krebs, produzindo mais NADPH.

\subsubsection{Hexoquinase e Lactato Desidrogenase na Hipertrofia Miocárdica.} Em situações de hipertrofia miocárdica patológica e de maior demanda energética, existe uma mudança da utilização de substratos energéticos, sendo a via glicolítica a principal. ${ }^{49}$ Essas alterações metabólicas foram evidenciadas por meio de mudanças de expressão gênica de enzimas mitocondriais dos ácidos graxos, maior atividade de enzimas da via 
glicolítica e maior concentração dos produtos finais de oxidação da Glicose $50,51,52,53,54$

Nestas situações, a Glicose utilizada como fonte de energia pelo miocárdio é preferencialmente derivada do glicogênio intracelular, além da Glicose e Lactato exógenos. ${ }^{55} \mathrm{~A}$ Glicose é metabolizada inicialmente em Glicose 6-Fosfato pela enzima Hexoquinase. A seguir, entra predominantemente na via glicolítica, produzindo uma pequena quantidade de ATP e também piruvato, o qual entra no ciclo de Krebs, e aumenta a produção de NADPH. Na ausência de oxigênio, a quantidade total de energia produzida por esses processos é insuficiente para atender as necessidades energéticas do coração. O piruvato é então metabolizado em Lactato pela enzima Lactato Desidrogenase. O esquema do metabolismo energético está representado de forma simplificada na Figura 1.

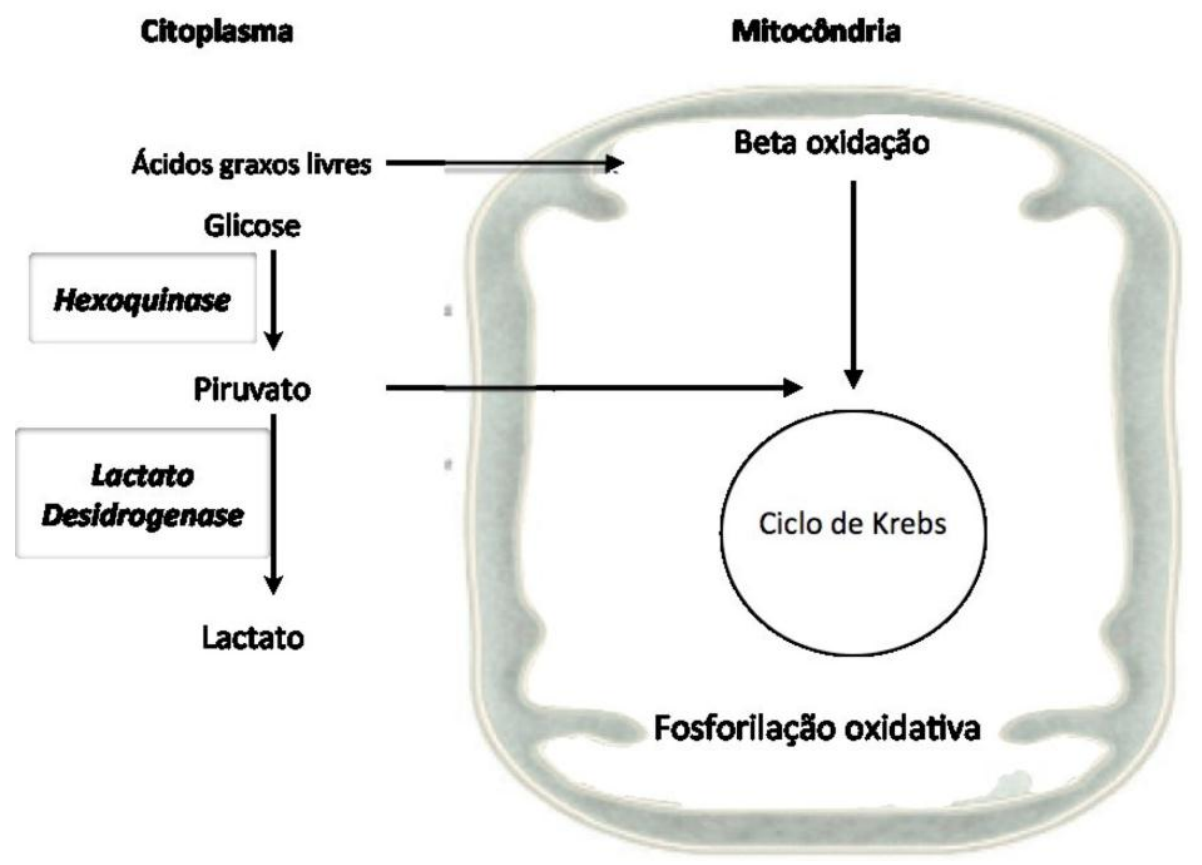

Figura 1 - Esquema simplificado do metabolismo da Glicose e dos ácidos graxos e as funções das enzimas Hexoquinase e Lactato Desidrogenase. 


\subsubsection{Glicose 6-Fosfato Desidrogenase: papel no estresse oxidativo e} redutivo. Uma pequena parte da Glicose 6-Fosfato entra na via das pentoses Fosfato, na qual a Glicose 6-Fosfato Desidrogenase (G6PD) é a primeira enzima reguladora, conforme representado na Figura 2. Ela converte Glicose 6-Fosfato em 6-fosfogluconolactona, e apresenta duas funções principais. A primeira função é fornecer equivalentes redutores na forma de coenzima nicotinamida adenina dinucleotideo Fosfato (NADPH), que podem ser utilizados na síntese de ácidos graxos livres e para a regeneração da glutationa oxidada para reduzida, criticamente importante na defesa celular contra lesões do estresse oxidativo ${ }^{56}$, participando em reações de remoção de radicais livres ${ }^{57} \mathrm{O}$ NADPH reduz a glutationa via glutationa redutase, que converte água oxigenada em água pela glutationa peroxidase. Se ausente, a água oxigenada seria convertida em radicais livres de oxigênio, com conseqüências maléficas para o cardiomiócito.

A segunda função da G6PD está relacionada à produção de ribose 5Fosfato, usada na síntese de nucleotídeos e ácidos nucléicos, indispensáveis para a hipertrofia miocárdica. A ribose 5-Fosfato é transformada em 5 -fosforibosil piroFosfato, um substrato essencial para a síntese "de novo" de purinas. Entretanto, a maior disponibilidade de ácidos nucléicos não se traduz necessariamente em melhor qualidade da hipertrofia. Embora uma capacidade aumentada de glicólise no miocárdio hipertrófico isquêmico leve a maior produção de ATP, isto pode agravar o dano miocárdico durante a isquemia devido à produção aumentada de 
produtos da reação glicolítica, tais como o Lactato, NADPH e acúmulo de radicais livres. ${ }^{58,59}$

\section{Glicose 6-Fosfato Desidrogenase}

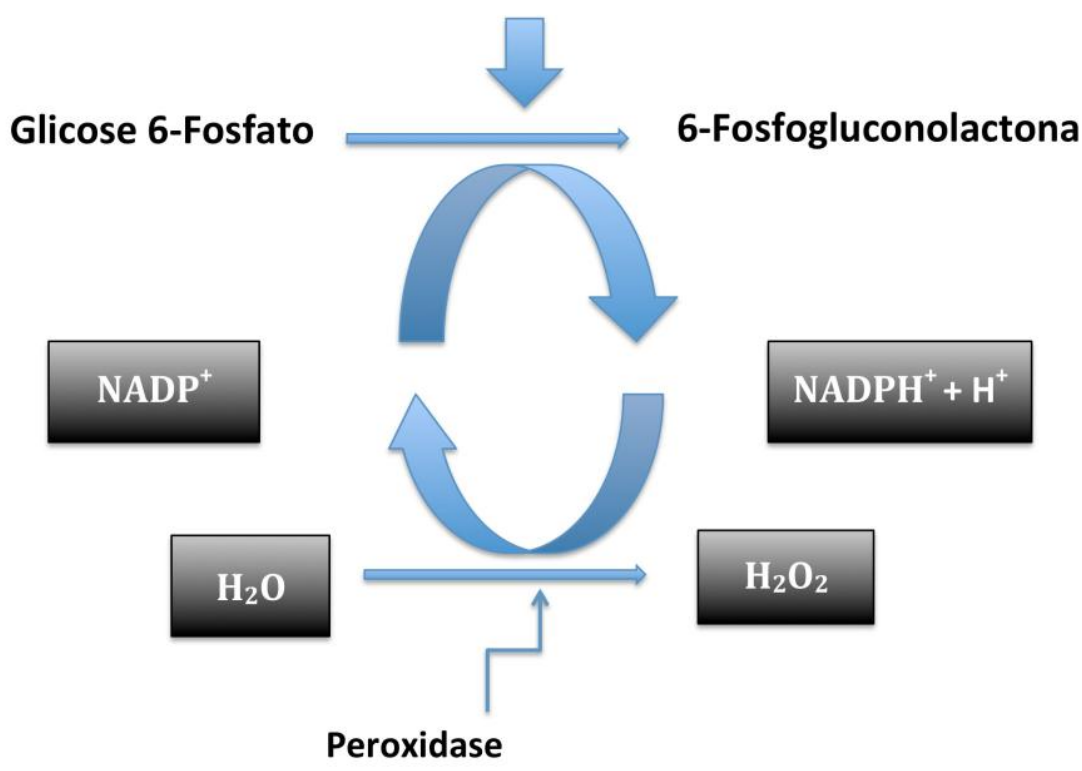

Figura 2 - Esquema simplificado do metabolismo da via das pentoses fosfato, destacando o papel da enzima glicose 6-fosfato desidrogenase na geração de ânions superóxido.

A enzima G6PD é indispensável para a manutenção do equilíbrio de NADPH citoplasmático, para atender as necessidades celulares de biosíntese redutiva e, consequentemente, o balanço celular redox. ${ }^{60} \mathrm{O}$ papel da G6PD, como uma enzima antioxidante tem sido reconhecida em eritrócitos há muito tempo, sendo que sua deficiência, o distúrbio da homeostase redox, pode levar a desregulação do crescimento celular, desenvolvimento embriônico anômalo, maior susceptibilidade a infecções virais, assim como doenças degenerativas. ${ }^{61}$ 
O oxigênio é fundamental na formação de radicais livres, tais como o peróxido de hidrogênio e o radical hidroxil. Eles induzem dano celular irreversível por alterações na estrutura proteica, no DNA mitocondrial e genômico. A G6PD é indispensável na manutenção do balanço redox e eliminação de radicais livres, desde que a deficiência de G6PD enfraquece a capacidade antioxidante da célula, levando a maior predisposição a apoptose. Além de uma função primordial na regulação da fisiologia celular, a G6PD é igualmente importante no funcionamento do sistema cardiovascular. A atividade da G6PD afeta a enzima óxido nítrico sintase e a biodisponibilidade de óxido nítrico. Regula assim a função das células endoteliais $^{62,63}$, além de participar da homeostase do cálcio intracelular e da contração miocárdica. ${ }^{64}$

O fato de que o estresse oxidativo, pela geração de radicais livres, está implicado em uma série de doenças é inquestionável. Entretanto, o desbalanço do chamado equilíbrio redox (balanço entre processos oxidativo e redutivo) a favor do estresse oxidativo é o fator mais relevante da fisiopatologia de múltiplas doenças, incluindo a aterosclerose, doenças neurodegenerativas, câncer e insuficiência cardíaca. Isso pode ser reproduzido experimentalmente pela ativação de enzimas oxidativas (NADPH oxidase e xantina oxidase), assim como inibição de enzimas que controlam as mesmas (catalase e glutationa peroxidase, superóxido dismutase e tioredoxina redutase). ${ }^{65}$ Entretanto, existem situações em que a ativação da G6PD incrementa a geração de superóxidos derivados da $\mathrm{NADPH}$ oxidase, o que favorece $\mathrm{o}$ estresse oxidativo e tem papel em 
doenças como o diabetes, insuficiência cardíaca e hipertensão. ${ }^{66,67}$ Todavia, Rajasekaran et al. ${ }^{68}$, utilizando um modelo transgênico em camundongos, descobriram que o estresse redutivo, definido como aumento anormal de equivalentes redutores (glutationa reduzida e NADPH) do estresse oxidativo, contribui para a patogênese molecular de um tipo específico de cardiomiopatia desencadeado por agregação proteica. Corroborando estes achados, o bloqueio da atividade da enzima controladora da atividade de NADPH, a G6PD, foi suficiente para 0 não desenvolvimento de cardiomiopatia. Portanto, o aumento da atividade da G6PD incrementa a produção de $\mathrm{NADPH}$, a fonte principal de equivalentes redutores, causando o estresse redutivo por agregação proteica. ${ }^{69}$

Portanto, o estresse oxidativo pode ocorrer durante processos de hipertrofia miocárdica, tanto como causa ou consequência de uma cascata de eventos patológicos. A ativação da enzima Glicose 6-Fosfato Desidrogenase pode levar a consequências tanto benéficas, quanto maléficas, na dependência da magnitude e da duração do estímulo hipertrófico.

Dentro deste contexto, o objetivo primário deste estudo tem relação com as alterações metabólicas encontradas nos dois tipos de treinamento ventricular. 
Objetivos 


\section{OBJETIVOS}

\section{Primário}

Comparar o processo hipertrófico agudo do ventrículo direito desencadeado por sobrecarga sistólica contínua e intermitente do ponto de vista metabólico.

\section{Secundário}

Analisar e comparar a hipertrofia rápida sob os pontos de vista hemodinâmico, morfológico, ecocardiográfico e ganho de água no miocárdio nos dois processos distintos de sobrecarga sistólica do ventrículo direito (intermitente e contínua). 
Métodos 


\section{MÉTODOS}

Este estudo foi realizado de acordo com as normas de uso de animais em ensino e pesquisa da Comissão de Fiscalização de Pesquisa Animal. Foram utilizados 27 cabritos hígidos, com idade entre 30 e 60 dias, divididos em três grupos: SHAM ou controle negativo $(n=7)$, contínuo $(n=9$, sobrecarga sistólica contínua do VD), intermitente $(\mathrm{n}=11,12$ horas/dia de sobrecarga sistólica intermitente do VD). As médias dos pesos corporais de cada grupo estão relacionadas na tabela 1 . Não houve diferença significativa entre os grupos $(p=0,38)$.

Tabela 1. Peso dos animais dos grupos SHAM, contínuo e intermitente

\begin{tabular}{cccc}
\hline $\begin{array}{c}\text { Sham } \\
\mathbf{n}=\mathbf{7}\end{array}$ & $\begin{array}{c}\text { Contínuo } \\
\mathbf{N}=\mathbf{9}\end{array}$ & $\begin{array}{c}\text { Intermitente } \\
\mathbf{N}=\mathbf{1 1}\end{array}$ & Valor de $\mathbf{p}$ \\
\hline $11,93 \pm 2,67$ & $10,74 \pm 2,62$ & $10,25 \pm 2,20$ & 0,38 \\
\hline
\end{tabular}

Valores $(\mathrm{Kg})=$ média \pm desvio padrão

6.1. Avaliação pré-operatória. $\mathrm{Na}$ entrada ao biotério, os animais foram examinados por veterinário para afastar doenças preexistentes. 
6.2. Anestesia. Os animais permaneceram 24 horas em jejum antes da cirurgia. A indução anestésica foi feita com quetamina $(20 \mathrm{mg} / \mathrm{kg}$, intramuscular). Os animais foram pesados e submetidos à tricotomia cervical e no hemitórax esquerdo ainda no biotério. Em seguida, uma linha de infusão venosa foi obtida através de punção da veia jugular com Jelco nํㅜ 18, para administração de drogas e infusão de soro fisiológico. $O$ animal foi então sedado com pentobarbital sódico ( 5 a $10 \mathrm{mg} / \mathrm{kg}$, intravenoso) e entubado. A ventilação mecânica (Harvard 708, South Natick, MA, E.U.A.) foi mantida com fração inspirada de oxigênio de $100 \%$ e volume corrente de 15 $\mathrm{ml} / \mathrm{kg}$. O animal foi posicionado em decúbito lateral direito, monitorizado com eletrocardiograma e preparado para procedimento estéril. A anestesia foi mantida com pentobarbital sódico (5-10 mg/Kg, via intravenoso) e quetamina (1 $\mathrm{mg} / \mathrm{kg}$ intravenoso). Todos os animais receberam antibioticoterapia (cefazolina $500 \mathrm{mg}$ e gentamicina $40 \mathrm{mg}$ por via intramuscular), iniciada imediatamente antes da cirurgia e mantida até o final do protocolo. Também foram administrados diariamente digoxina $(0,01 \mathrm{mg} / \mathrm{Kg}$ por via intravenosa) e heparina (5000 U por via subcutânea) até o final do protocolo.

6.3. Procedimento cirúrgico. Foi realizada toracotomia lateral esquerda no 4º espaço intercostal. O pulmão foi afastado para exposição adequada da via de saída do VD, do tronco pulmonar (TP) e da aorta torácica descendente. Foram então implantados três cateteres (intracath 17G) previamente heparinizados no VD, TP e aorta torácica descendente, respectivamente. Os cateteres foram fixados nas estruturas com prolene 5-0 
e exteriorizados através da parede torácica, próximos à coluna vertebral, onde também foram fixados à pele com fio de algodão 3-0. A seguir, estes cateteres foram testados (permeabilidade e curvas de pressão) e mantidos heparinizados. O tronco pulmonar foi então dissecado para implante do dispositivo de bandagem do TP. O dispositivo foi posicionado imediatamente acima da valva pulmonar, sendo fixado na adventícia do TP para evitar sua migração (Figura 3).

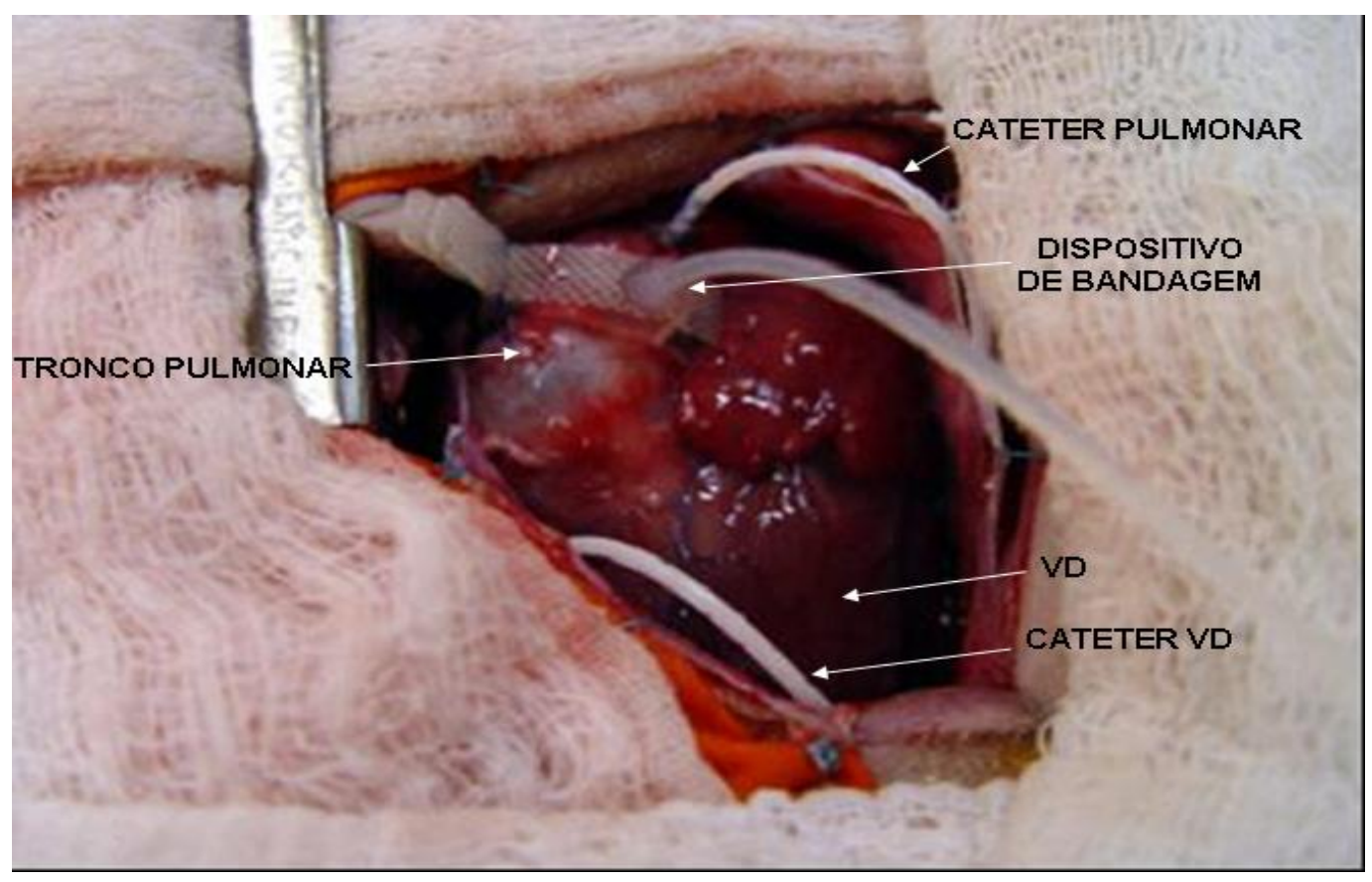

Figura 3. Foto cirúrgica do dispositivo de bandagem no tronco pulmonar e o posicionamento de cateteres de monitorização no ventrículo direito e artéria pulmonar.

As pressões, proximal e distal ao dispositivo de bandagem ajustável do TP, bem como a pressão arterial sistêmica, foram medidas através de 
sistema de software ACQ Knowledge 3.01 (Biopac Systems, Inc., Goleta, CA, EUA).

Após o implante do dispositivo, foi realizada a drenagem do tórax em selo d’água e síntese da toracotomia por planos (Figura 4).

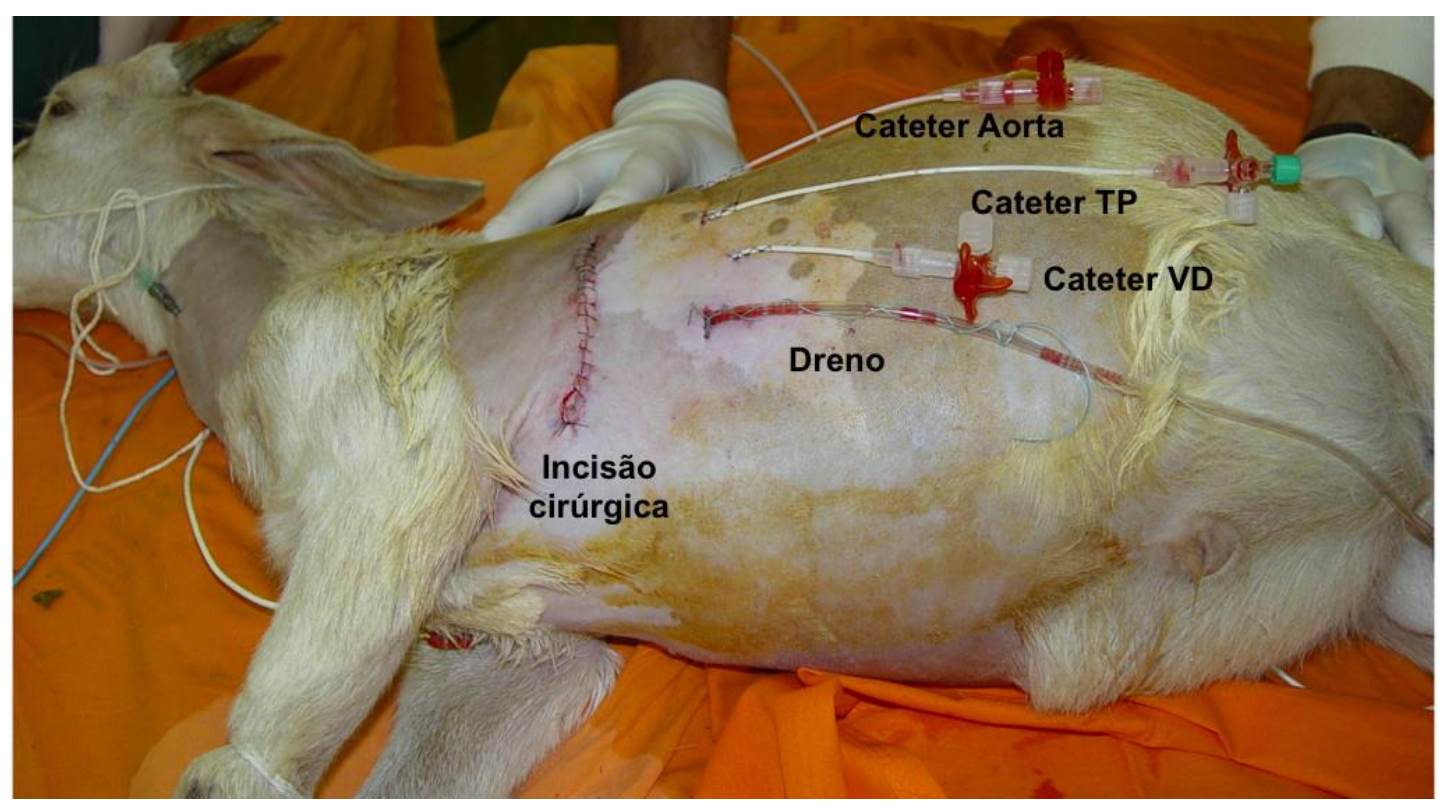

Figura 4. Animal após o implante do dispositivo, com cateteres e dreno pleural exteriorizados através da parede torácica. Presença da incisão da toracotomia lateral esquerda.

A recuperação anestésica completa do animal foi obtida no biotério, em maca especial para quadrúpedes (Figura 5). Cerca de seis horas de pósoperatório imediato, o dreno de tórax foi removido, após a constatação de drenagem mínima, ausência de fístula bronco pleural e boa expansibilidade pulmonar. 


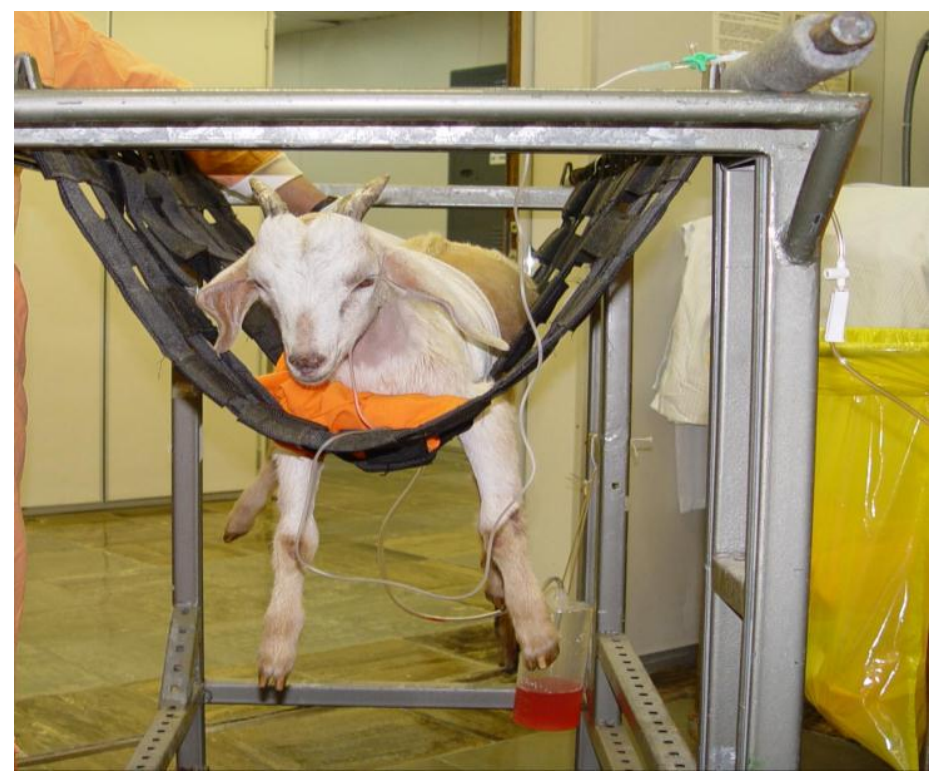

Figura 5. Animal em recuperação anestésica na maca especial para quadrúpedes.

6.4. Dispositivo de bandagem do tronco pulmonar. $O$ dispositivo de bandagem utilizado no presente estudo foi desenvolvido e aprimorado com colaboração da SILIMED, Silicone e Instrumental Médico-Cirúrgico e Hospitalar Ltda., Rio de Janeiro, RJ. O dispositivo é constituído por três partes totalmente revestidas por silicone biomédico: anel de bandagem, tubo extensor e botão de insuflação (Figura 6). O anel de bandagem é um manguito hidráulico em forma de C, cuja parede externa é constituída por uma camada externa rígida e mais fina que o protótipo anterior, reforçada por uma malha de poliéster, que impede a deformação centrífuga do anel. Apresenta diâmetro interno de $10 \mathrm{~mm}$ e largura de $7 \mathrm{~mm}$. Nas duas extremidades do anel, existem prolongamentos da camada rígida, que possibilitam a passagem de pontos para fechamento e fixação do anel no tronco pulmonar. 
O anel apresenta uma bolsa elástica interna, que é potencialmente capaz de dilatar seu volume em $500 \%$, promovendo uma variabilidade muito grande de constrição reversível do tronco pulmonar submetido à bandagem. Quando a bolsa interna é expandida através do volume injetado no reservatório de insuflação, comprime a luz do tronco pulmonar. Este reservatório consiste em um botão de silicone espesso, auto-selante, cuja base apresenta uma placa rígida de porcelana. Implantado no subcutâneo da região dorsal do animal, permite o ajuste fino do diâmetro do anel de bandagem por via percutânea. $O$ tubo conector comunica $\circ$ anel de bandagem com o botão de insuflação, com a finalidade de conduzir o líquido injetado no botão para o anel de insuflação. É flexível e possui dois milímetros de diâmetro interno por $250 \mathrm{~mm}$ de comprimento. Este sistema é hermeticamente blindado na fábrica, impossibilitando a desconexão.

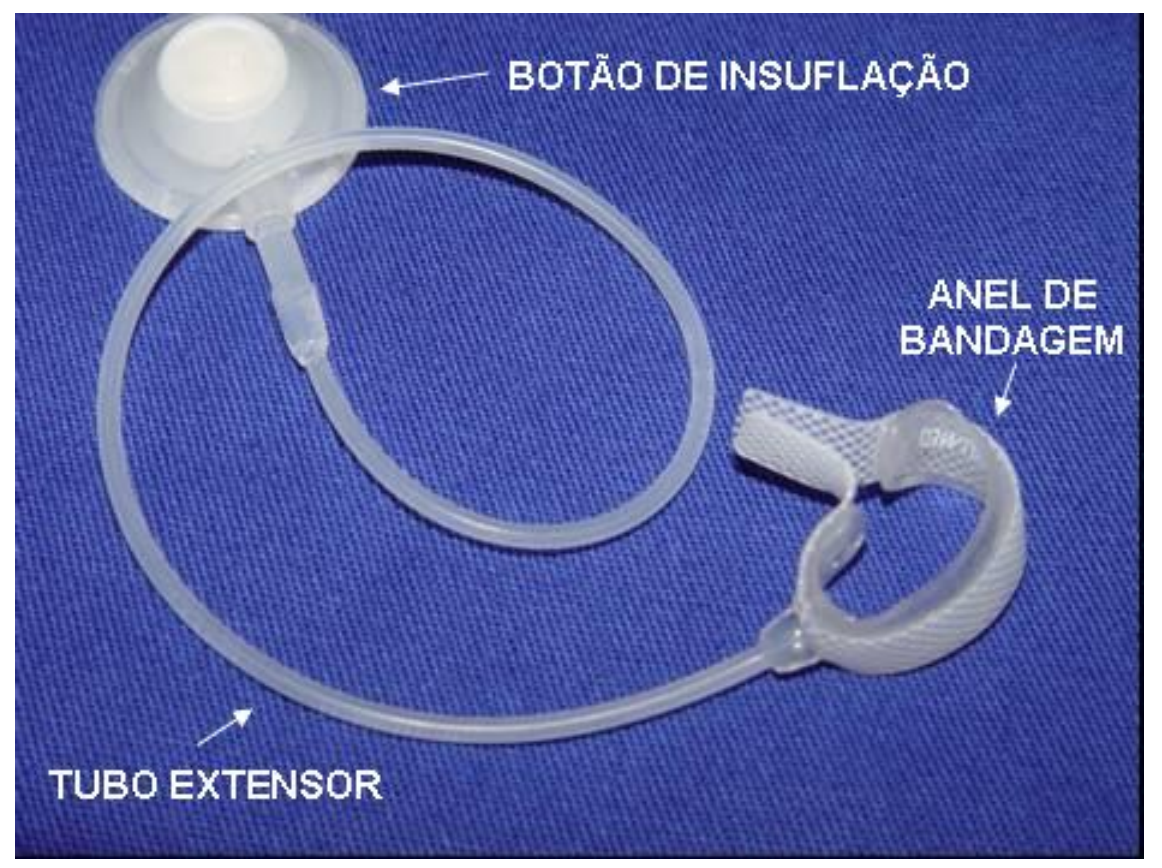

Figura 6. Dispositivo de bandagem ajustável do tronco pulmonar. 
6.5. Protocolo de sobrecarga sistólica do VD. O treinamento do VD foi iniciado após recuperação plena da cirurgia (72 horas de convalescença). Com o animal consciente e imobilizado na maca especial, procedeu-se à leitura das pressões basais de VD, TP e aorta, com o dispositivo completamente desinsuflado. Após a leitura das pressões basais, foi iniciada a insuflação percutânea do dispositivo com soro fisiológico (seringa de insulina), observando-se as curvas das pressões do VD e aorta e objetivando alcançar uma relação de pressão do VD de aproximadamente $70 \%$ da pressão sistólica sistêmica, desde que não provocasse uma queda superior a 10\% na mesma. Caso o animal apresentasse sinais clínicos de hipóxia importante, como agitação, dificuldade respiratória ou arritmias, o volume do dispositivo era reduzido para um valor tolerável pelo animal. Os dados hemodinâmicos foram então tomados após a insuflação do dispositivo (tempo zero - início do treinamento ventricular). A insuflação do dispositivo e a medida das pressões na aorta, VD e TP foram realizadas diariamente nos dois grupos treinados. O volume de soro do dispositivo foi medido e comparado com o do dia anterior para avaliar possível perda. Novamente, o dispositivo era insuflado, procurando-se atingir os parâmetros desejados, geralmente sendo possível acrescentar um maior volume a cada dia. Nesta avaliação diária, era necessária a correção da insulflação do dispositivo para manter a mesma relação de pressões inicialmente almejada, pois havia pequena perda de volume de insulflação por microporos do anel de bandagem, além de adaptação do sistema cardiovascular (resistência vascular e volume sistólico). O gradiente de pressão entre o VD e o tronco 
da artéria pulmonar foi calculado através da subtração de suas pressões sistólicas.

6.5.1. Grupo Contínuo. Os animais permaneceram em sobrecarga sistólica contínua do VD por um período de 96 horas, com insuflações progressivas do dispositivo de bandagem ajustável a cada 24 horas. As pressões foram tomadas apenas uma vez ao dia (todas as manhãs).

6.5.2. Grupo Intermitente. A figura 7 ilustra o diagrama cronológico da coleta de dados do grupo Intermitente. Foram tomadas quatro medidas de pressões a cada período de 12 horas, ou seja, na manhã de cada dia do protocolo, as pressões foram medidas antes de se insuflar o dispositivo de bandagem ( $1^{\text {a }}$ medida). Imediatamente a seguir, insufla-se o dispositivo até obter uma relação de pressões sistólicas VD/aorta de 70\% (2 $2^{\text {a }}$ medida). Após 12 horas (período noturmo), as pressões deixadas pela manhã foram novamente medidas ( $3^{a}$ medida) para avaliar a manutenção da sobrecarga sistólica durante as 12 horas de treinamento. O dispositivo foi então desinsuflado para permitir 12 horas de descanso. As pressões foram tomadas imediatamente após ser retirada a sobrecarga sistólica do VD (4⿳⺈冂a medida). Todas as medidas do Grupo Intermitente foram tomadas para se demonstrar o caráter intermitente da sobrecarga sistólica deste grupo. Os animais permaneceram com quatro períodos de 12 horas de sobrecarga sistólica do VD (período diurno), alternados com 12 horas de descanso (período noturno), durante o mesmo tempo de 96 horas do grupo contínuo. 
Após 96 horas de protocolo, foram tomadas medidas pressóricas finais com o dispositivo vazio e re-insuflado.

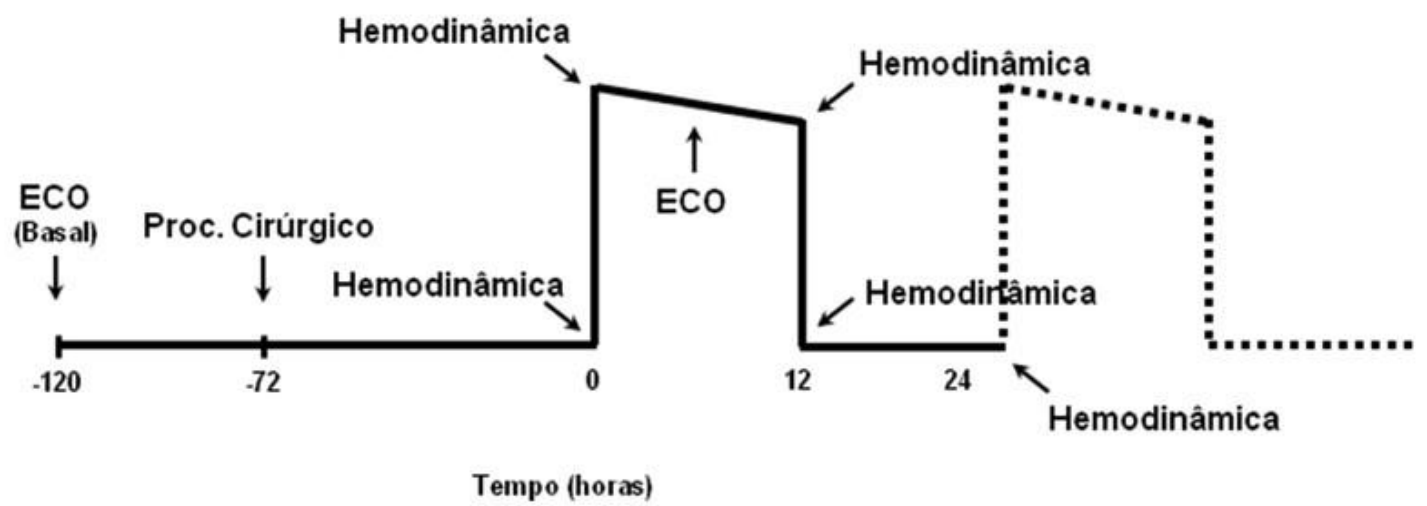

Figura 7: Diagrama cronológico da coleta de dados do grupo Intermitente

6.5.3. Grupo SHAM. Os animais deste grupo foram submetidos ao implante do dispositivo de bandagem ajustável no TP e cateteres de monitorização hemodinâmica, conforme previamente relatado. Foram tomadas medidas hemodinâmicas diariamente, porém com o dispositivo de bandagem ajustável desinsuflado até o final do período de estudo (96 horas), após o qual foram avaliados os parâmetros morfológicos e de metabolismo energético.

6.6. Estudo Ecocardiográfico. Todos os animais foram submetidos à avaliação ecocardiográfica pelo mesmo especialista, sob sedação (quetamina $15 \mathrm{mg}$ por via intramuscular) e posicionados em decúbito esternal. A primeira avaliação ecocardiográfica foi realizada cerca de 120 horas antes do início do treinamento ventricular (2o dia pré-operatório). Em 
relação ao tempo zero, os dados ecocardiográficos foram tomados logo após a insuflação do dispositivo de bandagem ajustável do tronco pulmonar (início do treinamento ventricular) e estabecimento das medidas hemodinâmicas protocolares. Durante o protocolo, o ecocardiograma foi realizado diariamente para avaliar todos os animais, tanto do grupo Sham como também de ambos os grupos submetidos à sobrecarga sistólica do VD. Foram utilizados transdutores de $7,5 \mathrm{MHz}$ para a obtenção das imagens e de 2,5 $\mathrm{MHz}$ para análise dos fluxos. As espessuras do septo interventricular e parede posterior do VE foram medidas no modo M, no final da diástole, por meio do corte paraesternal transverso, na altura dos músculos papilares. A espessura da parede livre do VD foi medida através do ecocardiograma bidimensional, no mesmo corte paraesternal, na altura dos vasos da base e dos músculos papilares, sempre no final da diástole. Estas medidas também foram tomadas no corte longitudinal quatro câmaras. O resultado da espessura da parede livre do VD representa a média das três medidas obtidas em cada exame. Neste mesmo corte, foram mensurados os volumes diastólico (VDF) e sistólico (VSF) finais do VD pelo método de Simpson modificado ${ }^{70}$. Estes volumes (VSF e VDF) foram obtidos através da fórmula área $x$ comprimento. Neste método, para o cálculo da área, procede-se a planimetria de todo o endocárdio ventricular direito, indo de um extremo a outro do anel da valva tricúspide. O comprimento é medido do ápice até o ponto que intercepte uma linha imaginária que ligue os dois lados do anel valvar tricúspide. Estes parâmetros são mensurados no final da diástole e da sístole. 
A eficiência hemodinâmica foi avaliada através da fração de ejeção do VD (FEVD), que foi obtida a partir da diferença dos volumes assim medidos, conforme a fórmula proposta por Pontes et al ${ }^{71}$ :

\section{FEVD $=$ VDFVD - VSFVD}

\section{VDFVD}

Foram considerados normais valores de FEVD iguais ou acima de $55 \%^{72,73}$. O índice de desempenho miocárdica do VD (IDMVD) foi também calculado segundo a fórmula:

\section{$I D M_{V D}=\underline{\text { TCIV }+ \text { TRIV }}$}

TE

Onde "TCIV" representa o tempo de contração isovolumétrica, "TRIV", o tempo de relaxamento isovolumétrico e "TE", o tempo de ejeção. Estes valores foram obtidos no corte longitudinal quatro câmaras, posicionando o volume da amostra no centro do anel valvar tricúspide e medindo o intervalo de tempo entre o início do fechamento valvar até o início da próxima diástole (tempo a). O tempo de ejeção do VD foi calculado com o volume da amostra localizado na via de saída desta câmara (tempo b), pelo corte paraesternal eixo curto. Subtraindo-se o tempo a pelo de b, obteve-se TCIV + TRIV. Este valor foi então dividido pelo TE, adquirindo- se o IDMVD. 
6.7. Coleta das Amostras Cardíacas. Após o encerramento do protocolo de cada animal, foi realizada eutanásia para ressecção do coração. Após anestesia geral com quetamina (30 $\mathrm{mg} / \mathrm{Kg}$, intramuscular) e pentobarbital sódico (15 mg/Kg, intravenoso) e entubação orotraqueal, foi realizada toracotomia esquerda sobre a incisão prévia, para exposição do coração. Foram realizadas lises de bridas e dissecção das veias cavas superior, inferior e grandes artérias. Após aprofundamento do plano anestésico, foi administrada heparina (5 mg/kg por via intravenosa). Após circulação da heparina, as veias cavas foram ligadas. Foi administrado cloreto de potássio até causar parada cardíaca. Neste momento, foram colhidas amostras do VD, VE e septo interventricular, pesadas e imediatamente acondicionadas em recipientes plásticos previamente identificados. Estas amostras foram armazenadas em nitrogênio líquido $\left(-80^{\circ} \mathrm{C}\right)$, até serem transportados ao Laboratório de Genética e Cardiologia Molecular, onde foram conservadas em freezer especial (Forma Scientific $-80^{\circ} \mathrm{C}$ ). Posteriormente, o coração foi ressecado. A gordura epicárdica foi cuidadosamente ressecada e as paredes ventriculares e septal separadas, de acordo com a técnica de FULTON et al. ${ }^{74} \mathrm{~A}$ aorta e TP foram ressecadas no plano das valvas semilunares. Os átrios, juntamente com as valvas átrio-ventriculares, foram ressecados. A parede livre do VD foi separada do septo interventricular, cortando-a paralelo ao trajeto das artérias interventricular anterior e posterior. O mesmo procedimento foi realizado para separação da parede livre do VE da parede septal. A seguir, O VD, VE, septo interventricular e átrios foram pesados em balança digital (METTLER AE-200, Mettler-Toledo 
AG, Greifensee, Suíça). Devido à variação de peso dos animais, as medidas foram normalizadas através da indexação de peso das massas musculares cardíacas pelo respectivo peso corporal do animal, conforme sugestão de BISHOP \& COLE $^{75}$. Os pesos indexados foram expressos em $\mathrm{g} / \mathrm{kg}$.

6.8. Conteúdo de Água dos Tecidos. A principal finalidade desta avaliação foi para esclarecer se o ganho de peso do VD dos grupos de estudo estaria associado ao edema miocárdico ou aquisição de massa muscular. Foram colhidas amostras de cada uma das paredes cardíacas e pesadas em balança de alta precisão para determinar o respectivo peso inicial (Pi). As amostras foram então acondicionadas em frascos apropriados, fechados com papel filtro e devidamente identificadas, antes de colocá-las na estufa (temperatura: $55-60^{\circ}$ C). Após cerca de 70 horas de desidratação, cada amostra foi novamente pesada para se obter o peso seco (Ps). O percentual do conteúdo de água $(\mathrm{CA})$ foi então obtido através da seguinte fórmula, assumindo que a distribuição de água foi homogênea no septo e nos ventrículos: $\mathrm{CA}(\%)=100-\left(\mathrm{Ps} \times \mathrm{Pi}^{-1} \times 100\right)$.

6.9. Análise do Metabolismo Energético. As atividades máximas das enzimas Hexoquinase (HK, EC 2.7.1.1) e Glicose-6-Fosfato Desidrogenase (G6PD, E.C. 1.1.1.4.9.) foram determinadas nas amostras do septo e dos ventrículos, para avaliar a utilização de carbohidratos pelo miocárdio. A atividade máxima da enzima Lactato Desidrogenase (LDH, EC 1.1.1.27) foi também analisada para fornecer informações quantitativas a respeito do 
ciclo do 3-Fosfato Glicerol na oxidação do NADH citoplasmático do miocárdio. As amostras foram armazenadas em nitrogênio líquido, que foram homogeneizadas em tampão de extração (proporção 1:5 peso/volume). 0 material mantido em gelo foi homogeneizado por 30 segundos usando Polytron (PT 3100, Kinematica AG, Littau-Lucerne, Suíça) na velocidade máxima e centrifugado (15.000 g, 15 minutos, $4^{\circ} \mathrm{C}$ ) em Centrifuga 5417 C/R- Eppendorf (Hamburgo, Alemanha) para separação dos restos celulares. O sobrenadante da última centrifugação foi utilizado para a análise da atividade enzimática. As proteínas foram quantificadas pelo kit de ensaio protéico BCA ${ }^{\mathrm{TM}}$ (PIERCE Biotechnology, Rockford, IL, E.U.A.). Os resultados foram expressos em nmol. $\mathrm{min}^{-1} \cdot \mathrm{mg}^{-1}$ de proteína presente no extrato.

\subsubsection{Dosagem da Atividade Máxima da Glicose-6-Fosfato} Desidrogenase (G6PD). O tampão de extração para a G6PD continha TrisHCl (50 mM) e EDTA (1 mM), pH 8,0. O tampão de ensaio utilizado (volume de $270 \mu \mathrm{L}$ por amostra) consistiu de Tris- $\mathrm{HCl}(8,6 \mathrm{mM}), \mathrm{MgCl}_{2}(6,9 \mathrm{mM})$, $\operatorname{NADP}^{+}(0,4 \mathrm{mM})$ e Triton X-100 0,05\% (volume/volume), pH 7,6. A reação foi iniciada com a adição de $15 \mu \mathrm{L}$ de Glicose-6-Fosfato $(1,2 \mathrm{mM})$ ao extrato enzimático (15 $\mu \mathrm{L}$ de amostra) e acompanhada por 10 minutos, a 25으 C. A absorbância foi monitorada a $340 \mathrm{~nm}$, sendo o coeficiente de extinção para este comprimento de onda igual a 6,22. O princípio da reação baseia-se na formação de Glicose-6-Fosfato a partir da Glicose e posterior formação de 6Fosfogluconato pela ação da enzima G6PD. A atividade da G6PD foi 
determinada indiretamente como medida da produção total de NADPH pela via das pentoses ${ }^{76}$.

6.9.2. Dosagem da Atividade Máxima da Hexoquinase (HK). O tampão de extração para a $\mathrm{HK}$ continha Tris- $\mathrm{HCl}(50 \mathrm{mM})$, EDTA (1 mM), Trietanolamina (50 mM), $\mathrm{MgCl}_{2} 6 \mathrm{H}_{2} \mathrm{O}$ (2 mM), $\beta$-mercaptoetanol (30 mM), $\mathrm{pH}$ 7,5. O tampão de ensaio utilizado (volume de $270 \mu \mathrm{L}$ por amostra) consistiu de Tris- $\mathrm{HCl}(75 \mathrm{mM}), \mathrm{MgCl}_{2} 6 \mathrm{H}_{2} \mathrm{O}(7,5 \mathrm{mM})$, EDTA $(0,8 \mathrm{mM}), \mathrm{KCl}(1,5 \mathrm{mM})$, $\beta$-mercaptoetanol (4 mM), $\operatorname{NADP}^{+}(0,4 \mathrm{mM}), \operatorname{ATP}(2,5 \mathrm{mM})$, creatina quinase (1,8 U/mL), fosfocreatina $(0,4 \mathrm{mM}), \mathrm{G} 6 \mathrm{PD}(1,4 \mathrm{U} / \mathrm{mL})$ e Triton $\mathrm{X}-1000,05 \%$ (volume/volume), $\mathrm{pH}$ 7,5. A reação foi iniciada com a adição de $15 \mu \mathrm{L}$ de Glicose $(0,2 \mathrm{mM})$ ao extrato enzimático (15 $\mu \mathrm{L}$ de amostra) e acompanhada por 10 minutos a $25^{\circ} \mathrm{C}$. A absorbância foi monitorada a $340 \mathrm{~nm}$, sendo o coeficiente de extinção para este comprimento de onda igual a 6,22. 0 princípio da reação baseia-se na formação de Glicose-6-Fosfato a partir da Glicose e posterior formação de 6-Fosfogluconato pela ação da enzima G6PD. A atividade da HK foi determinada indiretamente como medida da produção total de NADPH nessa última reação. ${ }^{77}$

\subsubsection{Dosagem da Atividade Máxima da Lactato Desidrogenase (LDH).} O tampão de extração para a LDH continha Tris-HCl (77 mM), EDTA (1 mM), $\mathrm{MgCl}_{2}$ (2 mM), $\beta$-mercaptoetanol (4 mM), pH 7,5. O tampão de ensaio utilizado (volume de $165 \mu \mathrm{L}$ por amostra) consistiu de Tris-HCl (120 mM), $\mathrm{NADH} \quad(3,4 \mathrm{mM})$, Antimicina $\mathrm{A} \quad(1 \mathrm{mM})$ e Triton $\mathrm{X}-100 \quad 0,05 \%$ 
(volume/volume), pH 7,5. A reação foi iniciada com a adição de $100 \mu \mathrm{L}$ de Piruvato (20 mM) ao extrato enzimático (35 $\mu \mathrm{L}$ de amostra) e acompanhada por 10 minutos a $25^{\circ}$ C. A absorbância foi monitorada a $340 \mathrm{~nm}$, sendo o coeficiente de extinção para este comprimento de onda igual a 6,22. O princípio da reação baseia-se na formação de Lactato a partir de piruvato. A atividade da LDH foi determinada indiretamente como medida do consumo total de $\mathrm{NADH}^{78}$

6.10. Análise Estatística. A normalidade da distribuição de cada variável foi avaliada por meio do teste de Kolmogorov-Smirnov. As comparações das médias foram realizadas por meio da análise de variância (ANOVA) de dois fatores, seguida do pós-teste de Bonferroni, exceto para os valores do peso corporal dos animais, áreas de sobrecarga ventricular, razão VD/aorta, relação volume/massa do VD, atividade máxima das enzimas do metabolismo energético, massas e conteúdos de água do VD, VE e septo, os quais foram comparados por meio de ANOVA de um fator, seguido das comparações múltiplas de Bonferroni. Os valores estão apresentados na forma de média \pm desvio padrão. Para todos os casos, o nível de significância utilizado foi de $5 \%$. As análises estatísticas foram realizadas através dos softwares utilizando o programa GraphPad Prism v.4 (San Diego, CA - EUA) e ESTATISTICA v.6 (Tulsa, OK - EUA). 
Resultados 


\section{RESULTADOS}

Em nenhum animal, foi observada qualquer falha do dispositivo de bandagem ajustável do tronco pulmonar. Foi observada uma perda mínima diária do volume injetado no dispositivo durante o período de estudo. Para se atingir os parâmetros preconizados de sobrecarga sistólica do VD, um volume progressivamente maior foi injetado no dispositivo de bandagem, ao longo do protocolo. Em apenas um dos animais do grupo Contínuo, não foi possível realizar as medidas de pressão distal ao dispositivo de bandagem, devido à problemas técnicos com o cateter do tronco pulmonar.

\subsection{Medidas Hemodinâmicas}

7.1.1 Pressão Arterial Sistêmica. A hemodinâmica sistêmica não foi afetada pelo protocolo de sobrecarga sistólica do VD, conforme apresentado na tabela 2. A Análise de Variância de dois fatores mostrou que não houve diferença entre as pressões arteriais sistólicas sistêmicas entre os grupos (fator grupo, $\mathrm{p}=0,645$ ). Em relação ao fator tempo, apesar da Análise de Variância ter identificado diferença neste fator $(p=0,029)$, o pós-teste de Boferroni não identificou diferenças ao longo do protocolo. 
Tabela 2: Pressão Sistólica Sistêmica dos grupos Sham, Contínuo e Intermitente, medida pelo cateter vascular.

\begin{tabular}{cccc}
\hline & \multicolumn{3}{c}{ Pressão Sistólica Sistêmica (mm Hg) } \\
\cline { 2 - 4 } Tempo (horas) & $\begin{array}{c}\text { Sham } \\
(\mathbf{n}=\mathbf{7})\end{array}$ & $\begin{array}{c}\text { Contínuo } \\
(\mathbf{n}=\mathbf{9})\end{array}$ & $\begin{array}{c}\text { Intermitente } \\
(\mathbf{n}=\mathbf{1 1})\end{array}$ \\
\cline { 2 - 4 } & $106,29 \pm 14,22$ & $113,44 \pm 18,78$ & $105,73 \pm 12,11$ \\
$\mathbf{0}$ & $99,00 \pm 8,94$ & $100,11 \pm 15,19$ & $100,64 \pm 12,07$ \\
$\mathbf{2 4}$ & $100,14 \pm 13,33$ & $103,00 \pm 12,35$ & $101,00 \pm 11,70$ \\
$\mathbf{4 8}$ & $93,29 \pm 14,44$ & $98,22 \pm 14,32$ & $100,18 \pm 13,50$ \\
$\mathbf{9 6}$ & $108,67 \pm 19,25$ & $106,44 \pm 19,99$ & $103,45 \pm 7,46$ \\
\hline
\end{tabular}

Valores = média \pm desvio padrão; Medidas: $\mathrm{mmHg}$;

7.1.2. Gradiente de Pressão VD/TP. A figura 8 mostra um aumento do gradiente de pressão VD/TP nos grupos submetidos à sobrecarga sistólica do VD (Contínuo e Intermitente) para cada momento observado $(0,24,48$, 72 e 96 horas). A Análise de Variância de dois fatores mostrou diferenças entre os grupos $(p<0,001)$ e ao longo do tempo $(p<0,001)$. Houve interação significativa entre os grupos e o fator tempo $(p<0,001)$. Todos os gradientes VD/TP gerados nos grupos Contínuo e Intermitente foram maiores que os do grupo Sham, a partir do início da sobrecarga sistólica do VD ( 0 hora) até o final do protocolo. 


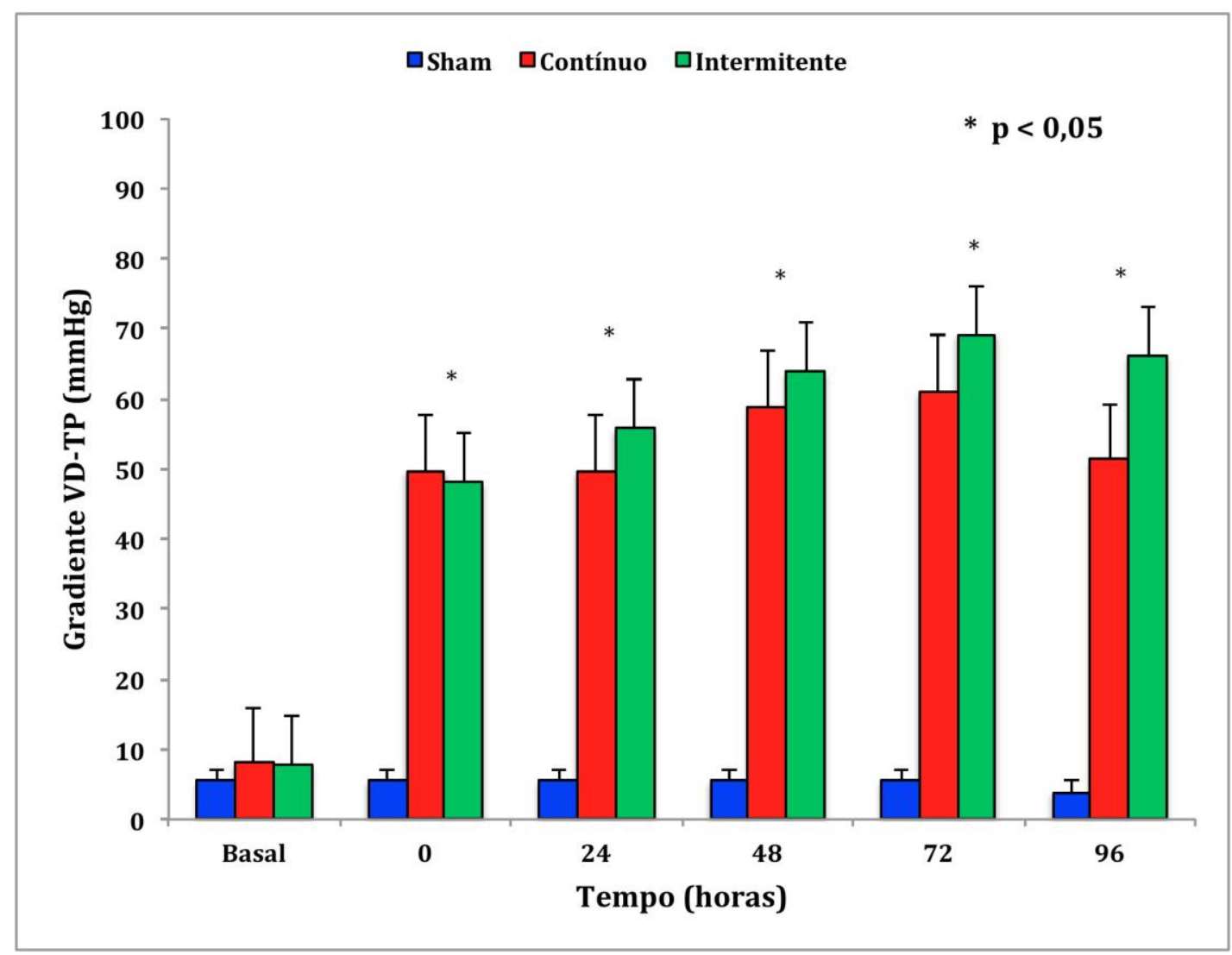

Figura 8: Evolução do gradiente pressórico sistólico entre o ventrículo direito e tronco pulmonar $(\mathrm{mm} \mathrm{Hg})$ nos grupos Sham, Contínuo e Intermitente.

* $p<0,05$ quando comparado ao seu respectivo instante Basal e ao grupo Sham para o mesmo instante.

O painel A da figura 9 mostra o padrão de sobrecarga sistólica (gradiente VD/TP) dos três grupos (Sham, Contínuo e Intermitente). Nota-se que o grupo Intermitente apresenta picos de gradientes sistólicos entre o ventrículo direito e o tronco pulmonar de 12 horas intercalados com períodos de descanso de 12 horas, correspondentes aos gradientes sistólicos próximos àqueles do grupo Sham. A partir das variações do gradiente VD/TP ao longo do período de estudo, foram calculadas as áreas sob a curva, como meio de se quantificar a sobrecarga sistólica imposta ao VD de cada grupo. 
No painel B da figura 9, observa-se um aumento significativo desta área nos grupos de sobrecarga sistólica contínua e intermitente $(p<0,001)$, quando comparados ao grupo Sham, sendo este aumento superior no grupo Contínuo em relação ao grupo Intermitente $(p<0,001)$.

Painel A

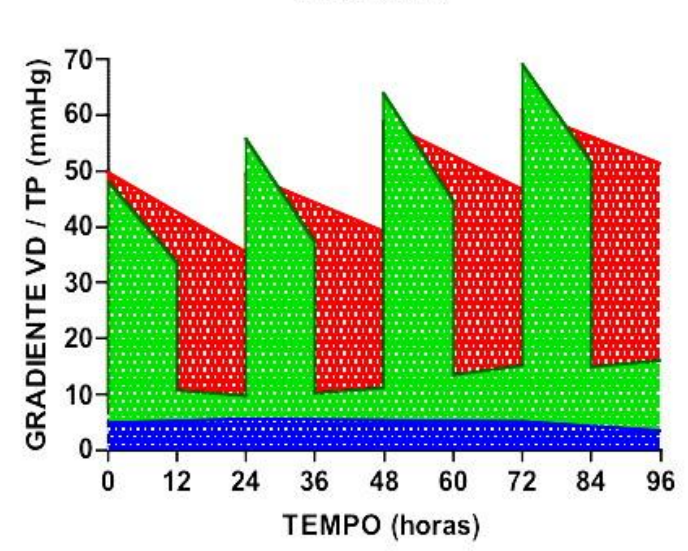

Painel B

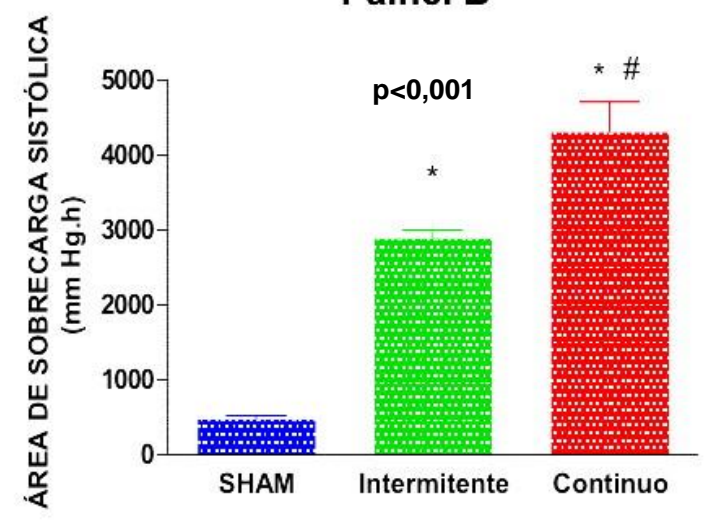

Figura 9: Painel A: Padrões de sobrecarga sistólica dos grupos Sham, Contínuo e Intermitente. Painel B: Áreas de sobrecarga sistólica dos grupos Sham, Contínuo e Intermitente. * $p<0,001$ quando comparado ao grupo Sham; $\# p<0,001$ quando comparado ao grupo Intermitente.

7.1.3. Relação de pressões entre Ventrículo direito e aorta. A relação de pressões VD/aorta dos grupos Sham e de sobrecarga sistólica de VD está demonstrada na figura 10. Paralelamente ao gradiente VD/TP, foi observado também um aumento da relação VD/aorta a partir do início do protocolo (0 hora) nos grupos Contínuo e Intermitente, quando comparados aos seus respectivos valores basais $(p<0,001)$. Apesar de ter sido observada uma queda dos valores desta relação no grupo Contínuo, entre os instantes 72 e 96 horas, não houve diferença significativa. A queda nos valores no instante 
96 horas em ambos os grupos de treinamento decorreu da presença de anestesia utilizada para a eutanásia.

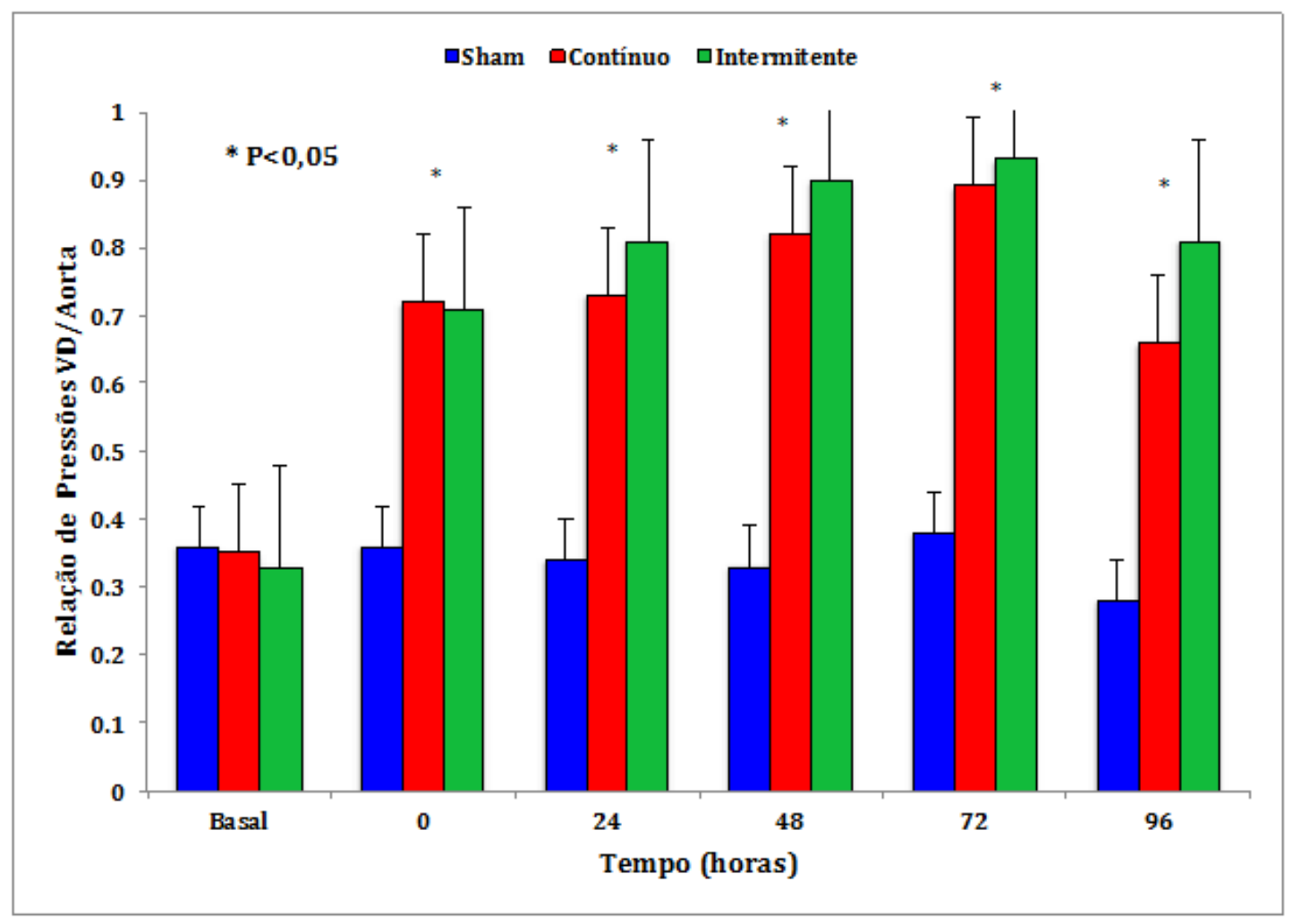

Figura 10: Evolução da relação de pressões sistólicas entre o ventrículo direito e aorta nos grupos Sham, Contínuo e Intermitente. * $p<0,05$ quando comparado ao seu respectivo instante Basal e ao grupo Sham para o mesmo instante.

O painel A da figura 11 mostra a relação de pressões sistólicas entre o VD e a aorta dos três grupos, ao longo do protocolo de estudo. Paralelamente ao gradiente VD/TP, foi observado o padrão de intermitência da sobrecarga sistólica do VD, através dos picos da relação VD/aorta e dos períodos de descanso do grupo Intermitente, quando a relação se aproximava aos valores encontrados no grupo Sham. A partir desses dados, foi calculada a área sob a curva da relação VD/aorta. Esta área, apresentada 
no painel $B$ da figura 11 , foi maior no grupo Contínuo $(p<0,01)$ em relação ao grupo Intermitente, que por sua vez foi superior ao grupo Sham $(p<0,001)$.
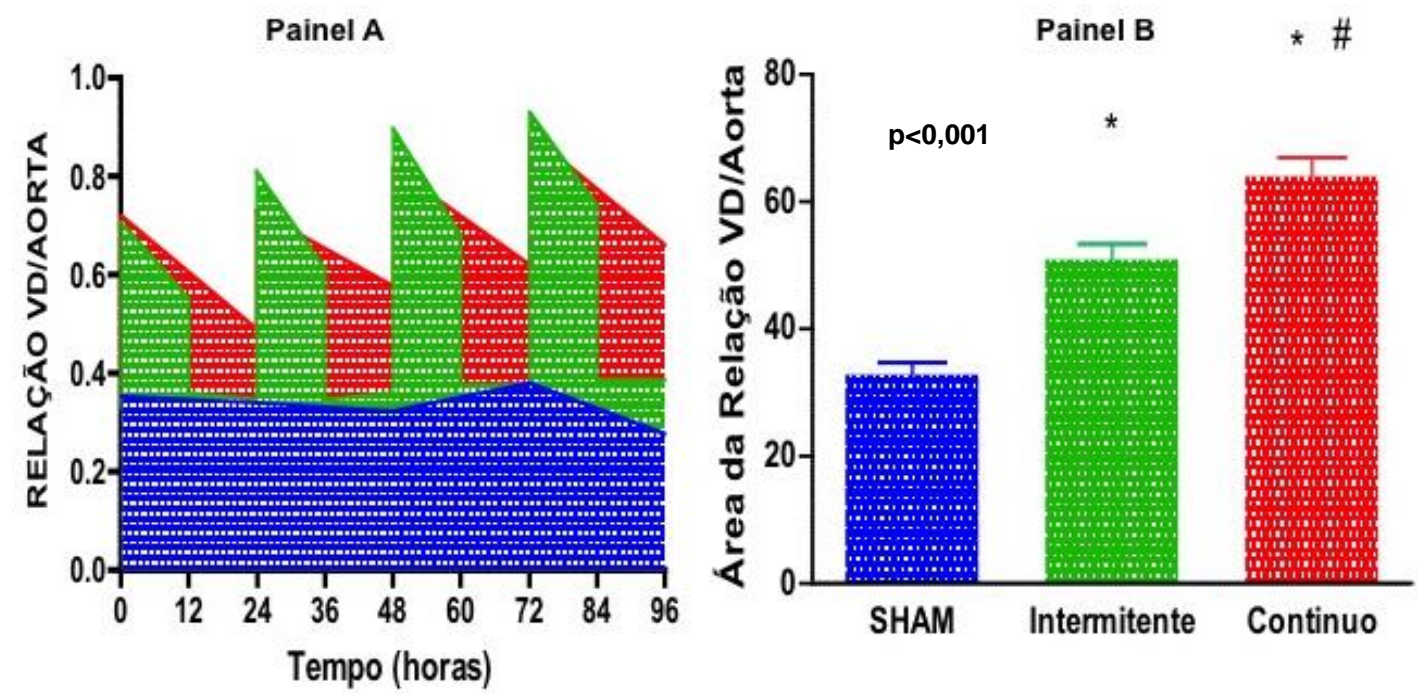

Figura 11. A: Razão de pressões sistólicas entre VD e aorta dos grupos Sham, Contínuo e Intermitente. B: Áreas da razão de pressões entre VD e aorta dos grupos Sham, Contínuo e Intermitente. * $p<0,001$ quando comparado ao grupo Sham; \# $p<0,001$ quando comparado ao grupo Intermitente

\subsection{Achados Ecocardiográficos}

7.2.1. Espessura de VD. Todos os animais incluídos no protocolo apresentavam espessura do VD inferior às do septo e do VE no momento pré-operatório (fator grupo $p=0.663$; fator tecido cardíaco $p<0,001$ ). A tabela 3 mostra a espessura da parede do VD dos grupos SHAM e de estudo ao longo do protocolo de sobrecarga sistólica. Ambos os grupos apresentaram aumento da espessura da parede livre do VD a partir de 48 horas no grupo Intermitente e de 72 horas no grupo Contínuo. Entretanto, o aumento da espessura do VD foi significativamente maior no grupo Intermitente, nos 
instantes 72 e 96 horas, quando comparado ao grupo Contínuo $(p<0,001$ para o fator grupo). Ao final do protocolo, foi observado um aumento de $103,8 \%$ da espessura do VD no grupo Intermitente comparado a um aumento de $38,4 \%$ do grupo Contínuo.

Tabela 3: Espessura do VD nos grupos Sham, Contínuo e Intermitente, medida pelo ecocardiograma.

\begin{tabular}{|c|c|c|c|}
\hline \multirow{2}{*}{$\begin{array}{l}\text { Tempo } \\
\text { (horas) }\end{array}$} & \multicolumn{3}{|c|}{ Espessura de VD (mm) } \\
\hline & $\begin{array}{l}\text { Sham } \\
(n=7)\end{array}$ & $\begin{array}{l}\text { Contínuo } \\
\qquad(n=9)\end{array}$ & $\begin{array}{c}\text { Intermitente } \\
\qquad(n=11)\end{array}$ \\
\hline Pré-op & $3,24 \pm 0,14$ & $3,28 \pm 0,35$ & $2,87 \pm 0,58$ \\
\hline 0 & $3,30 \pm 0,15$ & $3,31 \pm 0,33$ & $2,98 \pm 0,51$ \\
\hline 24 & $3,36 \pm 0,11$ & $3,37 \pm 0,33$ & $3,02 \pm 0,59$ \\
\hline 48 & $3,39 \pm 0,09$ & $3,63 \pm 0,68$ & $3,91 \pm 0,81^{*}$ \\
\hline 72 & $3,37 \pm 0,14$ & $4,40 \pm 0,64^{*} \dagger$ & $4,85 \pm 0,66 * \dagger$ \\
\hline 96 & $3,36 \pm 0,08$ & $4,54 \pm 0,51^{* \dagger}$ & $5,85 \pm 1,32 * \dagger a$ \\
\hline
\end{tabular}

A avaliação das variações percentuais da espessura do VD (figura 12) corroborou os dados observados nos valores absolutos da espessura do VD. Similarmente, as variações significativas da espessura do grupo Intermitente ocorreram a partir de 48 horas. Entretanto, este parâmetro foi observado apenas no momento 96 horas no grupo Contínuo. 


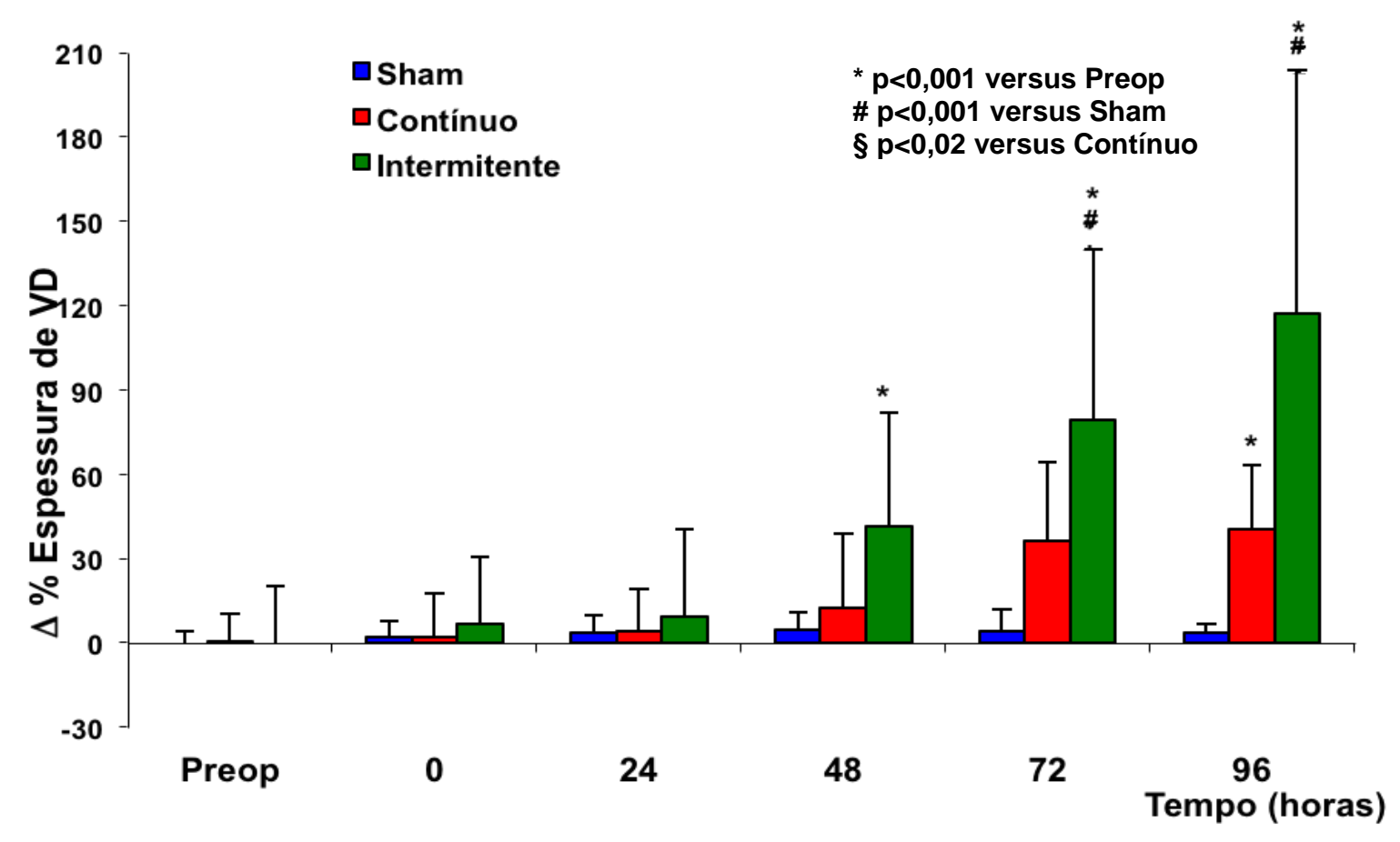

Figura 12. Variações percentuais da espessura da parede livre do VD dos grupos submetidos à sobrecarga sistólica contínua e intermitente.

${ }^{*} p<0,001$ quando comparado ao seu respectivo instante Basal;

\# $p<0,001$ quando comparado ao grupo Sham para o mesmo instante; $\S p<0,02$ quando comparado ao grupo Contínuo para o mesmo instante

7.2.2. Espessura Septal. A tabela 4 mostra a espessura da parede septal dos grupos Sham, Intermitente e Contínuo ao longo do protocolo de sobrecarga sistólica. Foi observado um aumento não significativo de $0,6 \%$ para o grupo Contínuo e de $3,5 \%$ para o grupo Intermitente ao final do protocolo ( $p=0,865$ para o fator tempo; $p=0,491$ para o fator grupo). 
Tabela 4: Espessura do septo interventricular nos grupos sham, Contínuo e Intermitente, medida pelo ecocardiograma.

\begin{tabular}{cccc}
\hline \multirow{2}{*}{$\begin{array}{c}\text { Tempo } \\
\text { (horas) }\end{array}$} & \multicolumn{3}{c}{ Espessura Septal $(\mathbf{m m})$} \\
\cline { 2 - 4 } & $\begin{array}{c}\text { Sham } \\
(\mathbf{n}=\mathbf{7})\end{array}$ & $\begin{array}{c}\text { Contínuo } \\
(\mathbf{n}=\mathbf{9})\end{array}$ & $\begin{array}{c}\text { Intermitente } \\
(\mathbf{n}=\mathbf{1 1})\end{array}$ \\
\hline Pré-op & $4,94 \pm 0,37$ & $4,98 \pm 0,59$ & $4,88 \pm 0,42$ \\
$\mathbf{0}$ & $4,97 \pm 0,54$ & $5,20 \pm 0,39$ & $5,06 \pm 0,44$ \\
$\mathbf{2 4}$ & $4,80 \pm 0,50$ & $5,06 \pm 0,55$ & $4,98 \pm 0,45$ \\
$\mathbf{4 8}$ & $4,97 \pm 0,31$ & $5,01 \pm 0,58$ & $4,88 \pm 0,37$ \\
$\mathbf{7 2}$ & $4,93 \pm 0,40$ & $5,00 \pm 0,56$ & $4,90 \pm 0,40$ \\
$\mathbf{9 6}$ & $5,00 \pm 0,30$ & $5,01 \pm 0,59$ & $5,05 \pm 0,43$ \\
\hline
\end{tabular}

Valores $(\mathrm{mm})=$ média \pm desvio padrão

7.2.3. Espessura do Ventrículo Esquerdo. A tabela 5 descreve a espessura da parede do VE dos grupos Sham, Intermitente e Contínuo ao longo do protocolo de sobrecarga sistólica. Não foram observadas variações da espessura do VE ao longo do protocolo ( $p=0,934$ para o fator tempo). Apesar da Análise de Variância de dois fatores detectar diferença significativa $(p<0,001)$ para o fator grupo, nos momentos zero e 24 horas, 0 protocolo de sobrecarga sistólica do VD não promoveu alterações significativas da parede livre do VE ao final do protocolo. 
Tabela 5: Espessura do ventrículo esquerdo nos grupos Sham, Contínuo e Intermitente, medida pelo ecocardiograma.

\begin{tabular}{lccc}
\hline Tempo & \multicolumn{3}{c}{ Espessura do VE $(\mathbf{m m})$} \\
\cline { 2 - 4 } (horas) & $\begin{array}{c}\text { Sham } \\
(\mathbf{n}=\mathbf{7})\end{array}$ & $\begin{array}{c}\text { Contínuo } \\
(\mathbf{n}=\mathbf{9})\end{array}$ & $\begin{array}{c}\text { Intermitente } \\
(\mathbf{n}=\mathbf{1 1})\end{array}$ \\
\hline Pré-op & $4,93 \pm 0,31$ & $4,68 \pm 0,47$ & $5,05 \pm 0,16$ \\
$\mathbf{0}$ & $4,91 \pm 0,30$ & $4,74 \pm 0,46$ & $5,17 \pm 0,21^{*}$ \\
$\mathbf{2 4}$ & $4,90 \pm 0,43$ & $4,74 \pm 0,37$ & $5,18 \pm 0,26^{*}$ \\
$\mathbf{4 8}$ & $5,00 \pm 0,28$ & $4,75 \pm 0,45$ & $5,14 \pm 0,24$ \\
$\mathbf{7 2}$ & $4,91 \pm 0,42$ & $4,74 \pm 0,39$ & $5,09 \pm 0,20$ \\
$\mathbf{9 6}$ & $5,01 \pm 0,34$ & $4,78 \pm 0,47$ & $5,16 \pm 0,24$ \\
\hline
\end{tabular}

Valores $(\mathrm{mm})=$ média \pm desvio padrão

* $p<0,03$ quando comparado ao grupo Contínuo para o mesmo instante.

7.2.4. Volume Diastólico Final do Ventrículo Direito. A tabela 6 mostra os dados do volume diastólico do VD ao longo do protocolo de sobrecarga sistólica. A Análise de Variância de dois fatores para este parâmetro mostrou diferença significativa entre os grupos $(p<0,001)$ e ao longo do tempo $(p=0,024)$. Não foram observadas variações significativas nos valores absolutos deste parâmetro no grupo Intermitente em relação ao grupo Sham. Por outro lado, o grupo Contínuo desenvolveu uma dilatação significativa do VD no momento 24 horas quando comparado ao grupo Sham, que regrediu 
discretamente até o final do protocolo, porém manteve-se significativamente maior que os grupos intermitente e Sham.

Tabela 6: Volume diastólico final do VD nos grupos sham, Contínuo e Intermitente, medido pelo ecocardiograma.

\begin{tabular}{|c|c|c|c|}
\hline \multirow[b]{2}{*}{ Tempo (horas) } & \multicolumn{3}{|c|}{ Volume Diastólico Final do VD } \\
\hline & $\begin{array}{l}\text { Sham } \\
(n=7)\end{array}$ & $\begin{array}{l}\text { Contínuo } \\
\qquad(n=9)\end{array}$ & $\begin{array}{c}\text { Intermitente } \\
\quad(n=11)\end{array}$ \\
\hline Pré-op & $2,05 \pm 0,34$ & $2,97 \pm 1,19$ & $2,44 \pm 0,59$ \\
\hline 0 & $2,01 \pm 0,77$ & $4,40 \pm 1,94 a$ & $3,46 \pm 1,70$ \\
\hline 24 & $2,49 \pm 0,77$ & $5,82 \pm 2,22^{*} a$ & $4,07 \pm 1,93$ \\
\hline 48 & $2,34 \pm 0,52$ & $4,92 \pm 1,68 \mathfrak{a}$ & $2,84 \pm 0,90 \dagger$ \\
\hline 72 & $2,13 \pm 0,50$ & $5,38 \pm 2,78 a$ & $2,72 \pm 0,76 \dagger$ \\
\hline 96 & $2,07 \pm 0,56$ & $5,32 \pm 3,00 a$ & $2,69 \pm 1,51 \dagger$ \\
\hline
\end{tabular}

A Figura 13 mostra o gráfico da variação percentual do volume diastólico do VD ao longo do protocolo de sobrecarga sistólica. Foi observada diferença significativa entre os grupos $(p<0,001)$ e ao longo do protocolo (fator tempo, $p=0,01$ ). Assim, foram também observados aumentos significativos deste parâmetro em ambos os grupos Contínuo $(96,1 \%)$ e Intermitente $(66,8 \%)$ no momento 24 horas. No entanto, a variação percentual do volume diastólico do VD, neste mesmo momento, estava 
significativamente maior apenas no grupo Continuo em relação ao grupo Sham $(p=0,007)$.

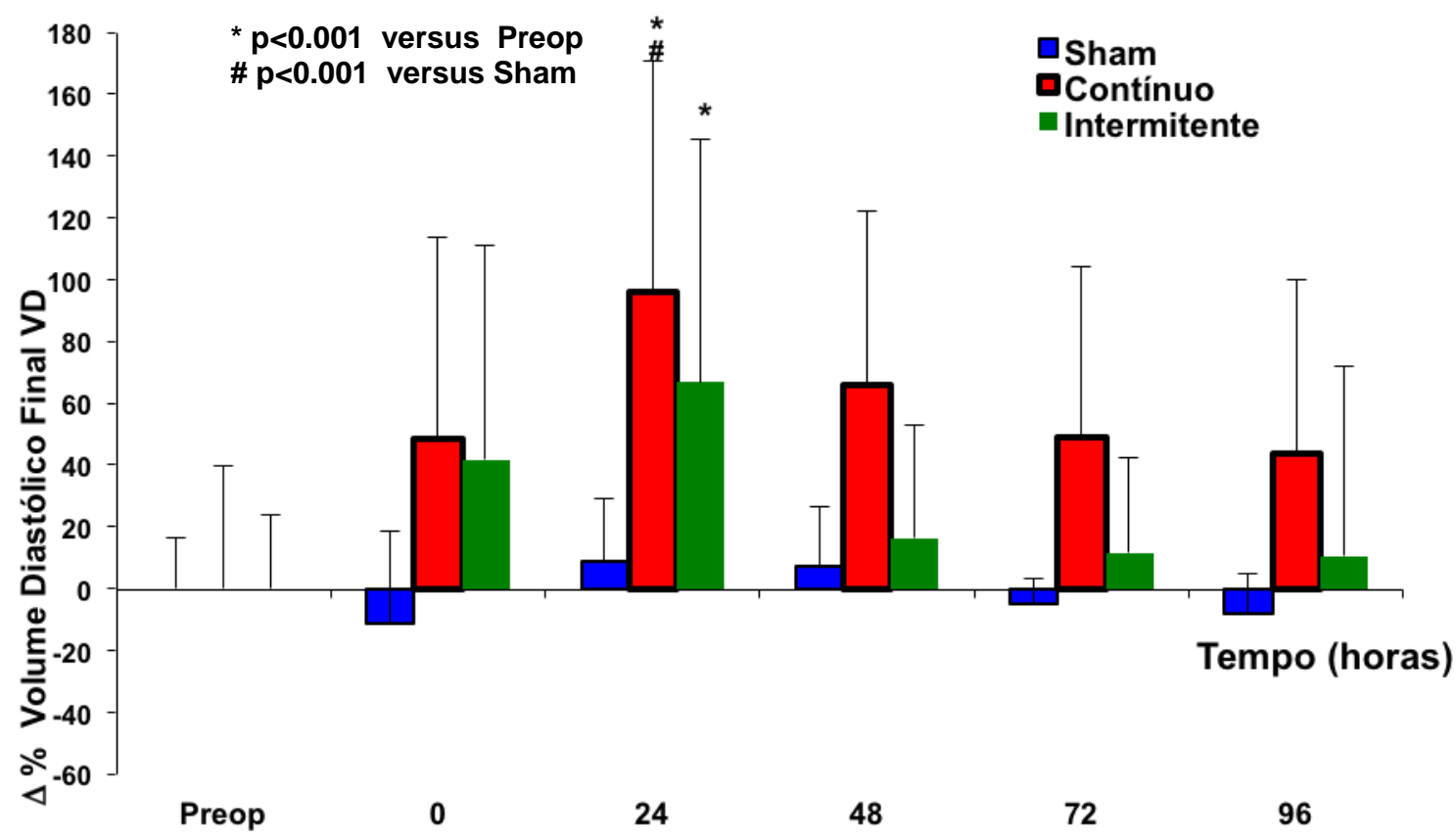

Figura 13: Variação percentual do volume diastólico do VD dos grupos Sham, Contínuo e Intermitente. $p<0,001$ quando comparado ao seu respectivo instante Basal $\# p<0,001$ quando comparado ao grupo Sham para o mesmo instante.

\subsubsection{Avaliação Funcional do VD}

7.2.5.1 Fração de Ejeção de Ventrículo Direito. A Tabela 7 mostra os dados da fração de ejeção do VD dos grupos Sham, Contínuo e Intermitente. 
A Análise de Variância deste parâmetro mostrou diferença significativa para o fator grupo $(p<0,001)$ e ao longo do tempo $(p<0,001)$, apesar da fração de ejeção do VD permanecer dentro dos limites da normalidade durante todo o protocolo de sobrecarga sistólica de VD. Os animais do Grupo Intermitente apresentaram uma queda significativa da fração de ejeção logo após o inicio do protocolo de treinamento (momento basal), retornando a valores próximos aos encontrados no momento pré-operatório. No momento 24 horas, ambos os grupos apresentaram redução significativa da fração de ejeção do VD, quando comparados ao grupo Sham. Após 48 horas de treinamento, houve recuperação deste parâmetro em ambos os grupos.

Tabela 7: Fração de ejeção do VD nos grupos sham, Contínuo e Intermitente, medido pelo ecocardiograma.

\begin{tabular}{|c|c|c|c|}
\hline \multirow[b]{2}{*}{ Tempo (horas) } & \multicolumn{3}{|c|}{ Fração de Ejeção do VD } \\
\hline & $\begin{array}{l}\text { Sham } \\
(n=7)\end{array}$ & $\begin{array}{l}\text { Contínuo } \\
\qquad(n=9)\end{array}$ & $\begin{array}{l}\text { Intermitente } \\
\qquad(\mathrm{n}=11)\end{array}$ \\
\hline Pré-op & $77,43 \pm 4,89$ & $67,89 \pm 6,68$ & $67,18 \pm 10,03$ \\
\hline 0 & $70,00 \pm 6,27$ & $53,00 \pm 22,76$ & $47,18 \pm 26,11^{*}$ \\
\hline 24 & $76,14 \pm 5,90$ & $48,33 \pm 20,45 \dagger$ & $56,45 \pm 18,83 \dagger$ \\
\hline 48 & $77,29 \pm 6,24$ & $61,11 \pm 20,43$ & $69,82 \pm 8,92$ \\
\hline 72 & $76,00 \pm 6,78$ & $65,89 \pm 13,18$ & $75,09 \pm 9,40$ \\
\hline 96 & $74,71 \pm 4,19$ & $65,56 \pm 11,54$ & $77,27 \pm 7,79$ \\
\hline
\end{tabular}


7.2.5.2 Índice de Desempenho Miocárdico do Ventrículo Direito. Na figura 14, encontram-se os valores do IDM do VD na condição de repouso e ao longo do protocolo. Foi observada diferença significativa apenas entre os grupos ( $p<0,001$ ), evidenciada no grupo Contínuo contra o grupo Sham, nos momentos 72 horas $(p=0,009)$ e 96 horas $(p=0,04)$, e contra o grupo Intermitente no momento 96 horas $(p<0,001)$. Em relação ao aspecto temporal, não houve diferenças significativas $(p=0,73)$.

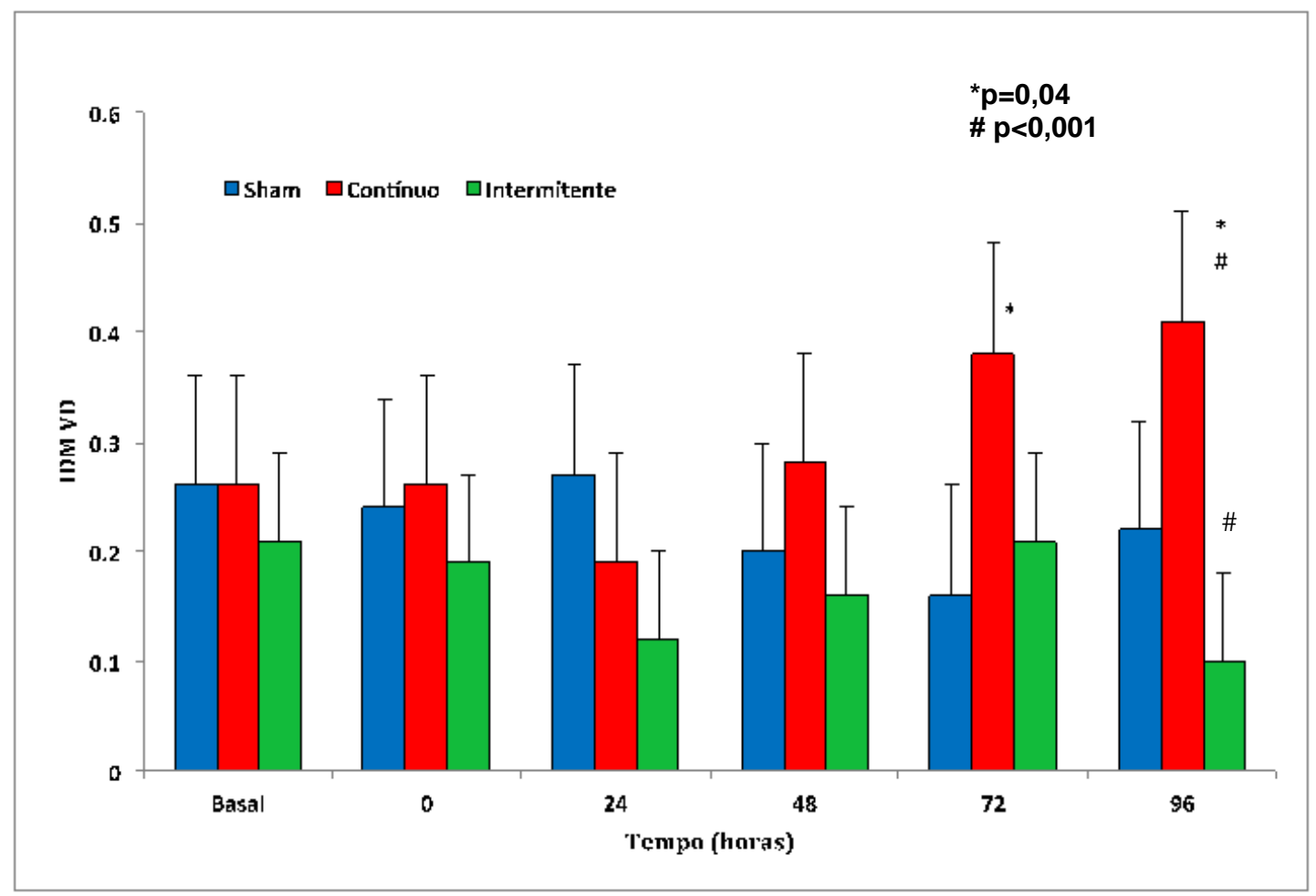

Figura 14: Evolução do índice de desempenho miocárdico nos grupos sham, contínuo e intermitente durante o protocolo de estudo. Valores = média \pm desvio padrão.

* $p=0,04$ quando comparado ao grupo Sham para o mesmo instante;

\# $p<0,001$ quando comparado ao grupo Intermitente para o mesmo instante. 


\subsection{Achados Morfológicos}

7.3.1. Pesagem das Massas Cardíacas. A figura 15 mostra a representação gráfica do peso das massas cardíacas, indexados para o peso corporal dos animais, nos grupos Sham, Contínuo e Intermitente. 0 grupo submetido ao protocolo de sobrecarga intermitente do VD apresentou aumentos significativos nas massas do VD $(92,1 \%)$ e Septo $(46,5 \%)$ em relação ao grupo Sham, enquanto que, no grupo Contínuo, foi observado um aumento significativo apenas da massa septal $(37,2 \%)$. O protocolo de sobrecarga sistólica do VD não influenciou a massa muscular do VE $(p=0,217)$.
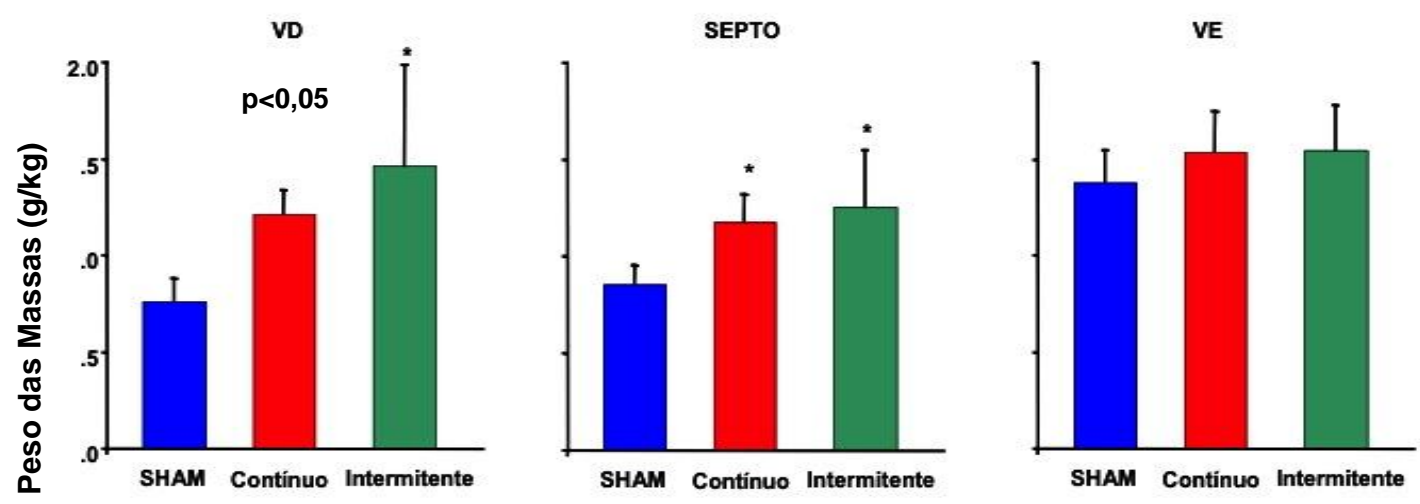

Figura 15: Massas do VD, Septo e VE (indexada para o peso corporal) nos grupos Sham, Contínuo e Intermitente. Valores $(\mathrm{g} / \mathrm{kg})=$ Média \pm Desvio Padrão. ${ }^{*} p<0,05$ quando comparado ao grupo Sham. 
7.3.2. Conteúdo de Água das Massas Cardíacas. A tabela 8 mostra o conteúdo de água do VD, Septo e VE nos grupos Sham, Contínuo e Intermitente. O VD e Septo dos grupos submetidos à sobrecarga sistólica contínua e intermitente do VD apresentaram um aumento discreto, porém significativo, do conteúdo de água (VD, $p=0,001$; Septo, $p=0,0004$ ) em relação ao grupo Sham. Já em relação ao conteúdo de água do VE, não foi observada diferença significativa do conteúdo de água entre os grupos $(p=0,17)$.

Tabela 8: Conteúdo de Água das Massas Cardíacas.

\begin{tabular}{|c|c|c|c|}
\hline \multirow[b]{2}{*}{$\begin{array}{c}\text { Massas } \\
\text { Cardíacas }\end{array}$} & \multicolumn{2}{|c|}{ Conteúdo de } & \multirow{2}{*}{$\begin{array}{l}\text { Á g u a } \\
\text { Intermitente } \\
\quad(n=11)\end{array}$} \\
\hline & $\begin{array}{l}\text { Sham } \\
(n=6)\end{array}$ & $\begin{array}{l}\text { Contínuo } \\
\qquad(n=9)\end{array}$ & \\
\hline VD & $78,84 \pm 2,41$ & $81,59 \pm 1,07^{\star}$ & $81,84 \pm 1,11^{*}$ \\
\hline SEPTO & $77,11 \pm 2,08$ & $79,69 \pm 0,62^{*}$ & $79,45 \pm 0,62^{*}$ \\
\hline VE & $78,20 \pm 1,89$ & $79,23 \pm 0,80$ & $79,13 \pm 0,67$ \\
\hline
\end{tabular}

7.3.3. Razão Volume/Massa do VD. 
A tabela 9 mostra a relação volume pela massa pesada e indexada do VD, após as 96 horas de estudo. Embora não tenha sido detectada diferença significante, observou-se uma tendência a menor relação volume / massa no grupo Intermitente, quando comparado aos demais grupos.

Tabela 9. Relação Volume / Massa do VD após 96 horas de estudo, medidos pelo ecocardiograma e por balança de precisão nos grupos Sham, Contínuo e Intermitente.

\begin{tabular}{cccc}
\hline $\begin{array}{c}\text { SHAM } \\
(\mathbf{n}=7)\end{array}$ & $\begin{array}{c}\text { CONTÍNUO } \\
(\mathbf{n}=5)\end{array}$ & $\begin{array}{c}\text { INTERMITENTE } \\
(\mathbf{n}=\mathbf{1 0})\end{array}$ & $\begin{array}{c}\text { Valor de } \\
\mathbf{p}\end{array}$ \\
\hline $2,83 \pm 0,86$ & $3,29 \pm 1,08$ & $2,28 \pm 1,24$ & 0,24 \\
\hline
\end{tabular}

Valores $(\mathrm{ml} / \mathrm{g} / \mathrm{kg})=$ média \pm desvio padrão

\subsection{Metabolismo Energético}

\subsubsection{Atividade máxima da enzima Glicose-6-Fosfato Desidrogenase. A} tabela 10 mostra os valores absolutos da atividade máxima da enzima G6PD nos grupos Sham, Contínuo e Intermitente, assim como a representação gráfica da dispersão dos valores (figura 16). Houve uma tendência a maior atividade desta enzima no VD do grupo Contínuo quando comparado aos demais grupos, não tendo atingindo significância estatística em função da grande variabilidade dos valores $(p=0,47)$. Além disso, não foram observadas diferenças significativas entre os grupos para o VE $(p=0,07)$ e Septo $(p=0,95)$. 
Tabela 10. Atividade máxima da enzima Glicose-6-Fosfato Desidrogenase (G6PD) no ventrículo direito (VD), ventrículo esquerdo (VE) e septo interventricular nos grupos Sham, Contínuo e Intermitente.

\begin{tabular}{ccccc}
\hline & $\begin{array}{c}\text { SHAM } \\
(\mathbf{n}=7)^{*}\end{array}$ & $\begin{array}{c}\text { CONTíNUO } \\
(\mathbf{n}=\mathbf{8})^{*}\end{array}$ & $\begin{array}{c}\text { INTERMITENTE } \\
(\mathbf{n}=10)^{*}\end{array}$ & $\begin{array}{c}\text { Valor } \\
\text { de } \mathbf{p}\end{array}$ \\
\hline VD & $3,03 \pm 0,86$ & $4,12 \pm 2,02$ & $3,39 \pm 1,92$ & 0,47 \\
\hline VE & $1,74 \pm 0,36$ & $1,39 \pm 0,30$ & $1,40 \pm 0,25$ & 0,07 \\
\hline Septo & $1,59 \pm 0,17$ & $1,62 \pm 0,34$ & $1,58 \pm 0,22$ & 0,95 \\
\hline
\end{tabular}

Valores = média \pm desvio padrão;

Medidas: $\mathrm{nmol} / \mathrm{min} / \mathrm{mg}$ de proteína;

- n variável para massa cardíaca (disponível para análise).
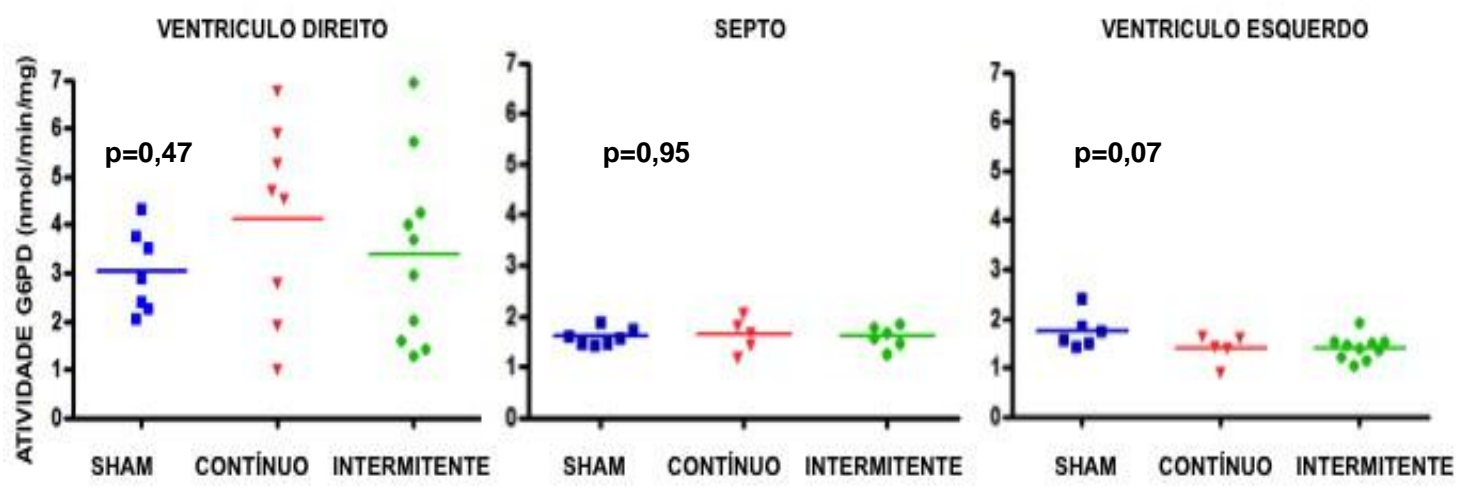

Figura 16. Atividade máxima da enzima Glicose-6-Fosfato Desidrogenase (G6PD) no miocárdio dos grupos Sham, Contínuo e Intermitente de acordo com o local de análise no miocárdio. Medidas: $\mathrm{nmol} / \mathrm{min} / \mathrm{mg}$ de proteína). Sham: $n=7$, Contínuo: $n=8$ e Intermitente: $n=10$ (disponíveis para análise). 
Em função desta maior variabilidade dos valores observados nos grupos submetidos à sobrecarga sistólica do VD, optou-se por analisar a razão dos valores da atividade máxima desta enzima no VD pelo VE. Esta análise revelou um aumento de $130,1 \%$ desta razão no grupo Contínuo $(p=0,01)$ e de $39,8 \%$ no grupo Intermitente $(p=0,76)$, quando comparados ao grupo Sham (figura 17). O fato de não ter sido observada diferença na atividade máxima da G6PD no VE dos grupos estudados reforça a idéia de que o aumento desta razão poderia ser explicado por uma maior atividade desta via metabólica no VD do grupo Contínuo. A mesma análise foi aplicada para a razão entre o Septo e o VE, não sendo evidenciada diferença estatística para a atividade máxima da G6PD ( $p=0,19)$.

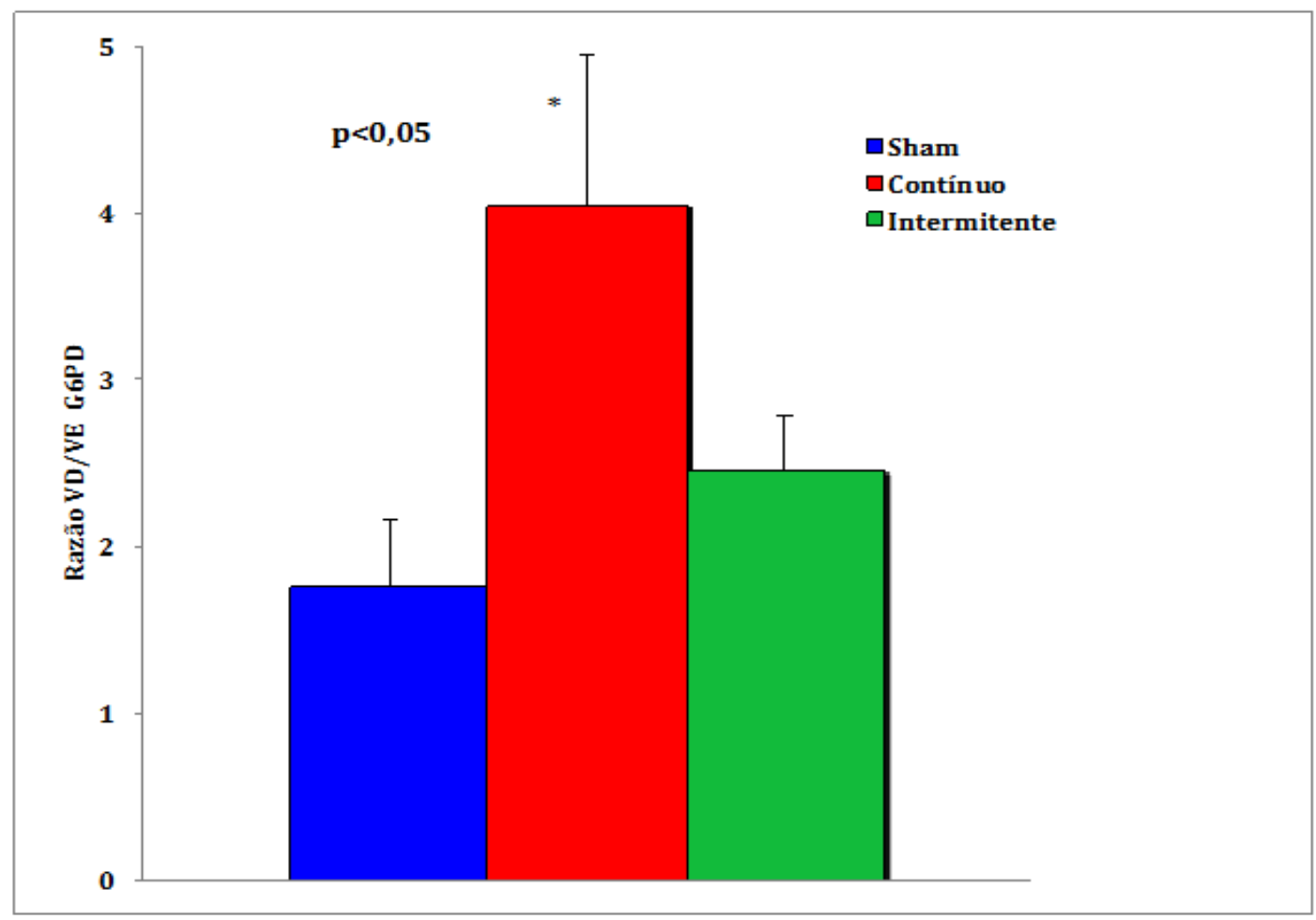

Figura 17; Razão da atividade máxima da enzima Glicose-6-Fosfato Desidrogenase (G6PD) do ventrículo direito, normalizada para sua atividade do ventrículo esquerdo nos grupos Sham, Contínuo e Intermitente. Valores = média \pm desvio padrão; Sham: $n=5$; Contínuo: $n=5$; Intermitente: $n=10$ (disponíveis para análise). ${ }^{*} p<0,05$ quando comparado aos grupos Sham e Intermitente. 
7.4.2. Atividade máxima da enzima Hexoquinase. Os dados da atividade máxima desta enzima estão demonstrados na tabela 11, bem como a representação gráfica da dispersão dos valores (figura 18). Não se evidenciou diferença significativa para as massas cardíacas entre os grupos.

Tabela 11. Atividade máxima da enzima Hexoquinase (HK) do miocárdio do ventrículo direito (VD), ventrículo esquerdo (VE) e septo interventricular nos grupos SHAM, Contínuo e Intermitente.

\begin{tabular}{ccccc}
\hline & $\begin{array}{c}\text { SHAM } \\
(\mathbf{n}=7)^{\star}\end{array}$ & $\begin{array}{c}\text { CONTÍNUO } \\
(\mathbf{n}=8)^{*}\end{array}$ & $\begin{array}{c}\text { INTERMITENTE } \\
(\mathbf{n}=\mathbf{1 0})^{*}\end{array}$ & Valor de $\mathbf{p}$ \\
\hline VD & $9,10 \pm 1,24$ & $7,38 \pm 3,56$ & $6,60 \pm 3,10$ & 0,98 \\
\hline VE & $2,87 \pm 0,46$ & $2,51 \pm 0,57$ & $2,56 \pm 0,72$ & 0,54 \\
\hline Septo & $7,37 \pm 1,29$ & $7,09 \pm 2,24$ & $6,77 \pm 1,55$ & 0,19 \\
\hline
\end{tabular}

Valores = média \pm desvio padrão; Medidas: $\mathrm{nmol} / \mathrm{min} / \mathrm{mg}$

* n variável para cada massa cardíaca (disponível para análise).
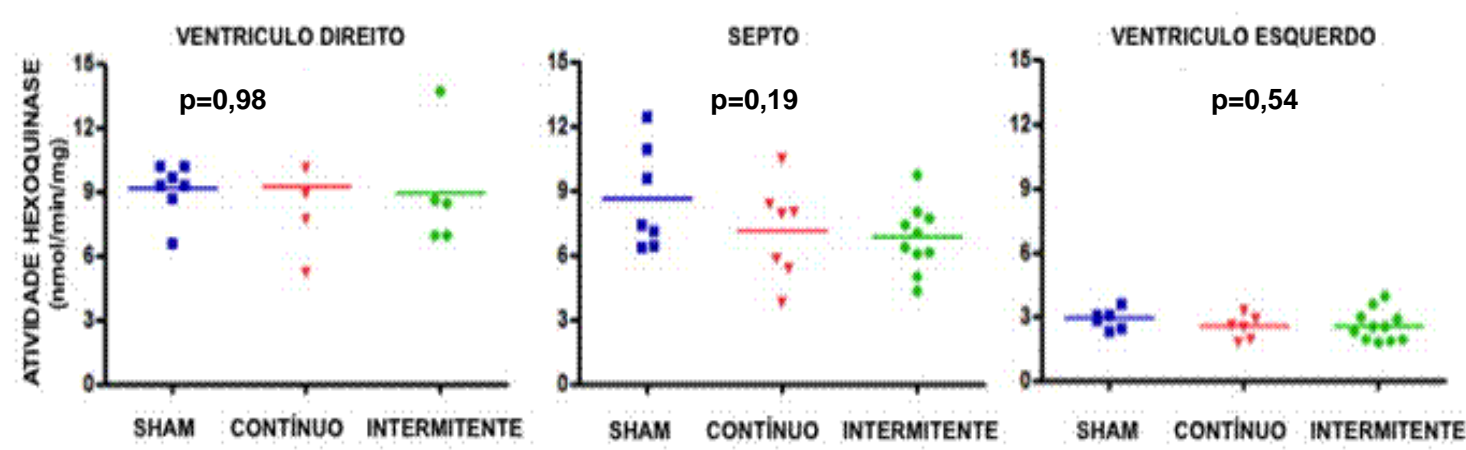

Figura 18. Atividade máxima da enzima Hexoquinase $(\mathrm{HK})$ do ventrículo direito, ventrículo esquerdo e septo interventricular dos grupos Sham, Contínuo e Intermitente. Medidas: $\mathrm{nmol} / \mathrm{min} / \mathrm{mg}$ de proteína. SHAM: $\mathrm{n}=7$, Contínuo: $n=8$ e Intermitente: $n=10$ (disponíveis para análise). 
À semelhança da análise da enzima G6PD, a razão dos valores da atividade máxima da Hexoquinase no VD pelo VE foi também obtida e não revelou diferença significativa entre os grupos $(p=0,40)$, conforme demonstrado na figura 19.

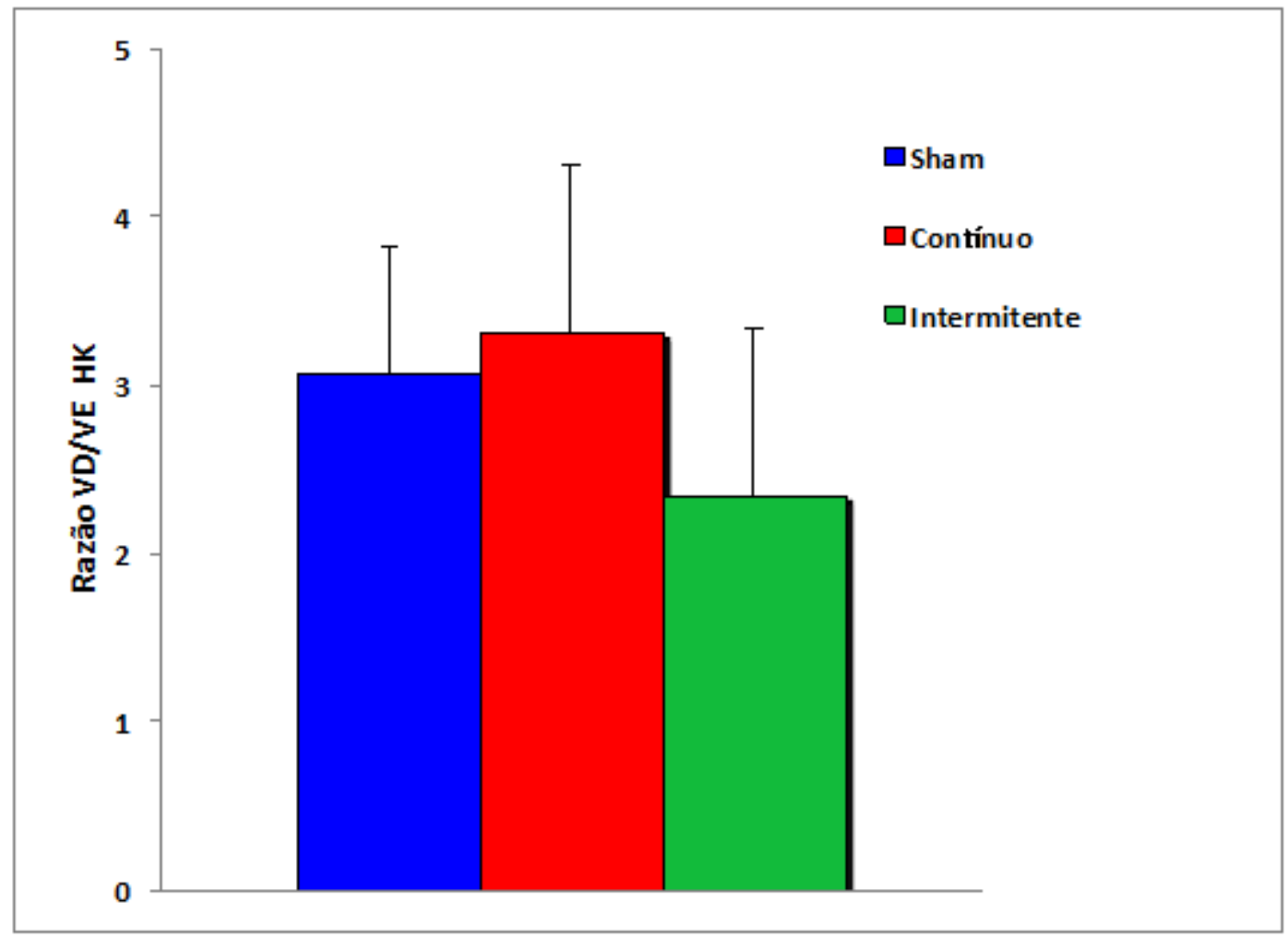

Figura 19: Razão da atividade máxima da enzima Hexoquinase (HK) do ventrículo direito, normalizada para sua atividade do ventrículo esquerdo nos grupos Sham, Contínuo e Intermitente. Valores $=$ média \pm desvio padrão; Sham: $\mathrm{n}=7$; Contínuo: $\mathrm{n}=8$; Intermitente: $\mathrm{n}=10$ (disponíveis para análise; $p=0,40$ ).

Quanto a razão da atividade máxima da hexoquinase no septo pelo VE, também não se observou diferença significativa entre os grupos $(p=0,82)$ 
7.4.3. Atividade máxima da enzima Lactato Desidrogenase. Os dados da atividade máxima desta enzima estão demonstrados na tabela 12, bem como a representação gráfica da dispersão dos dados (figura 20). Da mesma forma, não se evidenciou diferença significativa da atividade desta enzima entre as massas cardíacas dos grupos.

Tabela 12. Atividade máxima da enzima Lactato Desidrogenase (LDH) do miocárdio do ventrículo direito (VD), ventrículo esquerdo (VE) e septo interventricular nos grupos SHAM, Contínuo e Intermitente.

\begin{tabular}{ccccc}
\hline & $\begin{array}{c}\text { SHAM } \\
(\mathbf{n}=7)^{\star}\end{array}$ & $\begin{array}{c}\text { CONTíNUO } \\
(\mathbf{n}=7)^{\star}\end{array}$ & $\begin{array}{c}\text { INTERMITENTE } \\
(\mathbf{n}=6)^{*}\end{array}$ & Valor de P \\
\hline VD & $0,32 \pm 0,07$ & $0,41 \pm 0,33$ & $1,04 \pm 1,10$ & 0,17 \\
\hline VE & $2,80 \pm 2,57$ & $1,83 \pm 0,76$ & $5,23 \pm 3,75$ & 0,10 \\
\hline Septo & $3,14 \pm 3,03$ & $4,39 \pm 1,66$ & $6,25 \pm 3,48$ & 0,25 \\
\hline
\end{tabular}

Valores = média \pm desvio padrão; Medidas: $\mathrm{nmol} / \mathrm{min} / \mathrm{mg}$ - $\mathrm{n}$ variável para cada massa cardíaca (disponível para análise)
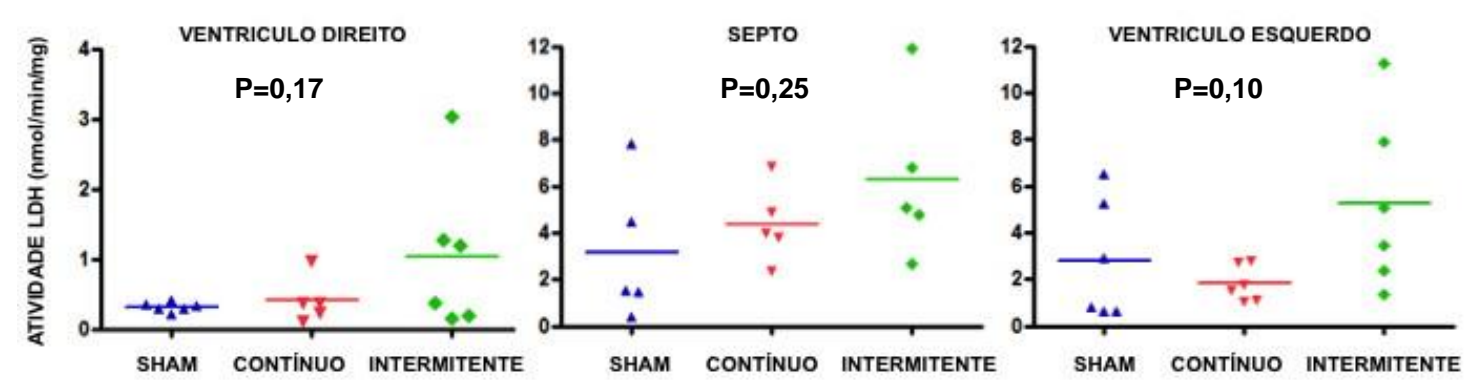

Figura 20. Atividade máxima da enzima Lactato Desidrogenase (LDH) do ventrículo direito, septo interventricular e ventrículo esquerdo dos grupos Sham, Contínuo e Intermitente. Medidas: $\mathrm{nmol} / \mathrm{min} / \mathrm{mg}$ de proteína. SHAM: $\mathrm{n}=7$, Contínuo: $n=7$ e Intermitente: $n=6$ (disponíveis para análise). 
A razão dos valores da atividade máxima da Lactato Desidrogenase no VD pelo VE foi também obtida e não revelou diferença significativa entre os grupos, conforme demonstrado na figura 21.

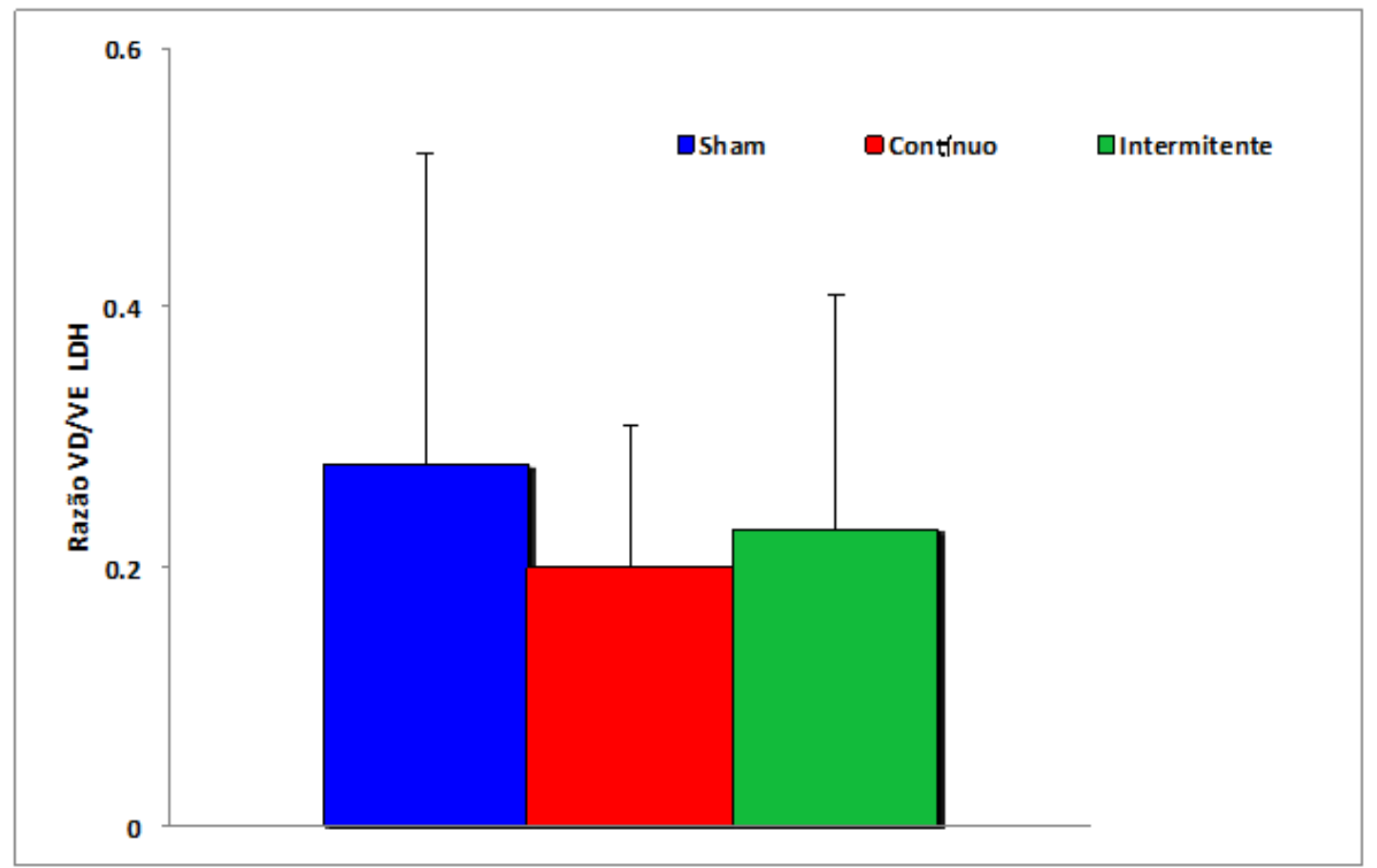

Figura 21: Razão da atividade máxima da enzima Lactato Desidrogenase do ventrículo direito, normalizada para sua atividade do ventrículo esquerdo nos grupos Sham, Contínuo e Intermitente. Valores = média \pm desvio padrão; Sham: $n=7$; Contínuo: $n=7$; Intermitente: $n=6$ (disponíveis para análise; $\mathrm{p}=0,78)$.

Em relação a razão da atividade da lactato desidrogenase no septo pelo VE, também não se observou alteração significativa entre os grupos $(p=0,45)$ 
Discussão 


\section{Discussão}

8.1 Achados Principais. $O$ presente estudo experimental procurou comparar o processo hipertrófico do ventrículo direito de cabritos jovens submetidos a sobrecarga sistólica intermitente versus contínua por meio de bandagem do tronco pulmonar. O grupo controle utilizado neste estudo divergiu dos estudos prévios. A utilização do grupo Sham (controle positivo) teve como objetivo expor a possível influência do procedimento cirúrgico na fisiologia cardíaca quando comparado com os grupos de estudo, os quais tiveram a participação adicional da bandagem do tronco pulmonar.

Do ponto de vista hemodinâmico, ambos os grupos de treinamento ventricular foram capazes de promover hipertrofia ventricular quando comparados ao grupo Sham. O grupo intermitente apresentou maior ganho de massa muscular do ventrículo direito e septo interventricular em relação ao grupo Sham, enquanto que o grupo contínuo somente apresentou maior ganho de massa no septo interventricular. Isso ocorreu a despeito de menor tempo de exposição a sobrecarga sistólica no grupo intermitente. O conteúdo de água no tecido, expressão de edema celular, ocorreu em ambos os grupos de treinamento de maneira similar, quando comparados ao grupo Sham. Apesar deste aumento de conteúdo de água no tecido ter ocorrido, a magnitude do mesmo foi pequena e o aumento de massa foi predominantemente às custas de síntese proteica.

Houve disfunção ventricular transitória nas primeiras 24 horas após a bandagem em ambos os grupos de treinamento quando comparados ao 
grupo Sham, mais pronunciada no grupo contínuo, que também evoluiu com aumento do diâmetro diastólico do ventrículo direito. Após 48 horas até o término do protocolo, houve normalização dos parâmetros ecocardiográficos nos grupos de estudo. O índice de desempenho miocárdico do grupo Intermitente mostrou superioridade funcional em relação aos demais grupos.

Houve aumento da razão da atividade máxima da atividade da enzima Glicose 6 Fosfato Desidrogenase do ventrículo direito, normalizada para sua atividade do ventrículo esquerdo, no grupo contínuo quando comparado ao grupo intermitente e ao grupo Sham.

8.2 Parâmetros hemodinâmicos. Não houve alteração significativa da pressão arterial sistêmica entre os grupos durante o protocolo. Como esperado, o aumento do gradiente de pressão entre o ventrículo direito e o tronco pulmonar foi reflexo da própria constrição do vaso pela bandagem, visto que os gradientes dos grupos contínuo e intermitente, semelhentes entre si, foram significativamente maiores que os do grupo Sham em todos os períodos do protocolo. Tanto a área de sobrecarga sistólica, quanto a área sob a curva da relação VD/aorta demonstraram que, por efeito de protocolo, o VD do grupo contínuo foi exposto à maior sobrecarga sistólica que o intermitente. Nos períodos de descanso noturnos, o grupo intermitente apresentava parâmetros hemodinâmicos semelhantes ao grupo Sham. Durante o período de sobercarga sistólica diurna, os parâmetros hemodinâmicos do grupo intermitente eram mais pronunciados que o grupo contínuo inicialmente, e progressivamente se aproximavam ao longo do dia. 
Estes achados podem ser explicados pela intermitência do estresse sistólico, com menor tensão da parede ventricular, melhor perfusão coronariana subendocárdica, permitindo assim melhor desempenho hemodinâmico do miocárdio nos períodos iniciais de sobrecarga sistólica.

8.3 Parâmetros ecocardiográficos. Os achados ecocardiográficos apontam um ganho significativo de espessura da parede livre do VD do grupo Intermitente a partir de 72 horas, corroborando com o respectivo aumento da massa do VD. Entretanto, as espessuras septais não se alteraram sob a análise ecocardiográfica, o que diverge do aumento significativo da massa septal de ambos os grupos na pesagem, ao final do protocolo. Talvez, esta divergência possa ser explicada pela dilatação ventricular e pelo maior teor de proteína e densidade muscular desta parede, ainda sem o proporcional aumento macroscópico visível ao ecocardiograma.

A maior dilatação do VD observada através do ecocardiograma nos animais do grupo contínuo pode representar um custo fisiopatológico maior para o miocárdio submetido ao estresse sistólico continuamente, sem o descanso alternado com a sobrecarga sistólica do grupo intermitente.

Houve queda significativa da fração de ejeção 24 horas após o início do protocolo em ambos os grupos de estudo, com recuperação nas próximas 24 horas. Este achado é compatível com o período de adaptação do ventrículo direito à sobrecarga sistólica aguda imposta pela bandagem. Tais achados são comuns na prática clínica em crianças submetidas a bandagem do tronco pulmonar, o que requer frequentemente suporte 
inotrópico transitório, a fim de vencer o período de adaptação miocárdica à sobrecarga aguda de pressão ${ }^{79}$.

Sabe-se que a avaliação da função do VD apresenta limitações importantes, pelas inferências geométricas assumidas para o cálculo da fração de ejeção, devido ao formato da cavidade em "lua crescente", sua grande relação área/volume e a separação entre suas vias de entrada e saída. Além disso, a FEVD, que avalia a função sistólica, foi realizada através do método de Simpson modificado, cujas limitações são relevantes para esta análise. Portanto, uma análise ecocardiográfica mais profunda do desempenho ventricular está sendo conduzida no laboratório, não somente em repouso, como também durante o estresse farmacológico, na tentativa de se evidenciar o protocolo de melhor retreinamento ventricular sob o ponto de vista funcional.

O índice de permormance miocárdica ou índice de Tei tem como objetivo refletir de maneira mais fidedigna as repercussões funcionais do ventrículo direito, por não depender da análise da morfologia ventricular, ser tecnicamente obtido em projeções ecocardiográficas limitadas ou frequência cardíaca elevada. O IDM é uma função ecocardiográfica calculada pela soma do tempo de contração isovolumétrico (refletindo a função sistólica ventricular) com o tempo de relaxamento isovolumétrico (refletindo a função diastólica ventricular), divididos pelo tempo de ejeção. Um índice elevado $(>0,47$ em adultos e $>0,34$ em crianças) indica pior função miocárdica e viceversa. Observou-se um aumento do índice de desempenho miocárdico no 
grupo Contínuo, nos períodos 72 horas e 96 horas do protocolo, quando comparados com os grupos Sham e Intermitente ao final do protocolo.

Perrino et al. ${ }^{19}$ analisaram a hipertrofia do VE em ratos submetidos à bandagem do arco aórtico, de forma contínua e intermitente, comparando-os a ratos submetidos a exercícios físicos de correr e nadar, durante o período de quatro semanas. Tanto os exercícios físicos, quanto a sobrecarga intermitente, foram realizados por 90 minutos, duas vezes ao dia. Foi observado um ganho de peso do VE do grupo intermitente semelhante aos grupos de correr e nadar, em contraste ao grupo submetido à sobrecarga contínua do VE, que apresentou uma resposta hipertrófica mais expressiva. Apesar da maior hipertrofia desenvolvida no grupo contínuo, houve significativa deterioração da função cardíaca após o protocolo de estudo, demonstrada pelo ecocardiograma, o que corrobora os achados deste estudo.

8.4 Parâmetros morfológicos. Inicialmente, previa-se uma hipertrofia diferenciada, em favor do grupo contínuo, pela maior exposição do miocárdio ao estímulo hipertrófico, quantificado pela maior área de sobrecarga sistólica do VD. Entretanto, o grupo intermitente apresentou maior ganho de massa do VD em relação ao grupo Contínuo. Além disso, o ganho de massa no grupo Intermitente ocorreu no VD e septo interventricular, enquanto que no grupo contínuo somente no VD. Pode-se inferir que o aumento de massa tenha ocorrido às custas de ganho muscular pois o aumento proporcional e de pequena magnitude do conteúdo de água não poderia explicar as diferenças entre os grupos de estudo. Os dados ecocardiográficos de maior espessura do ventrículo direito corroboram esta inferência. 
A maior eficiência da sobrecarga sistólica intermitente pode estar relacionada ao disparo do estímulo hipertrófico e da cascata de síntese protéica da mesma forma que no grupo contínuo, porém com menor gasto energético para o miocárdio. Provavelmente, o mecanismo deste processo hipertrófico desencadeado pela cascata molecular pode se desenvolver em boas condições durante os períodos de descanso e transporte de oxigênio ideal, e, por isso, sem o desenvolvimento de fibrose decorrente de isquemia relativa. Portanto, é necessário considerar o tipo de treinamento em relação ao grau e a duração da sobrecarga sistólica e seu impacto no miocárdio. Abduch et al. ${ }^{26}$ demonstraram não somente a presença de hipertrofia dos cardiomiócitos do ventrículo direito e dos seus respectivos núcleos, como também maior proliferação celular dos elementos contráteis e não contráteis para ambos os grupos estimulados, sem aumento do colágeno intersticial. É importante salientar que provavelmente não foram encontradas diferenças entre os grupos, no que se refere a ocorrência de fibrose, pois trata-se de estudo experimental de 96 horas de duração. Le Bret et al. ${ }^{42}$ obtiveram a hipertrofia do VD de ovelhas com apenas duas horas de sobrecarga sistólica do VD por dia, durante um período de cinco semanas. A fibrose foi, no entanto, observada nos animais submetidos ao regime de bandagem convencional e naqueles submetidos a apenas dois reajustes da sobrecarga sistólica do VD, durante o protocolo de cinco semanas. Focos de necrose celular em graus variáveis no miocárdio hipertrofiado ${ }^{7-10}$, e a conseqüente disfunção ventricular tardia também já foram demonstrados em corações 
submetidos a estresse sistólico agudo, provavelmente por desequilíbrio entre a relação de oferta e consumo de oxigênio no miocárdio hipertrófico. ${ }^{13}$

Talvez os períodos de descanso intermitente ao longo do protocolo possam otimizar o fluxo coronariano subendocárdico e, consequentemente, maior aporte de substratos para o processo hipertrófico do miocárdio, limitando assim a intensidade do estresse sistólico imposto ao VD do grupo contínuo.

8.5 Metabolismo Energético. Este estudo buscou avaliar diferenças qualitativas do processo de hipertrofia miocárdica induzida por sobrecarga de pressão contínua e intermitente, por meio de marcadores biológicos que expressem eventuais modificações fenotípicas do metabolismo energético. Foi demonstrado que a atividade das enzimas Lactato Desidrogenase e Hexoquinase não diferiu entre os grupos. Provavelmente, o período de 96 horas de sobrecarga sistólica não tenha sido suficiente para evidenciar diferenças entre os grupos, no que tange ao metabolismo anaeróbio e/ou incremento da glicólise no cardiomiócito.

Sabe-se que o grau de modulação metabólica é um importante determinante da mudança de substrato energético do cardiomiócito como função adaptativa ou mal adaptativa, no contexto de estados que levem à hipertrofia patológica. Foi demonstrado experimentalmente que a glicólise encontra-se aumentada na hipertrofia cardíaca da hipertensão induzida por bandagem aórtica ou pela hipertensão pulmonar. ${ }^{79,80,81,82}$ Por outro lado, a oxidação de ácidos graxos de cadeia longa encontra-se diminuída nos corações hipertrofiados, quando comparados aos corações normais. Estas 
alterações podem contribuir para uma maior suscetibilidade dos corações hipertrofiados à lesão durante a isquemia e reperfusão, e assim comprometer a função contrátil do miocárdio. Entretanto, esta observação depende do grau de hipertrofia cardíaca, da sobrecarga sistólica, e da expressão genética individual que codifica a atividade enzimática, cuja influência nos resultados deste modelo experimental agudo é desconhecida.

Por outro lado, o aumento significativo da razão da atividade da enzima G6PD no ventrículo direito submetido à sobrecarga sistólica contínua é relevante. Este achado denota uma exacerbação do ciclo das pentoses Fosfato. O significado desta maior atividade enzimática no grupo contínuo pode corresponder a perda do equilíbrio redox, com maior produção de NADPH e glutationa reduzida e o desencadeamento do estresse redutivo, além do estresse oxidativo derivado de ânions superóxido relacionados à NADPH oxidase ${ }^{68}$. Em condições patológicas, há formação de NADPH por ativação da G6PD após o estímulo de uma série de fatores como a angiotensina II, trombina e fator de necrose tumoral alfa. ${ }^{66,83,84} \mathrm{~A}$ cardiomiopatia relacionada a agregação protéica e lesão miocárdica seria a conseqüência final. Provavelmente, o modelo experimental crônico poderia identificar alterações estruturais e ecocardiográficas compatíveis com esta premissa.

Na literatura, tanto a maior, quanto a menor atividade de G6PD, estão associadas a doenças. Todavia, crescentes evidências apontam para a associação da maior atividade de G6PD com o estresse oxidativo e redutivo, 
sendo que novas drogas tem sido desenvolvidas a fim de inibir sua atividade. $^{85}$

Por exemplo, pacientes portadores de diabetes mellitus apresentam aumento da atividade de G6PD e dos níveis de NADPH e isso foi associado à disfunção endotelial por inibição da síntese de óxido nítrico. ${ }^{86}$ Embora os mecanismos responsáveis pela maior produção de radicais livres no coração não sejam completamente entendidos, foi proposto que a oxidação aumentada de Glicose aumente o potencial da membrana mitocondrial, incrementando assim a atividade de NADPH oxidase no sistema vascular, que aumenta a produção de ânions superóxido. ${ }^{87,88}$ Esses últimos seriam mediadores da vasculopatia do diabetes e precursores da disfunção miocárdica relacionada à doença. ${ }^{89,90}$

$\mathrm{Na}$ insuficiência cardíaca induzida por marcapasso, existe uma expressão aumentada em dez vezes de G6PD, quando comparada a corações normais. ${ }^{67,91}$ A inibição da atividade de G6PD melhora a hipertensão pulmonar hipóxica crônica. Finalmente, a G6PD participa na hipertrofia de células musculares lisas mediadas pela angiotensina II e no desenvolvimento de aterosclerose. Estudos recentes mostraram que a G6PD tem atividade aumentada em adipócitos de ratos, induzindo desregulação hormonal, que induz obesidade e resistência a insulina. ${ }^{92}$

Portanto, a maior expressão de G6PD observada no grupo Contínuo pode desencadear a lesão miocárdica induzida por acúmulo de ânions superóxido e agregação proteica, subsequentemente levando a disfunção ventricular, caso a sobrecarga persista. Entretanto, outros mecanismos de 
ação do G6PD na insuficiência cardíaca são desconhecidos e não podem ser descartados, fazendo parte de várias linhas de pesquisa em todo o mundo.

8.6 Limitações do estudo. $O$ estudo segue linha de pesquisa bem estabelecida na instituição, com modelo experimental consagrado em pesquisas prévias. Embora este modelo tenha tais características, existe limitação em transpor seus resultados para a prática clínica em humanos, por vários motivos listados a seguir:

1) Os aspectos morfológicos e de metabolismo podem divergir entre as espécies;

2) Os animais não eram portadores de transposição das grandes artérias, portanto o ventrículo em estudo (anatomicamente direito), não é o mesmo da população alvo em humanos (anatomicamente esquerdo).

3) Apesar de não se tratar de estudo crônico e o tempo máximo ser de 96 horas, a infra-estrutura do laboratório ainda é inadequada para a manutenção de animais em condições ideais de temperatura e cuidados pós-operatórios, o que poderia influenciar os resultados.

4) O método de análise da atividade enzimática foi dependente de um único examinador experiente com a técnica. Apesar disso, houve grande dispersão em parte dos resultados desta análise. O concurso de um segundo examinador, com análise de concordância entre eles, poderia minimizar este problema. 
A atividade enzimática do metabolismo energético do miocárdio, nos dois protocolos de sobrecarga sistólica, foi estudada apenas no momento do sacrifício do animal, podendo assim não expressar amplamente nos diversos momentos ao longo do estudo. Além disso, o ideal seria também analisar o produto final da atividade dessas enzimas, já que existem muitas influências de outras vias do metabolismo energético. Portanto, é difícil inferir definitivamente, com base na atividade de uma enzima específica, a respeito de um processo de hipertrofia que envolve múltiplos fatores. Nesta linha de raciocínio, a complementação da relação dos achados bioquímicos com aspectos morfológicos seria essencial. Assim, futuros estudos da produção de radicais livres e apoptose podem agregar informações interessantes a esta linha de pesquisa. 
Conclusões 


\section{CONCLUSÕES}

1- A sobrecarga sistólica de forma intermitente permitiu uma hipertrofia do VD mais eficiente que no grupo submetido à sobrecarga sistólica de forma contínua, considerando sua menor área de sobrecarga sistólica do VD;

2- O desempenho funcional do miocárdio submetido a sobrecarga sistólica Intermitente foi mais favorável que na sobrecarga sistólica contínua;

3- O ganho de massa atingido no VD do grupo Intermitente provavelmente foi devido à síntese protéica aumentada, não acompanhada de edema miocárdico importante;

4- Não houve diferenças na atividade máxima das enzimas Hexoquinase e Lactato Desidrogenase nos grupos submetidos à sobrecarga sistólica do VD.

5- Houve um aumento na atividade da G6PD no miocárdio do VD dos animais do grupo Contínuo, quando comparado ao grupo Intermitente. 
Anexos 


\section{ANEXOS}

Anexo 1: Atividade máxima da enzima Glicose 6 Fosfato Desidrogenase (nmol/min/mg de proteína) no VD dos animais do grupo Sham.

\begin{tabular}{|c|c|}
\hline animais & G6PD (VD) \\
\hline $290408-C$ & 2,04 \\
\hline $240408-A C$ & 3,78 \\
\hline $240408-B C$ & 4,32 \\
\hline $150408-C$ & 2,28 \\
\hline $6427(280208)$ & 2,9 \\
\hline $1503(290208)$ & 2,39 \\
\hline $290508-C$ & 3,53 \\
\hline
\end{tabular}

Anexo 2: Atividade máxima da enzima Glicose 6 Fosfato Desidrogenase (nmol/min/mg de proteína) no VD dos animais do grupo Contínuo.

\begin{tabular}{|c|c|}
\hline animais & G6PD (VD) \\
\hline $2706-A E C$ & 2,78 \\
\hline $2706-B E C$ & 1,92 \\
\hline $1608-E C$ & 1 \\
\hline $140308-E C$ & 5,92 \\
\hline $220808-E C$ & 4,7 \\
\hline $060209-A E C$ & 4,53 \\
\hline $170409-A E C$ & 5,28 \\
\hline $290509-E C$ & 6,79 \\
\hline
\end{tabular}


Anexo 3: Atividade máxima da enzima Glicose 6 Fosfato Desidrogenase (nmol/min/mg de proteína) no VD dos animais do grupo Intermitente.

\begin{tabular}{|c|c|}
\hline animais & G6PD (VD) \\
\hline $1605 \mathrm{AEI}$ & 2,02 \\
\hline $1605 \mathrm{BEI}$ & 1,58 \\
\hline 230596 & 1,43 \\
\hline $0606-\mathrm{El}$ & 1,27 \\
\hline $140308 \mathrm{EI}$ & 6,95 \\
\hline $141108-\mathrm{EI}$ & 4,02 \\
\hline $051208-\mathrm{El}$ & 3,7 \\
\hline 060209-BEI & 4,27 \\
\hline $170409-\mathrm{BEI}$ & 5,73 \\
\hline $220509-\mathrm{El}$ & 2,95 \\
\hline
\end{tabular}

Anexo 4: Atividade máxima da enzima Glicose 6 Fosfato Desidrogenase (nmol/min/mg de proteína) no VE dos animais do grupo Sham.

\begin{tabular}{|c|c|}
\hline animais & G6PD (VE) \\
\hline $280208-C$ & 1,43 \\
\hline $150408-C$ & 1,49 \\
\hline $240408-A C$ & 1,84 \\
\hline $240408-B C$ & 2,4 \\
\hline $290408-C$ & 1,72 \\
\hline $290508-C$ & 1,58 \\
\hline
\end{tabular}

Anexo 5: Atividade máxima da enzima Glicose 6 Fosfato Desidrogenase (nmol/min/mg de proteína) no VE dos animais do grupo Contínuo.

\begin{tabular}{|c|c|}
\hline animais & G6PD (VE) \\
\hline $140308-E C$ & 1,61 \\
\hline $220808-E C$ & 1,62 \\
\hline $060209-A E C$ & 0,89 \\
\hline $170409-A E C$ & 1,43 \\
\hline $290509-E C$ & 1,4 \\
\hline
\end{tabular}


Anexo 6: Atividade máxima da enzima Glicose 6 Fosfato Desidrogenase (nmol/min/mg de proteína) no VE dos animais do grupo Intermitente.

\begin{tabular}{|c|c|}
\hline Animais & G6PD (VE) \\
\hline $1605 \mathrm{AEI}$ & 1,2 \\
\hline $1605 \mathrm{BEI}$ & 1,45 \\
\hline $2305-\mathrm{AEI}$ & 1,05 \\
\hline $0606-\mathrm{El}$ & 1,91 \\
\hline $140308 \mathrm{EI}$ & 1,35 \\
\hline $051208-\mathrm{El}$ & 1,48 \\
\hline $060209-\mathrm{BEI}$ & 1,13 \\
\hline $170409-\mathrm{BEI}$ & 1,4 \\
\hline $220509-\mathrm{El}$ & 1,52 \\
\hline
\end{tabular}

Anexo 7: Atividade máxima da enzima Glicose 6 Fosfato Desidrogenase (nmol/min/mg de proteína) no septo interventricular dos animais do grupo Sham.

\begin{tabular}{|c|c|}
\hline Animais & G6PD (Septo) \\
\hline $280208-C$ & 1,45 \\
\hline $290208-\mathrm{C}$ & 1,44 \\
\hline $150408-\mathrm{C}$ & 1,73 \\
\hline $240408-\mathrm{AC}$ & 1,46 \\
\hline $240408-\mathrm{BC}$ & 1,89 \\
\hline $290408-\mathrm{C}$ & 1,56 \\
\hline $290508 \mathrm{C}$ & 1,59 \\
\hline
\end{tabular}

Anexo 8: Atividade máxima da enzima Glicose 6 Fosfato Desidrogenase (nmol/min/mg de proteína) no septo interventricular dos animais do grupo Contínuo.

\begin{tabular}{|c|c|}
\hline Animais & G6PD (Septo) \\
\hline $140308 \mathrm{EC}$ & 2,04 \\
\hline $220808 \mathrm{EC}$ & 1,82 \\
\hline $060209-\mathrm{AEC}$ & 1,67 \\
\hline $170409-\mathrm{AEC}$ & 1,43 \\
\hline $290509-\mathrm{EC}$ & 1,17 \\
\hline
\end{tabular}


Anexo 9: Atividade máxima da enzima Glicose 6 Fosfato Desidrogenase (nmol/min/mg de proteína) no septo interventricular dos animais do grupo Intermitente.

\begin{tabular}{|c|c|}
\hline Animais & G6PD (Septo) \\
\hline $140308 \mathrm{EI}$ & 1,76 \\
\hline $141108-\mathrm{El}$ & 1,24 \\
\hline $051208-\mathrm{El}$ & 1,68 \\
\hline $060209-\mathrm{BEI}$ & 1,45 \\
\hline $170409-\mathrm{BEI}$ & 1,83 \\
\hline $220509-\mathrm{El}$ & 1,55 \\
\hline
\end{tabular}

Anexo 10: Atividade máxima da enzima Hexoquinase (nmol/min/mg de proteína) no VD dos animais do grupo Sham.

\begin{tabular}{|c|c|}
\hline Animais & HK (VD) \\
\hline $290408-C$ & 10,16 \\
\hline $240408-A C$ & 6,56 \\
\hline $240408-B C$ & 8,67 \\
\hline $150408-C$ & 9,26 \\
\hline $6427(280208)$ & 9,68 \\
\hline $1503(290208)$ & 9,24 \\
\hline $290508 \mathrm{C}$ & 10,14 \\
\hline
\end{tabular}

Anexo 11: Atividade máxima da enzima Hexoquinase $(\mathrm{nmol} / \mathrm{min} / \mathrm{mg}$ de proteína) no VD dos animais do grupo Contínuo.

\begin{tabular}{|c|c|}
\hline Animais & HK (VD) \\
\hline $2706-A E C$ & 14,13 \\
\hline $2706-B E C$ & 10,11 \\
\hline $1608-E C$ & 5,2 \\
\hline $140308 E C$ & 8,89 \\
\hline $220808 E C$ & 7,68 \\
\hline $060209-A E C$ & 4,06 \\
\hline $170409-A E C$ & 3,82 \\
\hline $290509-E C$ & 5,16 \\
\hline
\end{tabular}


Anexo 12: Atividade máxima da enzima Hexoquinase $(\mathrm{nmol} / \mathrm{min} / \mathrm{mg}$ de proteína) no VD dos animais do grupo Intermitente.

\begin{tabular}{|c|c|}
\hline Animais & HK (VD) \\
\hline $1605 \mathrm{AEI}$ & 6,96 \\
\hline $1605 \mathrm{BEI}$ & 8,44 \\
\hline $2305-\mathrm{AEI}$ & 8,56 \\
\hline $0606-\mathrm{El}$ & 13,72 \\
\hline $141108 \mathrm{El}$ & 3,97 \\
\hline $051208-\mathrm{EI}$ & 3,66 \\
\hline $060209-\mathrm{BEI}$ & 4,94 \\
\hline $170409-\mathrm{BEI}$ & 4,92 \\
\hline $220509-\mathrm{El}$ & 3,93 \\
\hline
\end{tabular}

Anexo 13: Atividade máxima da enzima Hexoquinase $(\mathrm{nmol} / \mathrm{min} / \mathrm{mg}$ de proteína) no VE dos animais do grupo Sham.

\begin{tabular}{|c|c|}
\hline Animais & HK (VE) \\
\hline $280208 \mathrm{C}$ & 2,27 \\
\hline $150408 \mathrm{C}$ & 2,47 \\
\hline $240408 \mathrm{AC}$ & 3,55 \\
\hline $240408 \mathrm{BC}$ & 3,02 \\
\hline $290408 \mathrm{C}$ & 3,04 \\
\hline $290508 \mathrm{C}$ & 2,84 \\
\hline
\end{tabular}

Anexo 14: Atividade máxima da enzima Hexoquinase $(\mathrm{nmol} / \mathrm{min} / \mathrm{mg}$ de proteína) no VE dos animais do grupo Contínuo.

\begin{tabular}{|c|c|}
\hline Animais & HK (VE) \\
\hline $2706 \mathrm{AEC}$ & 2,56 \\
\hline $2706 \mathrm{BEC}$ & 1,77 \\
\hline $140308 \mathrm{EC}$ & 2,59 \\
\hline $060209 \mathrm{AEC}$ & 2,88 \\
\hline $170409 \mathrm{AEC}$ & 3,3 \\
\hline $290509 \mathrm{EC}$ & 1,95 \\
\hline
\end{tabular}


Anexo 15: Atividade máxima da enzima Hexoquinase $(\mathrm{nmol} / \mathrm{min} / \mathrm{mg}$ de proteína) no VE dos animais do grupo Intermitente.

\begin{tabular}{|c|c|}
\hline Animais & HK (VE) \\
\hline $1605 \mathrm{AEI}$ & 1,9 \\
\hline $1605 \mathrm{BEI}$ & 1,87 \\
\hline $2305-\mathrm{AEI}$ & 2,54 \\
\hline $2305 \mathrm{BEI}$ & 1,75 \\
\hline $0606 \mathrm{El}$ & 1,94 \\
\hline $140308 \mathrm{EI}$ & 2,96 \\
\hline $141108 \mathrm{EI}$ & 2,55 \\
\hline $051208 \mathrm{EI}$ & 2,88 \\
\hline $060209 \mathrm{BEI}$ & 3,56 \\
\hline $170409 \mathrm{BEI}$ & 3,92 \\
\hline $220509 \mathrm{El}$ & 2,27 \\
\hline
\end{tabular}

Anexo 16: Atividade máxima da enzima Hexoquinase (nmol/min/mg de proteína) no septo interventricular do grupo Sham

\begin{tabular}{|c|c|}
\hline Animais & HK (Septo) \\
\hline $280208 \mathrm{C}$ & 6,44 \\
\hline $150408 \mathrm{C}$ & 6,38 \\
\hline $240408 \mathrm{AC}$ & 7,09 \\
\hline $290408 \mathrm{C}$ & 9,54 \\
\hline $290508 \mathrm{C}$ & 7,4 \\
\hline
\end{tabular}

Anexo 17: Atividade máxima da enzima Hexoquinase $(\mathrm{nmol} / \mathrm{min} / \mathrm{mg}$ de proteína) no septo interventricular do grupo Continuo

\begin{tabular}{|c|c|}
\hline Animais & HK (Septo) \\
\hline $2706 \mathrm{AEC}$ & 5,35 \\
\hline $2706 \mathrm{BEC}$ & 3,77 \\
\hline $140308 \mathrm{EC}$ & 7,99 \\
\hline $220808 \mathrm{EC}$ & 8,37 \\
\hline 060209AEC & 5,83 \\
\hline 170409AEC & 10,45 \\
\hline
\end{tabular}




\begin{tabular}{lll}
\hline $290509 E C$ & 7,89
\end{tabular}

Anexo 18: Atividade máxima da enzima Hexoquinase (nmol/min/mg de proteína) no septo interventricular do grupo Intermitente

\begin{tabular}{|c|c|}
\hline Animais & HK (Septo) \\
\hline $1605 \mathrm{AEI}$ & 4,3 \\
\hline $1605 \mathrm{BEI}$ & 5,03 \\
\hline $2305 \mathrm{AEI}$ & 7,04 \\
\hline $2305 \mathrm{BEI}$ & 6,16 \\
\hline $0606 \mathrm{EI}$ & 6,05 \\
\hline $140308 \mathrm{EI}$ & 9,7 \\
\hline $141108 \mathrm{EI}$ & 7,7 \\
\hline $051208 \mathrm{EI}$ & 6,32 \\
\hline $060209 \mathrm{BEI}$ & 7,41 \\
\hline $220509 \mathrm{EI}$ & 8 \\
\hline
\end{tabular}

Anexo 19: Atividade máxima da enzima Lactato Desidrogenase (nmol/min/mg de proteína) no VD do grupo Sham

\begin{tabular}{|c|c|}
\hline Animais & LDH (VD) \\
\hline $280208 \mathrm{C}$ & 0,34 \\
\hline $150408 \mathrm{C}$ & 0,28 \\
\hline $240408 \mathrm{AC}$ & 0,41 \\
\hline $240408 \mathrm{BC}$ & 0,21 \\
\hline $290408 \mathrm{C}$ & 0,29 \\
\hline $290508 \mathrm{C}$ & 0,35 \\
\hline
\end{tabular}

Anexo 20: Atividade máxima da enzima Lactato Desidrogenase (nmol/min/mg de proteína) no VD do grupo Continuo

\begin{tabular}{|c|c|}
\hline Animais & LDH (VD) \\
\hline $140308 \mathrm{EC}$ & 0,23 \\
\hline $220808 \mathrm{EC}$ & 0,37 \\
\hline $060209 \mathrm{AEC}$ & 0,37 \\
\hline $170409 \mathrm{AEC}$ & 0,98 \\
\hline
\end{tabular}




290509EC 0,12

Anexo 21: Atividade máxima da enzima Lactato Desidrogenase (nmol/min/mg de proteína) no VD do grupo Intermitente

\begin{tabular}{|c|c|}
\hline Animais & LDH (VD) \\
\hline $140308 \mathrm{EI}$ & 0,38 \\
\hline $141108 \mathrm{EI}$ & 0,15 \\
\hline $051208 \mathrm{EI}$ & 3,03 \\
\hline $060209 \mathrm{EI}$ & 1,2 \\
\hline $170409 \mathrm{BEI}$ & 0,19 \\
\hline $220509 \mathrm{EI}$ & 1,28 \\
\hline & \\
\hline
\end{tabular}

Anexo 22: Atividade máxima da enzima Lactato Desidrogenase (nmol/min/mg de proteína) no VE do grupo Sham

\begin{tabular}{|c|c|}
\hline Animais & LDH (VE) \\
\hline $280208 \mathrm{C}$ & 0,65 \\
\hline $150408 \mathrm{C}$ & 0,62 \\
\hline $240408 \mathrm{AC}$ & 0,82 \\
\hline $240408 \mathrm{BC}$ & 2,9 \\
\hline $290408 \mathrm{C}$ & 6,5 \\
\hline $290508 \mathrm{C}$ & 5,28 \\
\hline
\end{tabular}

Anexo 23: Atividade máxima da enzima Lactato Desidrogenase (nmol/min/mg de proteína) no VE do grupo Continuo

\begin{tabular}{|c|c|}
\hline Animais & LDH (VE) \\
\hline $0407 \mathrm{EC}$ & 1,13 \\
\hline $140308 \mathrm{EC}$ & 1,04 \\
\hline $220808 \mathrm{EC}$ & 1,53 \\
\hline $060209 \mathrm{AEC}$ & 2,78 \\
\hline $170409 \mathrm{AEC}$ & 2,72 \\
\hline
\end{tabular}




\section{EC \\ 1,78}

Anexo 24: Atividade máxima da enzima Lactato Desidrogenase (nmol/min/mg de proteína) no VE do grupo Intermitente

\begin{tabular}{|c|c|}
\hline Animais & LDH (VE) \\
\hline $140308 \mathrm{EI}$ & 1,33 \\
\hline $141108 \mathrm{El}$ & 3,45 \\
\hline $051208 \mathrm{EI}$ & 11,27 \\
\hline $060209 \mathrm{BEI}$ & 2,36 \\
\hline $170409 \mathrm{BEI}$ & 7,93 \\
\hline $220509 \mathrm{El}$ & 5,06 \\
\hline
\end{tabular}

Anexo 25: Atividade máxima da enzima Lactato Desidrogenase (nmol/min/mg de proteína) no septo interventricular do grupo Sham

\begin{tabular}{|c|c|}
\hline Animais & LDH (septo) \\
\hline $280208 \mathrm{C}$ & 0,39 \\
\hline $150408 \mathrm{C}$ & 1,48 \\
\hline $240408 \mathrm{AC}$ & 1,55 \\
\hline $240408 \mathrm{BC}$ & 7,83 \\
\hline $290408 \mathrm{C}$ & 4,46 \\
\hline
\end{tabular}

Anexo 26: Atividade máxima da enzima Lactato Desidrogenase (nmol/min/mg de proteína) no septo interventricular do grupo Continuo

\begin{tabular}{|c|c|}
\hline Animais & LDH (septo) \\
\hline 0407EC & 6,85 \\
\hline
\end{tabular}




\begin{tabular}{|c|c|}
\hline $220808 \mathrm{EC}$ & 2,35 \\
\hline 060209AEC & 4 \\
\hline $170409 \mathrm{AEC}$ & 3,82 \\
\hline $290509 \mathrm{EC}$ & 4,92 \\
\hline
\end{tabular}

Anexo 27: Atividade máxima da enzima Lactato Desidrogenase (nmol/min/mg de proteína) no septo interventricular do grupo Intermitente

\begin{tabular}{|c|c|}
\hline Animais & LDH (septo) \\
\hline $140308 \mathrm{El}$ & 2,68 \\
\hline $141108 \mathrm{El}$ & 4,8 \\
\hline $060209 \mathrm{BEI}$ & 5,09 \\
\hline $170409 \mathrm{BEI}$ & 6,8 \\
\hline $220509 \mathrm{El}$ & 11,9 \\
\hline
\end{tabular}

Anexo 28: Peso das massas cardíacas do ventrículo direito, ventrículo esquerdo e septo interventricular, indexadas pelo peso do animal $(\mathrm{g} / \mathrm{kg})$ após a eutanásia no grupo Sham.

\begin{tabular}{|c|c|c|c|}
\hline Animais & Peso VD & Peso VE & Peso Septo \\
\hline $290408 \mathrm{C}$ & 0,85 & 1,52 & 0,88 \\
\hline $240408 \mathrm{AC}$ & 0,81 & 1,24 & 0,88 \\
\hline $240408 \mathrm{BC}$ & 0,81 & 1,34 & 0,85 \\
\hline $150408 \mathrm{C}$ & 0,56 & 1,14 & 0,74 \\
\hline $6427(280208)$ & 0,66 & 1,41 & 0,82 \\
\hline $1503(290208)$ & 0,73 & 1,35 & 0,78 \\
\hline $290508 \mathrm{C}$ & 0,91 & 1,64 & 1,04 \\
\hline
\end{tabular}

Anexo 29: Peso das massas cardíacas do ventrículo direito, ventrículo esquerdo e septo interventricular, indexadas pelo peso do animal $(\mathrm{g} / \mathrm{kg})$ após a eutanásia no grupo Contínuo.

\begin{tabular}{|c|c|c|c|}
\hline Animais & Peso VD & Peso VE & Peso Septo \\
\hline $2706 \mathrm{AEC}$ & 1,21 & 1,44 & 1,04 \\
\hline $2706 \mathrm{BEC}$ & 1,41 & 1,88 & 1,39 \\
\hline $1608 \mathrm{EC}$ & 1,19 & 1,31 & 0,96 \\
\hline $140308 \mathrm{EC}$ & 1,23 & 1,62 & 1,24 \\
\hline $220808 \mathrm{EC}$ & 1,15 & 1,66 & 1,37 \\
\hline
\end{tabular}




\begin{tabular}{|c|c|c|c|}
\hline 0407EC & 1,1 & 1,75 & 1,21 \\
\hline 060209AEC & 1,29 & 1,25 & 1,1 \\
\hline $170409 \mathrm{AEC}$ & 1,02 & 1,55 & 1,09 \\
\hline $290509 \mathrm{EC}$ & 1,35 & 1,36 & 1,21 \\
\hline
\end{tabular}

Anexo 30: Peso das massas cardíacas do ventrículo direito, ventrículo esquerdo e septo interventricular, indexadas pelo peso do animal $(\mathrm{g} / \mathrm{kg})$ após a eutanásia no grupo Intermitente.

\begin{tabular}{|c|c|c|c|}
\hline Animais & Peso VD & Peso VE & Peso Septo \\
\hline $1605 \mathrm{AEI}$ & 1,51 & 1,66 & 1,52 \\
\hline $1605 \mathrm{BEI}$ & 1,49 & 1,37 & 1,43 \\
\hline 2305 & 1,92 & 1,79 & 1,77 \\
\hline $0606 \mathrm{EI}$ & 2,86 & 2,21 & 1,67 \\
\hline $140308 \mathrm{EI}$ & 1,19 & 1,58 & 1,17 \\
\hline $2305 \mathrm{BEI}$ & 1,42 & 1,52 & 1,19 \\
\hline $141108 \mathrm{EI}$ & 1,13 & 1,17 & 1,12 \\
\hline $051208 \mathrm{EI}$ & 1,11 & 1,67 & 0,96 \\
\hline $060209 \mathrm{BEI}$ & 1,23 & 1,28 & 0,95 \\
\hline $170409 \mathrm{BEI}$ & 1,05 & 1,54 & 0,94 \\
\hline $220509 \mathrm{EI}$ & 1,19 & 1,91 & 1,11 \\
\hline
\end{tabular}

Anexo 31: Medidas ecocardiográficas de espessura da parede livre do ventrículo direito (VD), do septo interventricular (SIV) e da parede posterior do ventrículo esquerdo (VE) do grupo Sham ao longo do protocolo.

\begin{tabular}{|c|c|c|c|c|c|c|c|c|c|c|c|c|c|c|c|}
\hline \multicolumn{16}{|c|}{ Grupo Sham } \\
\hline \multirow[b]{2}{*}{ Animal } & \multicolumn{3}{|c|}{ Basal } & \multicolumn{3}{|c|}{$1^{\circ} \mathrm{dia}$} & \multicolumn{3}{|c|}{$2^{\circ}$ dia } & \multicolumn{3}{|c|}{$3^{\circ} \mathrm{dia}$} & \multicolumn{3}{|c|}{$4^{\circ} \mathrm{dia}$} \\
\hline & VD & SIV & VE & VD & SIV & VE & VD & SIV & VE & VD & SIV & VE & VD & SIV & VE \\
\hline $280208 C$ & 0,31 & 0,53 & 0,54 & 0,30 & 0,57 & 0,51 & 0,33 & 0,54 & 0,5 & 0,34 & 0,51 & 0,52 & 0,35 & 0,52 & 0,53 \\
\hline $290208 C$ & 0,31 & 0,54 & 0,5 & 0,34 & 0,54 & 0,51 & 0,33 & 0,5 & 0,56 & 0,34 & 0,51 & 0,52 & 0,34 & 0,51 & 0,53 \\
\hline $150408 \mathrm{C}$ & 0,33 & 0,46 & 0,46 & 0,34 & 0,46 & 0,48 & 0,33 & 0,46 & 0,48 & 0,34 & 0,45 & 0,48 & 0,35 & 0,45 & 0,46 \\
\hline 240408BC & 0,32 & 0,44 & 0,47 & 0,33 & 0,47 & 0,48 & 0,35 & 0,44 & 0,44 & 0,34 & 0.48 & 0,48 & 0,33 & 0.49 & 0,48 \\
\hline 240408 AC & 0,35 & 0,49 & 0,47 & 0,32 & 0,45 & 0,47 & 0,32 & 0,43 & 0,47 & 0,32 & 0.52 & 0,5 & 0,31 & 0.47 & 0,47 \\
\hline $290408 C$ & 0,33 & 0,52 & 0,53 & 0,34 & 0,55 & 0,54 & 0,35 & 0,55 & 0,53 & 0,35 & 0.54 & 0,54 & 0,34 & 0.56 & 0,54 \\
\hline $290508 C$ & 0,32 & 0,48 & 0,48 & 0,34 & 0,44 & 0,45 & 0,34 & 0,44 & 0,45 & 0,34 & 0.47 & 0,46 & 0,34 & 0.45 & 0,43 \\
\hline
\end{tabular}


Anexo 32: Medidas ecocardiográficas de espessura da parede livre do ventrículo direito (VD), do septo interventricular (SIV) e da parede posterior do ventrículo esquerdo (VE) do grupo Contínuo ao longo do protocolo.

\begin{tabular}{|c|c|c|c|c|c|c|c|c|c|c|c|c|c|c|c|}
\hline \multicolumn{16}{|c|}{ Grupo Contínuo } \\
\hline \multirow[b]{2}{*}{ Animal } & \multicolumn{3}{|c|}{ Basal } & \multicolumn{3}{|c|}{$1^{\circ} \mathrm{dia}$} & \multicolumn{3}{|c|}{$2^{\circ} \mathrm{dia}$} & \multicolumn{3}{|c|}{$3^{\circ} \mathrm{dia}$} & \multicolumn{3}{|c|}{$4^{\circ} \mathrm{dia}$} \\
\hline & VD & SIV & VE & VD & SIV & VE & VD & SIV & VE & VD & SIV & VE & VD & SIV & VE \\
\hline 2706-AEC & 3 & 5 & 5 & 3 & 5 & 5 & 3 & 5 & 5 & 3 & 5 & 5 & 5 & 5 & 5 \\
\hline 2706-BEC & 4 & 5 & 5 & 3 & 5 & 5 & 3 & 5 & 5 & 3 & 5 & 5 & 4 & 5 & 5 \\
\hline 1608-EC & 3 & 4 & 4 & 3 & 5 & 4 & 4 & 4 & 4 & 3.5 & 4 & 4 & 5 & 4 & 4 \\
\hline 140308EC & 3.5 & 5.1 & 4.5 & 3.3 & 5.4 & 4.3 & 3.5 & 5.4 & 4.6 & 3.7 & 5.4 & 4.7 & 4.2 & 5.3 & 4.4 \\
\hline $220808 E C$ & 3.6 & 5 & 4.1 & 3.5 & 5 & 4.4 & 3.4 & 5 & 4.4 & 3.4 & 4.6 & 4.1 & 4.1 & 4.7 & 4.5 \\
\hline 0407-EC & 3 & 6 & 5 & 4 & 6 & 5 & 3 & 6 & 5 & 5 & 6 & 5 & 5 & 6 & 5 \\
\hline 060209AEC & 3.1 & 4.4 & 4.5 & 3.1 & 4.8 & 4.8 & 3.5 & 5.1 & 4.9 & 3.3 & 5 & 5 & 3.2 & 5 & 5 \\
\hline 170409AEC & 3.1 & 5.3 & 5.3 & 3.4 & 5.4 & 5.4 & 3.4 & 5 & 5 & 3.3 & 5.1 & 5.2 & 4.1 & 5 & 5 \\
\hline 290509EC & 3.2 & & & 3.5 & & & 3.5 & & & 4.5 & & & 5 & & \\
\hline
\end{tabular}

Anexo 33: Medidas ecocardiográficas de espessura da parede livre do ventrículo direito (VD), do septo interventricular (SIV) e da parede posterior do ventrículo esquerdo (VE) do grupo Intermitente ao longo do protocolo.

\begin{tabular}{|c|c|c|c|c|c|c|c|c|c|c|c|c|c|c|c|}
\hline \multicolumn{16}{|c|}{ Grupo Intermitente } \\
\hline \multirow[b]{2}{*}{ Animal } & \multicolumn{3}{|c|}{ Basal } & \multicolumn{3}{|c|}{$1^{\circ} \mathrm{dia}$} & \multicolumn{3}{|c|}{$2^{\circ}$ dia } & \multicolumn{3}{|c|}{$3^{\circ} \mathrm{dia}$} & \multicolumn{3}{|c|}{$4^{\circ}$ dia } \\
\hline & VD & SIV & VE & VD & SIV & VE & VD & SIV & VE & VD & SIV & VE & VD & SIV & VE \\
\hline 1605AEI & 2 & 5 & 5 & 2 & 5 & 5 & 3 & 5 & 5 & 4 & 5 & 5 & 5 & 5 & 5 \\
\hline 1605BEI & 2 & 5 & 5 & 3 & 5 & 5 & 3 & 5 & 5 & 3 & 5 & 5 & 5 & 5 & 5 \\
\hline 2305 & 2 & 5 & 5 & 3 & 5 & 5 & 3 & 5 & 5 & 4 & 5 & 5 & 6 & 5 & 5 \\
\hline 0608El & 3 & 4 & 5 & 2 & 4 & 5 & 2 & 4 & 5 & 6 & 4 & 5 & 6 & 4 & 5 \\
\hline $140308 \mathrm{EI}$ & 3,3 & 4,9 & 5,1 & 3,1 & 4,9 & 5,6 & 2,8 & 4,6 & 5,5 & 4,2 & 5 & 5,6 & 4,3 & 4,5 & 5 \\
\hline 2305BEI & 3 & 5 & 5 & 3 & 5 & 5 & 2 & 5 & 5 & 4 & 5 & 5 & 4 & 5 & 5 \\
\hline $141108 \mathrm{EI}$ & 3,2 & 5,4 & 5,4 & 3,4 & 5,3 & 5,3 & 3,7 & 5,5 & 5,5 & 4 & 4,6 & 5,3 & 4,3 & 5 & 5,3 \\
\hline 051208EI & 3,4 & 5,4 & 5,2 & 3,4 & 5,5 & 5,2 & 3,4 & 5,4 & 5,4 & 3,4 & 5,4 & 5,5 & 4,5 & 5,4 & 5,4 \\
\hline 060209BEI & 3 & 4,6 & 4,8 & 3,3 & 5,5 & 5,2 & 3,2 & 4,8 & 4,9 & 3,1 & 4,8 & 5 & 5 & 4,8 & 4,8 \\
\hline 170409BEI & 3,5 & 4,5 & 5 & 3,3 & 5,4 & 5,4 & 3,3 & 5,5 & 5,5 & 3,4 & 5 & 5 & 4,8 & 5,3 & 5,4 \\
\hline 220509EI & 3,2 & & 5 & 3,3 & & & 3,8 & & & 3,9 & & & 4,4 & & \\
\hline
\end{tabular}


Anexo 34: Medidas ecocardiográficas de volume diastólico final do ventrículo direito $(\mathrm{ml})$ e fração de ejeção do ventrículo direito (\%) do grupo Sham.

\begin{tabular}{|c|c|c|c|c|c|c|c|c|c|c|c|c|c|c|c|}
\hline \multicolumn{16}{|c|}{ Grupo Sham } \\
\hline & \multicolumn{3}{|c|}{ Basal } & \multicolumn{3}{|c|}{$1^{\circ} \mathrm{dia}$} & \multicolumn{3}{|c|}{$2^{\circ} \mathrm{dia}$} & \multicolumn{3}{|c|}{$3^{\circ} \mathrm{dia}$} & \multicolumn{3}{|c|}{$4^{\circ} \mathrm{dia}$} \\
\hline Animal & VD & SIV & VE & VD & SIV & VE & VD & SIV & VE & VD & SIV & VE & VD & SIV & VE \\
\hline $280208 C$ & 0,31 & 0,53 & 0,54 & 0,30 & 0,57 & 0,51 & 0,33 & 0,54 & 0,5 & 0,34 & 0,51 & 0,52 & 0,35 & 0,52 & 0,53 \\
\hline $290208 C$ & 0,31 & 0,54 & 0,5 & 0,34 & 0,54 & 0,51 & 0,33 & 0,5 & 0,56 & 0,34 & 0,51 & 0,52 & 0,34 & 0,51 & 0,53 \\
\hline $150408 C$ & 0,33 & 0,46 & 0,46 & 0,34 & 0,46 & 0,48 & 0,33 & 0,46 & 0,48 & 0,34 & 0,45 & 0,48 & 0,35 & 0,45 & 0,46 \\
\hline 240408BC & 0,32 & 0,44 & 0,47 & 0,33 & 0,47 & 0,48 & 0,35 & 0,44 & 0,44 & 0,34 & 0.48 & 0,48 & 0,33 & 0.49 & 0,48 \\
\hline $240408 A C$ & 0,35 & 0,49 & 0,47 & 0,32 & 0,45 & 0,47 & 0,32 & 0,43 & 0,47 & 0,32 & 0.52 & 0,5 & 0,31 & 0.47 & 0,47 \\
\hline $290408 C$ & 0,33 & 0,52 & 0,53 & 0,34 & 0,55 & 0,54 & 0,35 & 0,55 & 0,53 & 0,35 & 0.54 & 0,54 & 0,34 & 0.56 & 0,54 \\
\hline $290508 C$ & 0,32 & 0,48 & 0,48 & 0,34 & 0,44 & 0,45 & 0,34 & 0,44 & 0,45 & 0,34 & 0.47 & 0,46 & 0,34 & 0.45 & 0,43 \\
\hline
\end{tabular}


Referências Bibliográficas 


\section{REFERÊNCIAS BIBLIOGRÁFICAS}

1- Iyer KS, Sharma R, Kumar K, Bhan A, Kothari SS, Saxena A, et al. Serial echocardiography for decision making in rapid two-stage arterial switch operation. Ann Thorac Surg 1995; 60:658-64.

2- Lacour-Gayet F, Piot D, Zoghbi J, Serraf A, Gruber P, Mace L, et al. Surgical management and indication of left ventricular retraining in arterial switch for transposition of the great arteries with intact ventricular septum. Eur J Cardiothorac Surg $2001 ; 20: 824-9$.

3- Assad RS, Cardarelli M, Abduch MC, Aiello VD, Maizato M, BarberoMarcial M, et al. Reversible pulmonary artery banding with a balloon catheter: assessment of rapid pulmonary ventricular hypertrophy. J Thorac Cardiovasc Surg 2000; 120: 66-72.

4- Jonas RA, Giglia TM, Sanders SP, Wernovsky G, Nadal-Ginard B, Mayer JE, et al. Rapid, two-stage arterial switch for transposition of the great arteries and intact ventricular septum beyond the neonatal period. Circulation 1989; 80 (3 Pt 1), I203-8.

5- Boutin C, Wernovsky G, Sanders SP, Jonas RA, Castaneda AR, Colan SD. Rapid two-stage arterial switch operation. Evaluation of left ventricular systolic mechanics late after an acute pressure overload stimulus in infancy. Circulation 1994;90:1294-1303.

6- Bishop SP, Melsen LR. Myocardial necrosis, fibrosis, and DNA synthesis in experimental cardiac hypertrophy induced by sudden pressure overload. Circ Res 1976; 39(2): 238-45. 
7- Siehl DL, Gordon EE, Kira Y, Chua BHL, Morgan HE. Protein degradation in the hypertrophic heart. In: Lysosomes: their role in protein breakdown. Glaumann H, Ballard FJ, 1 ed. London, Academic, 1987.

8- Zimmer HG, Ibel H, Gerlach E. Significance of the hexose monophosphate shunt in experimentally induced cardiac hypertrophy. Basic Res Cardiol 1980;75 (1): 207-13.

9- Marino TA, Kent RL, Oboh CE, Fernandez E, Thompson EW, Cooper G. Structural analysis of pressure versus volume overload hypertrophy of cat right ventricle. Am J Physiol 1985;249:H371-9.

10- Mann DL, Urabe Y, Kent RL, Vinciguerra S, Cooper G. Cellular versus myocardial basis for the contractile dysfunction of hypertrophied myocardium. Circ Res 1991;68:402-15.

11- Takahashi Y, Nakano S, Shimazaki Y, Kadoba K, Taniguchi K, Sano T, et al. Echocardiographic comparison of postoperative left ventricular contractile state between one and two-stage arterial switch operation for simple transposition of the great arteries. Circulation 1991; 84 (5 Suppl.), III180-6.

12- Irlbeck M, Iwai T, Lerner T, Zimmer HG. Effects of angiotensin II receptor blockade on hypoxia-induced right ventricular hypertrophy in rats. J Mol Cell Cardiol 1997;29:2931-9.

13- Colan SD, Boutin C, Castaneda AR, Wernovsky G. Status of the left ventricle after arterial switch operation for transposition of the great arteries. Hemodynamic and echocardiographic evaluation. J Thorac Cardiovasc Surg 1995;109:311-21. 
14- Bishop SP. The myocardial cell: normal growth, cardiac hypertrophy and response to injury. Toxicol Pathol 1990;18:438-53.

15- Leeuwenburgh BP, Steendijk P, Helbing WA, Baan J. Indexes of diastolic RV function: load dependence and changes after chronic RV pressure overload in lambs. Am J Physiol Heart Circ Physiol 2002; 282: H1350-8.

16- Meerson FZ. Compensatory hyperfunction of the heart and cardiac insufficiency. Circ Res 1962;10:250-8.

17- Grossman W, Jones D, McLaurin LP. Wall stress and patterns of hypertrophy in the human ventricle. J Clin Invest 1975;56:56-64.

18 - Dorn GW. The fuzzy logic of physiological cardiac hyperthrophy. Hypertension 2007; 49: 962-70.

19- Perrino C, Naga Prasad SV, Mao L, Noma T, Yan Z, Kim HS, et al. Intermittent pressure overload triggers hypertrophy-independent cardiac dysfunction and vascular rarefaction. J Clin Invest 2006; 116: 1547-60.

20- Assad RS, Cardarelli M, Abduch MCD, Aiello VD, Maizato M, Jatene AD. Bandagem reversível do tronco pulmonar: modelo experimental para preparo rápido do ventrículo pulmonar. Rev Bras Cir Cardiovasc 1998;13:239-48.

21- Caneo LF. Preparo do ventrículo subpulmonar através de dois modelos ajustáveis de estenose do tronco pulmonar: estudo experimental. São Paulo, 1999. 90 p. Tese (Doutorado) - Faculdade de Medicina, Universidade de São Paulo.

22- Caneo LF, Dias CA, Assad RS, Abduch MC, Aiello VD, Lourenço Jr D, Stolf NAG. Preparo do ventrículo subpulmonar através de dois modelos 
ajustáveis de estenose do tronco pulmonar: Estudo experimental. Rev Bras Cir Cardiovasc 2001; 16(1): 35-48.

23 - Dias CA. Modelo experimental de bandagem ajustável do tronco pulmonar: novo dispositivo para preparo rápido do ventrículo. São Paulo, 1998. 92 p. Tese (Doutorado) - Faculdade de Medicina, Universidade de São Paulo.

24- Dias CA, Assad RS, Caneo LF, Abduch MCD, Aiello VD, Dias AR. Modelo experimental de bandagem ajustável do tronco pulmonar: Novo dispositivo para preparo rápido do ventrículo. Rev Bras Cir Cardiovasc 2000;15(4):328-37.

25- Dias CA, Assad RS, Caneo LF, Abduch MC, Aiello VD, Dias AR, et al. Reversible pulmonary trunk banding. II. An experimental model for rapid pulmonary ventricular hypertrophy. J Thorac Cardiovasc Surg 2002; 124: 999-1006.

26- Abduch MC, Assad RS, Rodriguez MQ, Valente AS, Andrade JL, Demarchi LM, et al. Reversible pulmonary trunk banding III: assessment of myocardial adaptive mechanisms - contribution of cell proliferation. J Thorac Cardiovasc Surg 2007; 133: 1510-6.

27 - Rabello RR. Análise da Atividade da Enzima Conversora de Angiotensina na Hipertrofia Aguda do Ventrículo Direito em Modelo Experimental de Estenose Endovascular Ajustável do Tronco Pulmonar. São Paulo, 2000. 96 p. Tese (Doutorado) - Faculdade de Medicina, Universidade de São Paulo. 
28- Rabello RR, Assad RS, Krieger JE, Abduch MCD, Oliveira SA. Análise da Atividade da Enzima Conversora de Angiotensina na Hipertrofia Aguda do Ventrículo Direito em Modelo Experimental de Estenose Endovascular Ajustável do Tronco Pulmonar. Rev Bras Cir Cardiovasc 2001;16(4): 364-75. 29- Adams TD, Yanowitz FG, Fisher AG, Ridges JD, Lovell K, Pryor TA. Noninvasive evaluation of exercise training in college-age men. Circulation 1981; 64: 958-965.

30- Möckel M, Störk T: Diastolic function in various forms of left ventricular hypertrophy: contribution of active Doppler stress echo. Int J Sports Med 1996; 17: S184-S190.

31- Shapiro LM, Smith RG: Effect of training on left ventricular structure and function: an echocardiographic study. Br Heart J 1983; 50: 534-539.

32- Richey PA, Brown SP: Pathological versus physiological left ventricular hypertrophy: a review. J Sports Sci 1998; 16: 129-141.

33 - Panidis IP, Kotler MN, Ren JF, Mintz GS, Ross J, Kalman P: Development and regression of left ventricular hypertrophy. J Am Coll Cardiol 1984; 3: 1309-1320.

34- Reddy DS: Cellular and molecular biology of cardiac hypertrophy. Curr Sci 1997; 72: 13-30.

35- Takano H, Zou Y, Akazawa H, Toko H, Mizukami M, Hasegawa H, et al. Inhibitory molecules in signal transduction pathways of cardiac hypertrophy. Hypertens Res 2002; 25: 491-8. 
36 - Katona PG, McLean M, Dighton DH,Guz A. Sympathetic and parasympathetic cardiac control in athletes and nonathletes at rest. Appl Physiol. 1982;52:1652-657

37- Morganroth J, Maron BJ, Henry WL, Epstein SE. Comparative left ventricular dimensions in trained athletes. Ann Intern Med. 1975;82:524-525. 38- Negrão CE, Forjaz CLM, Brum PC. Exercício físico e hipertensão. Hiperativo 1994;1:18-22.

39- Krieger JE \& Baur WE. Molecular biology of hypertension. Hypertension 1991;18 (Suppl. 1):I3-I17.

40- Batlouni M. Coração de Atleta. In: O Exercício: Preparação Fisiológica, Avaliação Médica, Aspectos Especiais e Preventivos. Nabil Ghorayeb \& Turíbio Barros 1999 Editora Ateneu. Cap. 14:147-171

41- Barbanti VJ. Dicionário de Educação Física e do Esporte. 1994, Editora Manole, 1a Edição.

42- Le Bret E, Lupoglazoff JM, Borenstein N, Fromont G, Laborde F, Bachet J, et al. Cardiac "fitness" training: an experimental comparative study of three methods of pulmonary artery banding for ventricular training. Ann Thorac Surg. 2005; 79(1): 198-203.

43- Taegtmeyer $\mathrm{H}$. Energy metabolism of the heart: from basic concepts to clinical applications. Curr Probl Cardiol 1994; 19:59-113.

44- Grynberg A, Demaison L. Fatty acid oxidation in the heart. J Cardiovasc Pharmacol 1996; 28: S11-S17.

45- Opie LH. Metabolism of the heart in health and disease. I. Am Heart $\mathrm{J}$ 1968; 76: 685-698. 
46- Van der Vusse GJ, Glatz JF, Stam HC, Reneman RS. Fatty acid homeostasis in the normoxic and ischemic heart. Physiol Rev 1992; 72: 881940.

47- Shipp JC, Opie LH, Challoner D. Fatty acid and glucose metabolism in the perfused heart. Nature 1961; 189: 1018-9.

48- Bing RJ, Siegel A, Ungar I, Gilbert M. Metabolism of the human heart. II. Studies on fat, ketone and amino acid metabolism. Am J Med 1954; 16: 50415.

49- Huss JM, Kelly DP. Mitochondrial energy metabolism in heart failure: a question of balance. J Clin Invest 2005;115:547-55.

50- Christe ME, Rodgers RL. Altered glucose and fatty acid oxidation in hearts of the spontaneously hypertensive rat. J Mol Cell Cardiol 1994; 26 : $1371-1375$.

51- Sack MN, Rader TA, Park S, Bastin J, McCune SA, Kelly DP. Fatty acid oxidation enzyme gene expression is downregulated in the failing heart. Circulation 1996; 94: 2837-42.

52- lemitsu M, Miyauchi T, Maeda S, Sakai S, Fujii N, Miyazaki H, et al. Cardiac hypertrophy by hypertension and exercise training exhibits different gene expression of enzymes in energy metabolism. Hypertens Res. 2003; 26(10): 829-37.

53- El Alaoui-Talibi Z, Guendouz A, Moravec M, Moravec J. Control of oxidative metabolism in volume-overloaded rat hearts: effect of propionyl-Lcarnitine. Am J Physiol 1997; 272: H1615-H1624. 
54- Allard MF, Henning SL, Wambolt RB, Granleese SR, English DR, Lopaschuk GD. Glycogen metabolism in the aerobic hypertrophied rat heart. Circulation 1997; 96: 676-682.

55- Henning SL, Wambolt RB, Schonekess BO, Lopaschuk GD, Allard MF. Contribution of glycogen to aerobic myocardial glucose utilization. Circulation 1996;93:1549-55.

56- Lee SM, Koh HJ, Park DC, Song BJ, Huh TL, Park JW. Cytosolic $\mathrm{NADP}(+)$-dependent isocitrate dehydrogenase status modulates oxidative damage to cells. Free Radic Biol Med. 2002; 32(11):1185-96.

57- Salvemini F; Franze A; Lervolino A; Filosa S; Salzano S; Ursini MV. Enhanced glutathione levels and oxidoresistance mediated by increased glucose-6-phosphate dehydrogenase expression. J Biol Chem 1999; 274(5):2750-7.

58- Anderson PG, Allard MF, Thomas GD, Bishop SP, Digerness SB. Increased ischemic injury but decreased hypoxic injury in hypertrophied rat hearts. Circ Res 1990; 67: 948-959.

59- Allard MF, Emanuel PG, Russell JA, Bishop SP, Digerness SB, Anderson PG. Preischemic glycogen reduction or glycolytic inhibition improves postischemic recovery of hypertrophied rat hearts. Am J Physiol 1994; 267 : $\mathrm{H} 66-\mathrm{H} 74$.

60- Luzzato L, Battistuzzi G. Glucose-6-phosphate dehydrogenase. Adv Hum Genet 1985; 14:217-329. 
61- Ho H, Cheng M, Chiu DT. Glucose-6-phosphate dehydrogenase: from oxidative stress to cellular functions and degenerative diseases. Redox Report 2007; 12: 109-18.

62- Leopold JA, Walker J, Scribner AW, Voetsch B, Zhang YY, Loscalzo AJ, et al. Glucose 6-phosphate dehydrogenase modulates vascular endothelial growth factor-mediated angiogenesis. J Biol Chem 2003;278:3210-6.

63- Leopold JA, Zhang YY, Scribner AW, Stanton RC, Loscalzo J. Glucose 6-phosphate dehydrogenase overexpression decreases endothelial cell oxidant stress and increases bioavailable nitric oxide. Arterioscler Thromb Vasc Biol 2003; 23:411-7.

64- Jain M, Brenner DA, Cui L, Lim CC, Wang B, Pimentel DR, et al. Glucose-6-phosphate dehydrogenase modulates cytosolic redox status and contractile phenotype in adult cardiomyocytes. Circ Res 2003;93:e9-e16.

65- Giordano FJ. Oxygen, oxidative stress, hypoxia, and heart failure. J Clin Invest 2005;115: 500-8.

66- Gupte SA, Levine RJ, Gupte RS, Young ME, Lionetti V, Labinskyy V, et al. Glucose-6-phosphate dehydrogenase-derived NADPH fuels superoxide production in the failing heart. J Mol Cell Cardiol 2006;41:340-9.

67- Gupte RS, Vijay V, Marks B, Levine RJ, Sabbah HN, Wolin MS, et al. Upregulation of glucose-6-phosphate dehydrogenase and $\mathrm{NAD}(\mathrm{P}) \mathrm{H}$ oxidase acitivity increases oxidative stress in failing human heart. J Card Fail 2007;13:497-506.

68- Rajasekaran NS, Connell P, Christians ES, Yan LJ, Taylor RP, Orosz A, et al. Cell 2007; 130: 427-39. 
69- Dimmeler S, Zeiher AM. A "reductionist" view of cardiomyopathy. Cell $2007 ; 130: 401-2$

70- Lang RM, Bierig M, Devereux RB, Flachskampf FA, Foster E, Pellikka PA, et al. Recommendations for chamber quantification: a report from the American Society of Echocardiography's Guidelines and Standards Committee and the Chamber Quantification Writing Group, developed in conjunction with the European Association of Echocardiography, a branch of the European Society of Cardiology. J Am Soc Echocardiogr. 2005; 18:144063.

71- Pontes Jr SC, Assef JE, Barretto RBM, Chaccur P, Moreira DAR, Nina VJS, et al. Estimation of right ventricular mass by two- dimensional echocardiography. J Am Soc Echocardiography 2005;18:427-34.

72- Morhy SS, Andrade JL, Soares AM, Ribeiro ZV, Wilberg TM, Mathias Jr W, et al. Non-invasive assessment of right ventricular function in the late follow-up of the Senning procedure. Cardiol Young. 2005; 15:154-9.

73- Tei C, Nishimura RA, Seward JB, Tajik AJ. Noninvasive Doppler-derived myocardial performance index: correlation with simultaneous measurements of cardiac catheterization measurements. J Am Soc Echocardiogr. 1997;10:169-78.

74- Fulton RM, Hutchinson EC, Jones AM. Ventricular weight in cardiac hypertrophy. Br Heart J 1952;14:413-20.

75- Bishop SP, Cole CR. Production of externally controlled progressive pulmonic stenosis in the dog. J Appl Physiol 1969; 26: 659-63. 
76- Bergmeyer, HU, Bernt E. D-glucose determination with hexokinase and glucose-6-phosphate dehydrogenase. In: Bergmeyer HU. ed. Methods of Enzymatic Analysis. Academic Press, London, 1196-1201, 1974.

77- Crabtree B. Techniques in life sciences. Amsterdam 189, 1979.

78- Zammit, VA, Newsholme EA. The maximum activities of hexokinase, phosphorylase, phosphofructokinase, glycerol phosphate dehydrogenases, lactate dehydrogenase, octopine dehydrogenase, phosphoenolpyruvate carboxykinase, nucleoside diphosphatekinase, glutamate-oxaloacetate transaminase and arginine kinase in relation to carbohydrate utilization in muscles from marine invertebrates. Biochem J 1976; 160(3):447-62.

79- Yerebakan C, Klopsch C, Niefeldt S, Zelsig V, Vollmar B, Liebold B, Sandica E, Steinhoff G. Acute and chronic response of the right ventricle to surgically induced pressure and volume overload - an analysis of pressurevolume relations. Interact Cardiovasc Thorac Surg 2010;10:519-25.

79- Bishop SP, Altschuld RA. Increased glycolytic metabolism in cardiac hypertrophy and congestive failure. Am J Physiol 1970; 218: 153-159.

80- Kagaya Y, Kanno Y, Takeyama D, Ishide N, Maruyama Y, Takahashi T, et al. Effects of long-term pressure overload on regional myocardial glucose and free fatty acid uptake in rats: a quantitative autoradiographic study. Circulation 1990; 81: 1353-61.

81- Sack MN, Kelly DP. The energy substrate switch during development of heart failure: gene regulatory mechanisms. Int J Mol Med 1998; 1: 17-24.

82- Wittels B, Spann JF Jr. Defective lipid metabolism in the failing heart. J Clin Invest 1968; 47: 1787-1794. 
83- Matsui R, Xu S, Maitland KA, Hayes A, Leopold JA, Handy DE, et al. Glucose 6-phosphate dehydrogenase deficiency decreases the vascular response to angiotensin II. Circulation 2005; 112: 257-63.

84- Li JM, Mullen AM, Yun S, Wientjes F, Brouns GY, Thrasher AJ, et al. Essential role of the NADPH oxidase subunit p47phox in endothelial cell superoxide production in response to phorbol ester and tumor necrosis factor-alpha. Circ Res 2002; 90: 143-50.

85- Gupte SA. Glucose-6-phosphate dehydrogenase: a novel therapeutic target in cardiovascular diseases. Current opinion in investigational drugs (London, England : 2008); 9: 993-1000.

86- Guzik TJ, Mussa S, Gastaldi D, Sadowski J, Ratnatunga C, Pillai R, et al. Mechanisms of increased vascular superoxide production in human diabetes mellitus: role of NADPH oxidase and endothelial nitric oxidase synthase. Circulation 2002; 105: 1656-62.

87 - An D, Rodrigues B. Role of changes in cardiac metabolism in development of diabetic cardiomyopathy. Am J Physiol Heart Circ Physiol 2006; 291: H1489-H1506.

88- Hink U, Li H, Mollnau H, Oelze M, Matheis E, Hartmann M, et al. Mechanisms underlying endothelial dysfunction in diabetes mellitus. Circ Res 2001; 88: E14-E22.

89- Park J, Rho HK, Kim KH, Choe SS, Lee YS, Kim JB. Overexpression of glucose 6-phosphate dehydrogenase is associated with lipid dysregulation and insulin resistance in obesity. Moll Cell Biol 2005; 25: 5146-57. 
90- Serpillon S, Floyd BC, Gupte RS, George S, Kozicky M, Neito V, et al. Superoxide production by $\mathrm{NAD}(\mathrm{P}) \mathrm{H}$ oxidase and mitochondria is increased in genetically obese and hyperglycemic rat heart and aorta before the development of cardiac dysfunction. The role of glucose-6-phosphate dehydrogenase-derived NADPH. Am J Physiol Heart Circ Physiol 2009; 297:H153-162.

91- Recchia FA, McConnell PI, Bernstein RD, Vogel TR, Xu X, Hintze TH. Reduced nitric oxide production and altered myocardial metabolism during the decompensation of pacing-induced heart failure in the conscious dog. Circ Res 1998; 83: 969-79.

92- Lopaschuk GD, Folmes CD, Stanley WC. Cardiac energy metabolism in obesity. Circ Res 2007; 101: 335-47. 